\title{
An interpretive inquiry of the case law of teacher evaluation in the Southern Regional Education Board states: Forecasting pressing problems
}

Kathy S. Kidder-Wilkerson
West Virginia University

Follow this and additional works at: https://researchrepository.wvu.edu/etd

\section{Recommended Citation}

Kidder-Wilkerson, Kathy S., "An interpretive inquiry of the case law of teacher evaluation in the Southern Regional Education Board states: Forecasting pressing problems" (2009). Graduate Theses, Dissertations, and Problem Reports. 3498.

https://researchrepository.wvu.edu/etd/3498

This Dissertation is protected by copyright and/or related rights. It has been brought to you by the The Research Repository @ WVU with permission from the rights-holder(s). You are free to use this Dissertation in any way that is permitted by the copyright and related rights legislation that applies to your use. For other uses you must obtain permission from the rights-holder(s) directly, unless additional rights are indicated by a Creative Commons license in the record and/ or on the work itself. This Dissertation has been accepted for inclusion in WVU Graduate Theses, Dissertations, and Problem Reports collection by an authorized administrator of The Research Repository @ WVU.

For more information, please contact researchrepository@mail.wvu.edu. 
An Interpretive Inquiry of the Case Law of Teacher Evaluation in the Southern Regional Education Board States:

Forecasting Pressing Problems

Kathy S. Kidder-Wilkerson

Dissertation submitted to the College of Human Resources \& Education

at West Virginia University in partial fulfillment of the requirements

for the degree of

Doctor of Education

In

Educational Leadership Studies

Helen M. Hazi, Ph.D., Chair

Paul Chapman, Ph.D.

Richard Hartnett, Ed.D. Bonnie Ritz, Ed.D.

Neal Shambaugh, Ph.D.

Richard Walls, Ph.D.

Department of Educational Leadership Studies

Morgantown, West Virginia

2009

Keywords: Teacher Dismissal, Teacher Evaluation, Case Law Copyright 2009 Kathy S. Kidder-Wilkerson 


\section{ABSTRACT \\ An Interpretive Inquiry of the Case Law of Teacher Evaluation in the Southern Regional Education Board States: \\ Forecasting Pressing Problems}

\section{Kathy S. Kidder-Wilkerson}

The purpose of this study was to analyze case law related to teacher evaluation between 1980 and 2008 in the SREB states to determine the problems associated with teacher evaluation and if these problems were documented in the literature. Content analysis of teacher dismissal cases revealed many types of teacher evaluation problems. The two most frequent were in the categories of process and data. Problems revealed in case law provide evidence that teacher evaluation is a problematic practice and may be prevented from achieving its accountability goal. Since not all problems that were identified in case law were revealed in the literature, a conclusion of the study was that there were partial but selective gaps that exist. 


\section{DEDICATION}

My dissertation is dedicated to the memory of my brother, Terry L. Kidder, whose demonstration of unconditional love for his family and friends, competitive spirit, and business acumen were inspirations to all who knew him, and especially to me. A day does not pass without thoughts of him. Through God's promise, we will be together again someday. 


\section{ACKNOWLEDGEMENTS}

The completion of this document is a life-long dream and one that I could never have achieved without the assistance and support of several wonderful people.

My deepest gratitude is extended to Dr. Helen Hazi, the quintessential teacher, who has been the pillar of my support system, my mentor, my confidante, my cheerleader and my friend. The inordinate amount of time that she has given me can never be repaid. I am eternally grateful for her patience, her vast knowledge, her intuition, and her superb guidance. She is the type of teacher I had always hoped to be.

A special thank you to my committee: Dr. Chapman, Dr. Hartnett, Dr. Ritz, Dr. Shambaugh and Dr. Walls. Their leadership, time and wisdom were greatly appreciated as they conducted the doctoral classes, read my document, provided me feedback and offered me their suggestions.

Many thanks to members of my doctoral cohort study team: Dan Doyle, Dianna Vargo, and Diane Watt. Preparing for our comprehensive exam was made enjoyable as each shared their wisdom and wit. Also from the cohort, a thank you to Dr. Hazi's other advisees: David Agnew, Karen Davies, Vic Fisher, Robin Lewis, David Tupper and Diane Watt. The time we spent together and the exchange of constructive criticism was invaluable to me.

Thank you to those who contributed to the verification of the quality of my study: Ron Branch, Karen Davies, Frank Devono, Wayne Neely, Suzan Smith, Dr. James Stronge, Dianna Vargo, Tammy Wells and Nick Zervos. The time they so graciously gave from their busy schedules will never be forgotten. 
Thank you to my colleagues in the Brooke County School System for their interest and support. Superintendent Mary K. Hervey DeGarmo’s enthusiasm, cooperation and flexibility assisted me immensely in reaching my goal. She made my journey less complicated.

I am forever indebted to my Mother, Dorothy Kidder, and my daughter, Bre Wilkerson, for their continuous belief in me and for the constant care they offered. I cherish their daily presence in my life, without which I would not have succeeded in this accomplishment. I am equally grateful for my son, Ryan Wilkerson, along with his wife, Jessica, and son, Anthony, for their long-distance endorsement of my endeavors. I treasure both their love and support.

A special thank you to my brothers, Kent and John, my sister-in-laws, Donna, Diann and Lindy, my nieces and nephews, and my friends, Dorothy Scheetz and Janet Caprarese, for their love, never-ending support, and words of encouragement. I appreciate their understanding of my absences at many events in the last four years.

My appreciation, gratitude and love are extended to Marty Bartz for his understanding and his willingness to accompany me on this perseverant journey. His support and wisdom have meant so much. A counselor, a friend, and a partner - he has made a world of difference in my life.

And lastly, to the "Wiz Kid" of Wellsburg High's Class of 1943, for all of the values he instilled in me, for encouraging my love of reading, for believing that I could accomplish anything, and for continuing to motivate me from his place among the stars, "This is for you, Dad!" 


\section{TABLE OF CONTENTS}

ABSTRACT

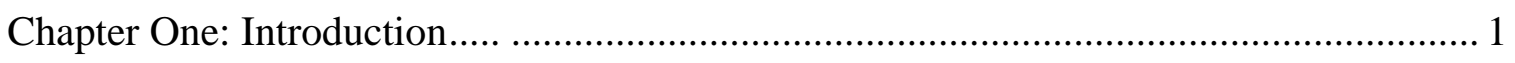

Justification for Research ................................................................... 2

The $1980 \mathrm{~s}$.......................................................................... 2

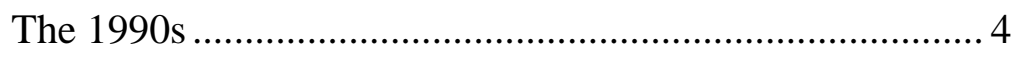

The 2000s ........................................................................... 5

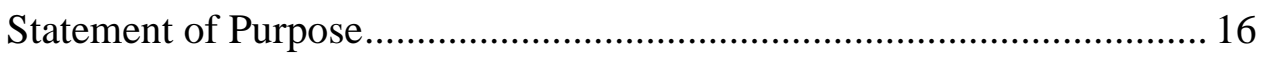

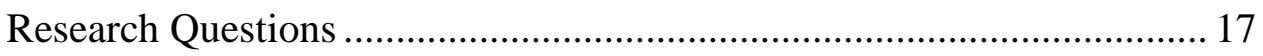

Research Design .................................................................................. 17

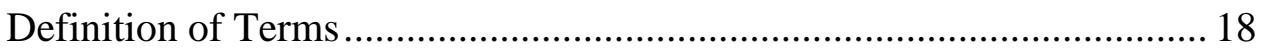

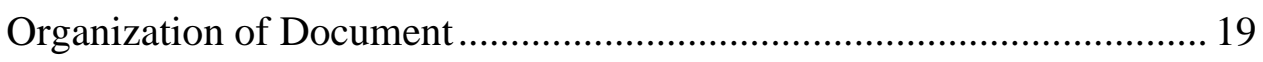





Purposes of Teacher Evaluation .............................................................. 24

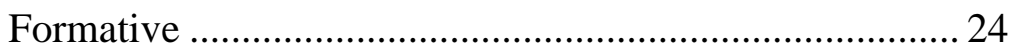



The Evaluation Process .......................................................................... 28

Process Similarities ………………………………...... 28

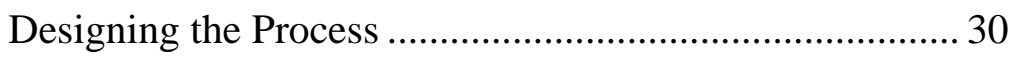

Beginning v. Veteran Teachers ........................................... 34 
The Politics of Teacher Evaluation .............................................................. 36

Legal Requirements of Teacher Evaluation ................................................ 40

Uniform Guidelines............................................................ 40

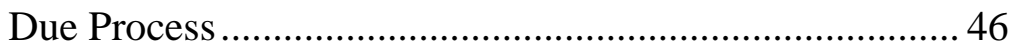

Progressive Discipline ........................................................... 50

Remediation Plans............................................................. 55

Open Records .................................................................... 57

Collective Bargaining ........................................................ 58

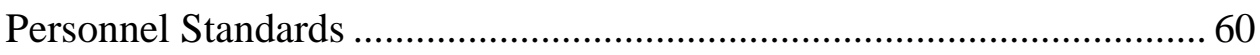

The Joint Committee Standards ........................................... 62

Danielson's System of Standards ......................................... 65

National Board for Professional Standards ......................... 66



Pickering v. BOE TownshipDistrict 205 (1968) ................ 70

Griggs v. Duke Power Co. (1971)..................................... 70

Perry v. Sinderman (1972) ............................................. 71

Board of Regents v. Roth (1972) ....................................... 72

Brito v. Zia Co. (1973) ..................................................... 72

Chance v. Board of Examiners (1974) ............................... 73

Mount Healthy City School District v. Doyle (1977)........ 73

Problems with Teacher Evaluation .......................................................... 74

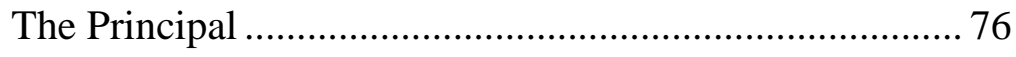

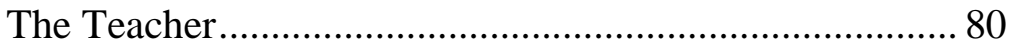


The Evaluation Process ....................................................... 81

National Trends in Teacher Evaluation................................................... 85

Peer Assistance and Review............................................... 86

Portfolios for Teacher Evaluation ........................................ 91

Performance Based Pay Programs ..................................... 93



Batagiannis Dissertation....................................................... 100

Metcalf Dissertations......................................................... 101



Research Theoretic for Education Law Inquiry ………............................ 104

The Three Paradigms of Research ..................................... 104

Qualitative Research …................................................... 107

Traditional Legal Research ............................................ 110

Education Law Inquiry .................................................... 113

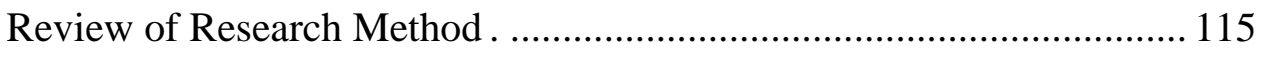

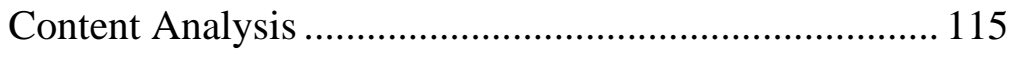

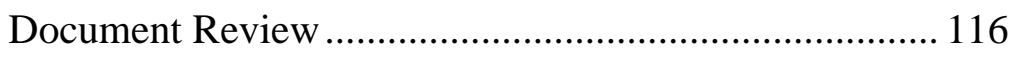

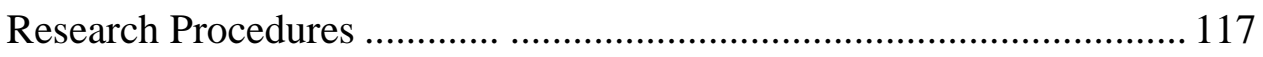

Rationale for Examining Case Law of the SREB ........... 117

Rationale for Timeline .................................................... 120

Criteria for Selecting Case Law ...................................... 121

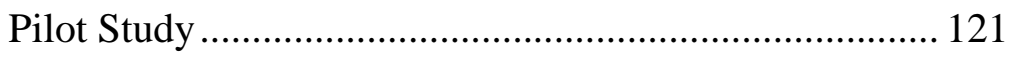

Data Collection Method ................................................... 124 
Procedure for Data Analysis ................................................................ 125



Research Question Number One ...................................... 131

Research Question Number Two .................................... 131

Research Question Number Three ................................... 132

Ensuring Quality of the Research............................................................. 133



Rigor



Chapter Four: Case Law and Its Interpretation ........................................................ 141

Presentation of Findings .................................................................... 142

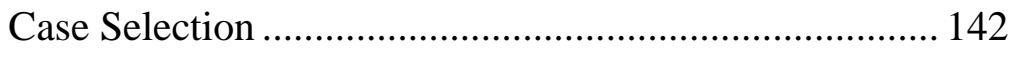

Categories and Subcategories of Problems ...................... 144

Frequency of Problems...................................................... 146

Illustrated Problems of Case Selection.............................. 151

Types of Problems ......................................................... 151

Problems of Teacher Evaluation in Case Law and in the Literature....... 164

An Exemplar Case: Maxey v. McDowell Co. (2002) ……....................... 168

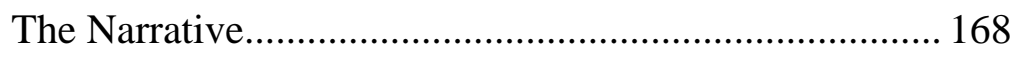

The Court's Decision ......................................................... 175

The Researcher's Interpretation ....................................... 177

Chapter Five: Summary of Findings, Discussion, Conclusion and Recommendations.. 185




Research Question One .................................................... 187

Research Question Two ................................................ 188

Research Question Three ................................................. 189

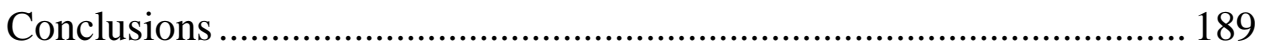

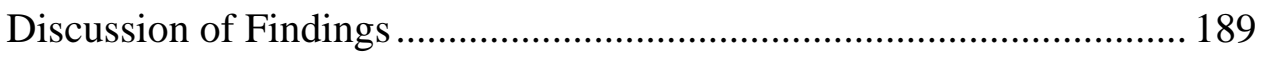

Process and Data Problems with Teacher Evaluation..... 190

Factors Possibly Effecting Teacher Evaluation Problems192

The Practice of Personnel Evaluations............................... 194

The Literature Gap ……………………………………...... 196

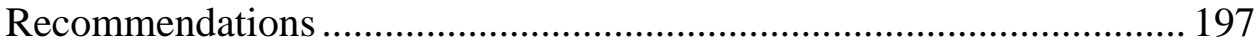

Recommendations for Evaluator Training ....................... 197

Recommendations for Practice........................................... 198

Recommendations for Research...................................... 199

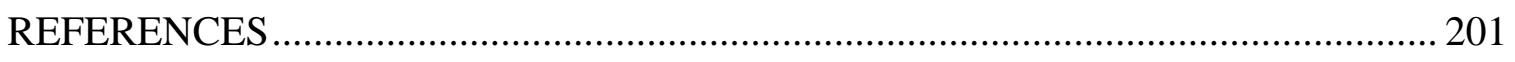

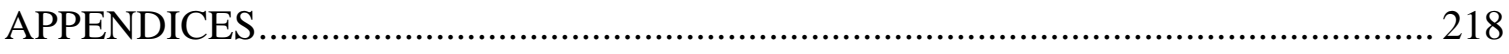

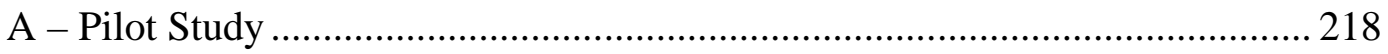

B - Problems with Teacher Evaluation as Revealed in Literature by Source..... 223

C - Data Matrix: Problems with Teacher Evaluation ............................................. 225

D - Revised Data Matrix: Problems with Teacher Evaluation ............................. 228

E - Number of Cases Illustrating Each Subcategory ............................................. 259

F - Problems of Teacher Evaluation Found in the Literature and in Case Law . 261

$\mathrm{G}$ - Cases Cited in this Research ................................................................ 264








\section{LIST OF TABLES}

1. Titles Indicating Research Span and Dismissal Cause ........................................99

2. The Number of Court Cases Found by State................................................. 143

3. The Number of Cases by Category ….............................................. 147

4. Problems of Teacher Evaluation Found in the Literature and in Case Law ....... 165

5. Teacher Evaluation Problems Evidenced in Maxey v. McDowell (2002)........178 


\section{CHAPTER ONE}

Introduction

The quality of America's teachers and their accountability for student

performance are oft-addressed issues when discussing the public education system in the United States. Determining teacher quality and providing accountability for a teacher's performance requires an effective, credible evaluation system -- something that many of our school systems lack. Traditional teacher evaluation is a systematic process that has been described by scholars as being ritualistic (Hazi \& Arredondo Rucinski, 2006), cursory (Goldrick, 2002), an administrative burden (Halverson, Kelley \& Kimball, 2004) and a bureaucratic necessity (Wise \& Darling-Hammond, 1984). Some researchers believe effective teacher evaluation systems have the potential to provide accountability for the quality and performance of teachers (Darling-Hammond, 1988; Duke \& Stiggins, 1986; Peterson, 1987) while others disagree (Hazi \& Arredondo Rucinski, 2006; Marshall, 2005).

There is evidence in existence that portrays decades of ineffective teacher evaluations that have provided accountability for neither the quality nor the performance of the majority of public school teachers. Reform efforts may have failed in their goal to produce an effective teacher evaluation system. Major problems exist with teacher evaluation. One source of evidence of the problems with teacher evaluation is found in our judicial system in the form of case law.

Chapter one provides the justification of the research, the purpose of conducting the research, the research questions and the research design. Terms relevant to this study are defined and the organization of the document is provided. 


\section{Justification for Research}

Evaluation processes and practices have been the targets for change during the last two decades. Prior to the 1980s teacher evaluation was left to local discretion, according to Veir and Dagley (2002). "Relatively little legislation focused directly on teacher evaluation" (Veir \& Dagley, 2002, p. 3) before 1983. This section examines reform efforts from 1980 through 2008 that were related to teacher evaluation. The 1980s.

Teacher evaluation was addressed during the accountability movement of the 1980s as a problem in our school systems. "A consistent theme stressed by reform studies during the 1980s was the need to change the way school personnel are evaluated, encouraged, recognized, and rewarded" (Furtwengler, 1995, p. 1). The 1980s' accountability movement produced numerous reform reports (e.g., National Commission on Teaching and America's Future [NCEE], 1983) and studies (e.g., Furtwengler, 1995) that addressed teacher evaluation.

In 1983, the report A Nation at Risk (NCEE), provided momentum for school improvement efforts. The NCEE (1983) report sought school improvement by offering ten recommendations, one of which was for the creation of effective teacher evaluation systems. The recommendation to create effective teacher evaluation systems stated that teacher salary, promotion, tenure and retention decisions should be linked to an effective evaluation system so that exemplary teachers would be rewarded, average teachers would be encouraged and poor teachers would be remediated or terminated. "We're in the student learning business, and if we're going to have effectiveness in terms of student 
learning we've got to have good teachers, and we've got to have sound management" (NCEE, 1983, Appendix D).

Teacher evaluation legislation was the focus of reform in the 1980s. In an effort to create effective teacher evaluation systems, policymakers from most states began requiring specific instruments and procedures for the evaluation of teacher performance, strengthening the teacher evaluation process (Darling-Hammond, Wise \& Pease, 1983). Thirty-eight states enacted sixty-seven teacher evaluation policies from 1983 through 1992 (Furtwengler, 1995). Of the 12 states taking no action on teacher evaluation policy, "nearly one-half of the states... were in the northeast section of the country" (Furtwengler, 1995, p. 3). The northeast section of the country is primarily made up of collective bargaining states which historically allow greater autonomy for its school districts.

The legislative actions of the 1980s were indicative of several trends emerging in teacher evaluation policy: state involvement in the specification of evaluation procedures and criteria, training of evaluators, and performance pay (Furtwengler, 1995). Many of the states enacting teacher evaluation policies legislated the procedural features of the evaluation process such as timeline and number of classroom observations, according to Furtwengler (1995). Twenty-six states required specific criteria for teacher evaluation in their policies. Some states addressed the training and use of state administrators as personnel evaluators while other states trained local administrators as evaluators (Furtwengler, 1995).

Despite the number of states addressing teacher evaluation in policy during the 1980s, "the inadequacy of teacher evaluations stifled efforts to improve teaching and 
learning in the school system" (Veir \& Dagley, 2002, p. 2). One inadequacy was the accuracy of principals' judgments as evaluators (Medley \& Coker, 1987). Another inadequacy was the use of a single source of data instead of multiple sources, according to Peterson (1987).

The 1990s.

Efforts to reform teacher evaluation continued through the 1990s. "The focus was school restructuring and career development" (Veir \& Dagley, 2002, p. 3) instead of how evaluations encouraged, recognized and rewarded teachers. Teacher quality and effectiveness were to become topics of future reports and legislative acts.

In 1996 a report by the National Commission on Teaching and America's Future (NCTAF), What Matters Most: Teaching for America's Future, addressed effective and qualified teachers. The NCTAF (1996) report proposed the "audacious goal" (p.10) of providing a qualified teacher to every student in America citing it as an "educational birthright" (p. 10). This birthright is most often overlooked in educational reform, according to the NCTAF (1996) report. School reform efforts have ignored the obvious, "what teachers know and can do makes the crucial difference in what children learn" (NCTAF, 1996, p. 5).

The 1996 NCTAF report stated that providing students with competent, effective teachers was not a privilege but a necessity. According to the NCTAF (1996), reform efforts centered on relevant and rigorous curriculum or increased assessment results may be embraced and tried by school systems but often fail due to ineffective teachers. "Quality controls must work to ensure that those who cannot teach effectively do not enter or stay in the profession" (NCTAF, 1996, p. 8). The report stated that, "teaching is 
the most important element of successful learning. Teaching quality will make the critical difference not only to the futures of individual children but to American's future as well" (NCTAF, 1996, p.2).

The 2000s.

The public demanded greater levels of teacher accountability in the first decade of the $21^{\text {st }}$ century (Stronge \& Tucker, 2003; Veir \& Dagley, 2002). Efforts on the national level (e.g., the development of The National Board for Professional Teaching Standards) and the local level, as well as changes in state and district teacher evaluation policies were made to meet the demands, according to Stronge and Tucker (2003). Demands included performance standards, tangible measures of student achievement and "support of the fundamental decision-making quality of teaching that is context-specific" (Stronge \& Tucker, 2003, p. 13).

Teacher evaluation policies changed in order to "enhance teaching and thus improve schools," in the opinion of Stronge and Tucker (2003, p. 13). Changes included the addition of student performance data and parental input (Veir \& Dagley, 2002). The focus of teacher evaluation changed from critical thinking to authentic pedagogy, in the opinion of Danielson and McGreal (2000). Teachers were to teach for understanding by engaging the learner in the teaching process.

Forty-two states had introduced statutory language regulating the evaluation of teachers and seven of the 42 states required teacher evaluation (Veir \& Dagley, 2002). Thirty-six states either required or allowed for the use of a locally developed teacher evaluation system. Fourteen state statutes identified thirty-one different criteria for teacher evaluation. Six statutes required that student performance be a portion of teacher 
evaluation criteria. Five statutes required the partial focus of evaluation to be on instructional techniques and methodologies.

In addition to changes in state statutes, a federal law was enacted that would affect teacher evaluation. Passed into law in 2002, No Child Left Behind [NCLB] (U. S. Department of Education [USDE]), mandated educational reform "on an unprecedented scale" (Smith, 2008, p. 611). Federal funding for education was linked to both improvement and accountability of public schools. The goal of NCLB (USDE, 2002) was to raise student achievement. The three objectives essential to this goal were improving students' basic skills, ensuring teacher quality, and teacher training and recruitment (USDE, 2002).

NCLB (USDE, 2002) addressed the second objective, teacher quality, by demanding that teachers be highly qualified in every subject they taught. This impacted teacher evaluation policies by requiring the addition of an alternative method of evaluation for veteran teachers who did not meet the highly qualified criteria. "For teachers who are not new to the profession, use the High Objective Uniform State Standard of Evaluation (HOUSSE) procedures developed by the State. These are procedures that may use a combination of education and experience to demonstrate subject-area competence" (USDE, 2007, n.p.).

To be highly qualified, teachers must have obtained full state certification or passed the state teacher licensing examination and have a license to teach in that state. Teachers employed after the 2002-2003 school year must have held a minimum of a bachelor's degree and have passed the state teachers' test or must have completed an academic major or equivalent coursework or must have possessed a graduate degree for 
each teaching area to be highly qualified. Veteran teachers must meet the same criteria or must have demonstrated competence in subjects taught by being evaluated by the HOUSSE process (USDE, 2002). A HOUSSE evaluation:

(a) is designed by the State, (b) aligned with the State academic content standards, (c) developed by core content specialists, teachers, principals, and school administrators, (d) an objective documentation of the teacher's knowledge of each core content area the teacher teaches, (e) applied uniformly throughout the State to all teachers in the same content area and the same grade level, (f) considerate of the time the teacher has been teaching in the content area, (g) available to the public upon request, and (h) designed to include multiple, objective measures of teacher competency, if desired. (n.p.)

Requirements for HOUSSE evaluations varied from state to state but addressed subject matter knowledge and teaching practices. NCLB (USDE, 2002) generated definitions of highly qualified for the following: an elementary or secondary public school teacher, a beginning elementary teacher, a beginning middle school or secondary teacher, a veteran elementary teacher, and a veteran middle school or secondary teacher. NCLB afforded states the opportunity to further identify requirements for veteran teachers to be evaluated and satisfy the definition of a highly qualified teacher (e.g., West Virginia (WV) State Policy 5202, section 8.2.2, defines highly qualified teacher, highly qualified Title I Reading teacher and highly qualified Special Education teacher by listing the criteria required for NCLB compliance in WV; WVDE, 2008a).

Also in 2002 in an issue brief for the National Governors Association (NGA), Goldrick stated that "the inclusion of evaluation into broader reform efforts can 
strengthen the perceived and actual connections between teacher quality, classroom instruction, and student learning" (p. 2). Goldrick (2002) offered six suggestions state policymakers should employ to improve teacher evaluation:

- define teacher quality by specifying requisite knowledge and skills,

- focus evaluation policy on improving teaching practice (e.g., peer review, portfolio assessment),

- incorporate student learning into teacher evaluation and change evaluation from the traditional input-based process into an outcome-driven one,

- create professional accountability (e.g., career ladders, professional classifications),

- train evaluators, and

- broaden participation in evaluation design to include all education stakeholders. (p.1)

State policymakers complying with these six recommendations could change teacher evaluation into a more effective tool to use for improving instructional practice and for raising student achievement (Goldrick, 2002).

State policymakers transformed teacher evaluation policies in response to NCLB (USDE, 2002) and the NGA Issue Brief (Goldrick, 2002). An analysis of state statutes and department of education regulations for changes in teacher evaluation developed and implemented since the NCLB legislation was completed by Hazi and Arredondo Rucinski (2006/2009). Trends were identified in their studies that showed "the majority of states adopted NGA strategies, asserted more oversight and involvement in local evaluation practices, decreased the frequency of veteran teacher evaluation, and increased 
the data used in evaluation" (Hazi \& Arredondo Rucinski, 2009, p. 23). The studies revealed:

1. A majority of states adopted at least one of the NGA strategies.

2. A majority of the states were "becoming more aggressively involved in teacher evaluation" (2006, p. 17). Teacher evaluation policy was not being left to local discretion.

3. A majority of the states did not require annual evaluation of veteran teachers, but did so "in increments of every 3, 5, or some other variable number of years" (2006, p. 19).

4. A majority of changes in teacher evaluation focused on data: adding new types of data requirements, procedures to obtain the data, and how the data was used. "Whether or not the changes will 'transform and revolutionize' teacher evaluation in the long run remains to be seen" (Hazi \& Arredondo Rucinski, 2009, p. 23). Teacher evaluation may become more complicated depending upon which and how many NGA strategies a state adopts, according to the scholars. Evaluation may become further complicated and more ritualistic if certain practices (e.g., classroom walkthroughs, use of student achievement data) are added to the evaluation process. In addition, including recommended practices in state statutes may "reinforce the view of teacher evaluation as ritual" (Hazi \& Arredondo Rucinski, 2009, p. 20).

In 2007 the Commission on NCLB (2007) in a report, Beyond NCLB: Fulfilling the Promise to Our Nation's Children proposed the term "highly qualified effective teacher" (HQET; p. 48) to facilitate a teacher's demonstration of effectiveness in the classroom, not just the qualifications needed to enter it. To be recognized as a HQET, the 
teacher must be positively evaluated by an administrator or a peer review process, and must make evident students' learning gains in the subject taught by achievement data. States would use longitudinal data systems to track student achievement and determine teacher effectiveness.

Three years of a student's achievement data and a principal's evaluation or a teacher's peer review would be used to determine if a teacher was highly qualified and effective, according to the Commission on NCLB's (2007) report. A value-added methodology would be used to determine HQET. According to the Commission's (2007) report, "a value-added methodology, as it relates to measuring teacher quality, uses measures of achievement gains by individual students over a period of time to determine the effect that teachers have on learning" (p. 48). Statistical methods would be used to adjust for the influence of non-school related factors on academic growth (e.g., students' socioeconomic backgrounds). According to the Commission's (2007) report, to achieve HQET status:

Under this system, teachers would need to produce learning gains and receive positive principal or teacher peer review evaluations. Student achievement can count for no less than 50 percent of the determination of HQET status. Teachers who fall in the top 75 percent of producing learning gains in the state and receive positive evaluations would achieve HQET status. (p. 48)

Also in 2007, the National Council on Teacher Quality (NCTQ), a nonpartisan research and advocacy group, published the State Teacher Policy Yearbook: What States Can Do to Improve Teacher Quality. According to NCTQ (2007), its members are 
"advocates for reforms in a broad range of teacher policies and seek to lend transparency and accountability to the three institutions that have the greatest impact on teacher quality: state governments, colleges of education, and teachers' unions" (p. 2). The project was funded by several private foundations (e.g., IBM Foundation, Milken Family Foundation, Thomas B. Fordham Foundation).

The yearbook analyzed state teacher policies, graded the states in six areas, and recommended specifics to improve state policies. "Any and every policy that states have that impact the quality of teacher, specifically their recruitment, preparation, licensing, evaluation and compensation" (NCTQ, 2007, p. 1) was investigated with the belief that state governments had a stronger impact on teacher work than federal government. Every state received a letter grade for each of the six areas as well as an overall performance rating. The ratings reflected the content of the policies and not policy implementation (NCTQ, 2007).

Teacher evaluation and compensation was one of six areas addressed in the NCTQ (2007) report. The findings relevant to the five goals of teacher evaluation and compensation were:

1. The state should require instructional effectiveness to be the preponderant criterion of any teacher evaluation.

a. Florida had the best practice.

b. The majority of states met a small part of the goal.

2. The state should install strong value-added instruments to add to schools' knowledge of teacher effectiveness.

a. Tennessee had the best practice. 
b. The majority of states met a small part of the goal.

3. The state should require that schools formally evaluate teachers on an annual basis.

a. Pennsylvania had the best practice.

b. The majority of states did not meet this goal.

4. The state should encourage, not block, efforts at compensation reform.

a. Florida had the best practice.

b. The majority of states met the goal partly.

5. The state should not give teachers permanent status (tenure) until teachers have been teaching for five years.

a. Indiana and Missouri had the best practice.

b. The majority of states met a small part of the goal.

An additional finding from the research done by NCQT (2007) was that "a few investigative reports strongly suggest that teacher evaluations have become a meaningless process, failing to identify the strongest and weakest teachers" (p. 3).

The 2008 report Rush to Judgment: Teacher Evaluation in Public Education (Toch \& Rothman), sponsored by Education Sector, a private policy think-tank devoted to developing innovative solutions to education problems, addressed "the causes and consequences of the crisis in teacher evaluation" (p. 1) and warned that raising teacher quality will be jeopardized unless teacher evaluation is taken seriously. According to Toch and Rothman (2008), teacher evaluation is a "potentially powerful lever of teacher and school improvement" (p.1) that is being squandered. "Only 14 states require school 
systems to evaluate their public school teachers at least once a year" (Toch \& Rothman, 2008, p. 2).

Ten recommendations were offered by Toch and Rothman (2008). They were:

1. evaluate teachers on the basis of instruction and student achievement,

2. train evaluators,

3. use district evaluation teams in lieu of principals,

4. use an out-sourcing option to electronically observe teachers in the classroom,

5. evaluate the evaluations for validity,

6. provide school and principal rewards,

7. grant principals staffing authority,

8. target professional development to individual teacher weaknesses,

9. implement performance pay and,

10. obtain a new definition of qualified teacher from Congress that includes the term effective. (p. 19-20)

Following these recommendations would assist in the use of evaluations to improve teaching, according to Toch and Rothman (2008).

Teacher evaluation remains a controversial subject as the 2000s progress.

"Political debate and decision-making concerning the quality of U.S. schools directly affects teacher evaluation thinking and practice" (Peterson, 2008, n.p.). Continued political discussion concerning America's educational system and by association teacher quality, will continue to be reflected in future evaluation practices. "Notwithstanding the reform and accountability movement of the past twenty years, state legislatures are still 
attempting to mandate more effective teacher evaluation systems" (Veir \& Dagley, 2002, p. 2).

Two current examples of political activity include the creation of a state task force in WV and a federally funded reform package. The effects of both of these may be reflected in future evaluation practices. The formation of the WV Task Force on Professional Teaching Standards was undertaken by State Superintendent Dr. Steven L. Paine. The task force began meeting September 29, 2008 and was given the task of reviewing and providing feedback on a draft of teaching standards. The new standards must "reflect the skills and knowledge needed for $21^{\text {st }}$ century teaching and learning" and be the basis for teacher evaluation (WVDE, 2008b, n.p.). The taskforce is meeting monthly to create teaching standards to be used in the evaluation of WV public school teachers.

A federally funded reform package was recently unveiled by President Barack Obama. On March 10, 2009, during a speech explaining his educational reform package, The American Recovery and Reinvestment Act (ARRA), President Obama stated that "it is time to start rewarding good teachers and stop making excuses for bad ones" (Obama, 2009). The reinvestment act addressed teacher evaluation and represented "the largest single federal investment in education in history" (Sawchuk \& Robelen, 2009, p. 15). Later that month, the U.S. Department of Education released guidance on how states may spend the money from the $\$ 39.8$ billion State Fiscal Stabilization Fund and the $\$ 8.8$ billion Government Service Fund.

To advance core educational reform each state receiving ARRA money must meet four assurances. One of the assurances focused on improving teacher quality and directed 
the states to concentrate on "teacher effectiveness and equitable distribution of effective teachers" (USDE, 2009). In addition to their commitment to meeting the assurances, school systems must provide accountability with transparency. "Each state must report the number and percentage of teachers and principals scoring at each performance level on local teacher- and principal-evaluation instruments" (Sawchuk \& Robelen, 2009, p. $15)$.

Much debate is expected about whether access to such a large amount of money for education "will lead to fundamental reform in the nation's education system or have the opposite effect of ossifying current features that may hinder improvement" (Sawchuk \& Robelen, 2009, p. 15). Thomas Toch, co-director of Education Sector, remarked that "I think we're seeing an increase in attention to teacher evaluation in reform discussions at the district, state, and now the federal level, and that's a good thing" (as cited in Sawchuk \& Robelen, 2009, p. 16). He believes that the majority of our country's evaluation systems are "superficial" (as cited in Sawchuk \& Robelen, 2009, p. 16) and not capable of distinguishing a teacher's job performance. Randi Weingarten, American Federation of Teachers president, "said she hoped the reporting would encourage stakeholders to craft more-nuanced evaluation systems in collaboration with teachers, through collective bargaining agreements" (as cited in Sawchuk \& Robelen, 2009, p. 16). Weingarten was concerned about data being used in an unfair manner and as another way to catch teachers.

Reform efforts have not achieved their goal of producing an effective evaluation system. As revealed in both the literature of the field and in case law, teacher evaluation, as a means to provide accountability for teacher quality and classroom performance, 
remains a problematic area. In addition, teacher evaluation, as the primary means of providing validation for the removal of poor quality teachers, has not proven to be legislatively and judicially sound. In many school districts, the removal of ineffective teachers is a rare occurrence. Negative teacher evaluations have often failed to protect school districts from poor performing teachers by failing to be upheld in court cases for a variety of reasons.

Looking to the court systems by examining judicial interpretations as found in case law of teacher dismissals based upon evaluation may provide additional information that is needed to assist in the development of an effective evaluation system. Reform relying solely on the information that has been discussed in the literature of the field has not produced the changes that are needed.

\section{Statement of Purpose}

There are inherent problems within the evaluation process. Writers in the field of teacher evaluation have written about its problems for nearly three decades and teacher evaluation has been a subject of educational reform during the same time period. Are the problems that are being written about the same as those being manifested in case law? It is important to determine if the literature is addressing the problems that are causing teachers to seek judicial resolution. By identifying teacher evaluation problems that are manifested in case law, writers may become aware of the problems that need to be written about, and educators may be provided guidance concerning problematic areas of teacher evaluation that have led to appeals. This is one step towards developing an effective teacher evaluation system. The purpose of this study is to analyze case law related to teacher evaluation between 1980 and 2008 in 16 SREB states to determine the 
problems associated with teacher evaluation and to determine if these problems are documented in the literature or are not.

\section{Research Questions}

Through the review of literature and collection, analysis and interpretation of the data, the researcher seeks to provide responses to the following questions:

1. What are the problems of teacher evaluation as found in selected teacher dismissal cases of the states in the Southern Regional Education Board (SREB) between 1980 and 2008 and what is the frequency of each?

2. Which of these problems are documented in the literature of teacher evaluation?

3. Which of these problems are not documented in the literature of teacher evaluation?

\section{Research Design}

This is a qualitative study. The research is a content analysis providing an interpretation of legal text. Case law of teacher dismissals based on evaluation and appealed to a court of appeals in one of the 16 states of the SREB during the 1980 to 2008 time period will be analyzed. The five criteria for case law selection: dismissal case, educator was a classroom teacher at the time of dismissal, occurred between 1980 and 2008, appealed in an SREB state and had a judicial reference to teacher evaluation, were determined from a pilot study (See Appendix A).

The research theoretic addresses the three paradigms of research (i.e., positivism, constructivism and critical theory), qualitative research, qualitative researchers and the researcher's role in the research, traditional legal research, and education law inquiry. Document review and content analysis are the research methods. The research procedures 
provide the rationale for examining case law of the SREB, criteria for selecting case law, a brief explanation of a pilot study, data collection methods, data analysis and interpretation of the data. Integrity, rigor and utility will determine the quality of the study.

\section{Definition of Terms}

1. Appeal - a written request by an appellant (i.e., the losing party) to a higher court (i.e., the appellate court) to modify or reverse the judgment of a lower court (Nolo, 2008).

2. Content analysis - a type of interpretive inquiry utilizing the proof of daily social life to allow for the self-disclosure of the structure of understanding and to let things be seen as they really are (Mclaughlin, 2006; Soltis, 1984).

3. Problems of teacher evaluation - a difficult situation arising from the practice of rating a teacher's performance that is proposed for a solution (Allee, 1984).

4. SREB states - Alabama (AL), Arkansas (AR), Delaware (DE), Florida (FL), Georgia (GA), Kentucky (KY), Louisiana (LA), Maryland (MD), Mississippi (MS), North Carolina (NC), Oklahoma (OK), South Carolina (SC), Tennessee (TN), Texas (TX), Virginia (VA) and West Virginia (WV) created the first interstate compact in the United States for education and called it the Southern Regional Education Board (SREB, n.d.).

5. Teacher dismissal case law - judicial opinions related to the termination of a tenured teacher or a probationary teacher within the contract period and for cause that use precedence in interpreting and applying the law (CambronMcCabe, McCarthy \& Thomas, 2004; Russo, 2006). 
6. Teacher evaluation - the practice of rating a teacher's classroom performance.

\section{Organization of Document}

The dissertation consists of four additional chapters. The review of literature will be provided in chapter two and cover the following topics: evaluation defined, purposes of teacher evaluation, the evaluation process, politics of teacher evaluation, legal requirements of teacher evaluation, personnel standards, relevant court decisions, problems with teacher evaluation, national trends in teacher evaluation, and related dissertations. Chapter three explains the research design, rationale, methods and procedures that are used to address the research questions. Chapter four provides an interpretation of the data. Chapter five provides the conclusions of the study, a discussion of the findings and recommendations resulting from the study.

The appendices include: The Pilot Study, Problems with Teacher Evaluation as Revealed in Literature by Source, a data matrix entitled Problems with Teacher Evaluation, a revised data matrix, Number of Cases Illustrating Each Subcategory, Problems of Teacher Evaluation Found in the Literature and in Case Law, and Cases Cited in this Research. 


\section{CHAPTER TWO}

Review of the Literature

Teacher evaluation has been studied during the last three decades to improve schools and to ensure teacher quality. "Teacher evaluation is one of the primary means of improving education instruction, enhancing educational services, and justifying the removal of substandard teachers" [authors' emphasis] (Veir \& Dagley, 2002, p. 2). Teacher evaluation was viewed as a school system problem during the 1980s' accountability movement and was "a prime concern of educational reformers as well as a focus for state-level initiatives during the reform era" (Furtwengler, 1995, p. 2). Reports by the NCEE (1983) and the Carnegie Forum (1986) advocated for the development of new teacher evaluation systems or the update of existing systems (as cited in Sclan, 1994).

A 1983 report, A Nation at Risk: The Imperative for Educational Reform, provided the impetus for reform that focused on "the need for accountability on educators' actions" (Veir \& Dagley, 2002, p. 1) and was the origin of a recurring theme in educational reform, "accountability-based teacher evaluation" (p. 2). The report forced the American public to acknowledge the deficiencies in American school systems and challenged the nation to overcome these weaknesses. Educational mediocrity in the United States, equity in American schools and the need for a national commitment to educational reform were among the topics discussed in the report. The report contained five categories of recommendations: curriculum content, standards and expectations, time allotted to education, teacher quality, and leadership and financial support. Recommendation D, teacher quality, stated that "salary, promotion, tenure, and retention 
decisions should be tied to an effective evaluation system that includes peer review so that superior teachers can be rewarded, average ones encouraged, and poor ones either improved or terminated" (NCEE, 1983, n.p.).

Teacher evaluation as a tool for ensuring teacher quality presents multiple problems for public educators. The types of problems will be discussed in a later section. According to Veir \& Dagley (2002), evaluation presents problems for teachers, administrators, school boards and legislatures as:

They are given the great task of determining legally viable methods of evaluating teachers, taking appropriate and reasonable steps to improve teaching performance, and ultimately moving toward termination based on ineffective classroom performance. Additionally, to meet the burden of proof, each evaluation must be based upon sound procedures and documentation. (p. 4) Traditional teacher evaluation has not always proven to be legislatively sound. "Presently there is no model statute from which a legally and legislatively sound evaluation system can be developed" (Veir \& Dagley, 2002, p. 4).

Veir and Dagley (2002) analyzed state statutes on teacher evaluation and found "regular incongruencies in the legislation--its language, structure, procedures, and requirements" (p. 4). The rationale found in state statutes was incongruent with the reasoning behind teacher evaluation legislation in many states. The researchers concluded that the incongruencies often prevented the evaluation processes from being carried out. Therefore, the researchers considered the legislation unsound. Developmentally sound legislation governing teacher evaluation systems is needed for school districts to be able to remove poor or problematic teachers (Veir \& Dagley, 2002). 
In many school districts, the removal of ineffective teachers is a rare occurrence, according to Goldstein and Noguera (2006). One possible reason is offered by Scriven (1980). Negative teacher evaluations have "failed to protect us from bad teaching" (Scriven, 1980, p. 4) by failing to be upheld in court cases. There are multiple reasons cases may not be upheld in court. Poor case preparation by administrators (Scriven, 1980), inconsistency in the observation process (Allen \& Jarvis, 1983), the lack of consensus for a definition of incompetence (Menuey, 2005), violations of due process (Scriven, 1997) and inferior teacher evaluation policies developed by states and districts

(Scriven, 1980) are five deterrents to successful court cases. According to Scriven (1980), unions and administrators have sought to keep in place "a system that is scientifically indefensible and completely unethical, a combination of virtues that will ensure its demise the moment some teacher with the relevant knowledge appeals to the courts without relying on the union" (p. 4).

Through a review of literature teacher evaluation will be addressed in ten sections: evaluation defined, the purposes of teacher evaluation, the evaluation process, the politics of teacher evaluation, legal requirements of teacher evaluations, personnel standards, relevant court decisions, problems with teacher evaluation, national trends in teacher evaluation, and related dissertations.

\section{Evaluation Defined}

Evaluation is an assessment, a rating, an appraisal, an estimation of worth or a determination of value (Allee, 1984). The meaning conveyed is dependent upon the field of use since the context of evaluation is so diverse (e.g., medicine, cuisine, jewelry, performance). An evaluation may consist entirely of skilled observation and may rely on 
a combination of procedures and data sources to derive a judgment. A medical practitioner assesses presenting manifestations to discern a diagnosis. A connoisseur of cuisine critically reviews the taste and presentation of an entrée, as well as the service provided by the wait staff, to offer an expert rating of a particular restaurant. A gemologist surveys the cut and clarity of a gem stone before determining the gem's value. A principal uses data from classroom observations to evaluate a teacher's classroom performance. No matter the area of use, an evaluation is a value judgment about something or someone against accepted standards (Scriven, 2001).

According to Scriven (2001), there exists "about 20 recognized (and often named) fields of apparently skilled evaluation" (p. 302). Personnel evaluation is one division of skilled evaluation. There is no one definition used in the field of teacher evaluation. A NGA Issue Brief (Goldrick, 2002) defined teacher evaluation as a process principals and school administrators use to professionally assess job performance and assure the basic competency of educators. Teacher evaluation has also been defined as "a series of activities and actions that are interconnected and relate to a specific purpose" (Sawa, 1995, p. 3). Teacher evaluation is "a formal means for school leaders to communicate organizational goals, conceptions of teaching, standards, and values to teachers" (Wise, Darling-Hammond, McLaughlin \& Bernstein, 1984, p. 2). Hazi and Arredondo Rucinski (2009) chose to define evaluation by its purpose, "the personnel function" (p. 7), differentiating it from supervision, "the helping or teacher professional development function" (p. 7). 


\section{Purposes of Teacher Evaluation}

It is important to first distinguish between the two major categories of purposes of teacher evaluation, formative and summative, because the evaluation process used is sometimes dependent upon the intended purpose (Peterson \& Kauchak, 1982). Formative evaluation is the gathering of information "for the purpose of improving and developing teaching....this information is meant to inform change" (Lenze \& Warner, 1995, p. 1). Others in the field of teacher evaluation have cited the following formative purposes of teacher evaluation: improvement of instructional quality (Duke \& Stiggins, 1986; Peterson, 2001; Sawa, 1995), opportunities to increase effective teaching behaviors (Enz \& Searfoss, 1993; Marshall, 2005; Ponticell \& Zepeda, 2004), enhancement of teacher professionalism (Ponticell \& Zepeda, 2004), and opportunities for greater dialogue between administrators and teachers (Sawa, 1995; Trenta, Newman, Newman, Salzman, Lenigan \& Newman, 2004).

Formative Evaluations

Formative evaluations are oriented toward improvement, analyzing strengths and weaknesses to provide input for professional growth, improved instruction, improved performance, enhancement of the curriculum and improved educational services (Veir \& Dagley, 2002). Aspects of teaching performance needing improvement are identified and suggestions for correction are shared between the administrator and teacher. According to McNergney and Herbert (1998), the feedback is provided for collaborative decision making by the administrator and the teacher about improving the teacher's classroom performance. The authors state that the premises behind formative evaluation are: 
(a) professional teachers constantly strive for continued individual excellence; (b) given sufficient information, professional teachers can and will evaluate themselves and modify their performance as well or better than others; and (c) the evaluation procedures provide feedback designed to assist teachers in making judgments about how they can best improve their teaching. (McNergney \& Herbert, 1998, p. 26)

According to Wiliam (2006), formative evaluations may influence a teacher's performance. "The evaluation is formative if the information generated is used to make changes to what would have happened in the absence of such information" (Wiliam, 2006, p. 284). Information gained from formative evaluations may be used to cause a transformation in the teaching performance. "The crucial feature is that evidence is evoked, interpreted in terms of learning needs, and used to make adjustments to better meet those learning needs" (Wiliam, 2006, p. 285). A formative evaluation may not only indicate where a teacher currently is but may indicate how the teacher can improve.

\section{Summative Evaluations}

A summative evaluation "is a judgment about teaching that is used to make a decision" (Lenze \& Warner, 1995, p. 1). Summative purposes include: assurance of teacher quality (Danielson \& McGreal, 2000; Sawa, 1995), personnel rating (Danielson \& McGreal, 2000; Darling-Hammond et al., 1983; Duke \& Stiggins, 1986; Sawa, 1995), and personnel decisions (Conley \& Glasman, 2008; Darling-Hammond et al., 1983; Duke \& Stiggins, 1986; Hazi \& Arredondo Rucinski, 2009; Peterson, 1987; Sawa, 1995; Trenta, et al., 2004). 
Summative evaluations are judgment or outcome-oriented evaluations usually used in the decision making process for employment (Peterson \& Kauchak, 1982). Summative evaluations may be used to identify large trends and patterns of performance and to judge the teacher's performance against standards in order to provide a performance rating. According to McNergney and Herbert (1998):

Evaluating teacher' competence and teaching outcomes are examples of summative assessments, in which data is collected and interpreted at the end of a specified period of time. Results are used to make decisions about teachers on matters such as hiring, compensation, status, tenure, and termination. (p. 27) Summative evaluation does not promote collaboration between the administrator and the teacher as well as formative evaluation (Weiss \& Weiss, 1998).

The purpose of teacher evaluation varies with the stakeholder's (e.g., administrator, teacher, parent, school board members) perspective. The differing views of stakeholders concerning the basic purpose of teacher evaluation may create tension and should be taken into consideration before designing an evaluation process (DarlingHammond et. al., 1983). Administrators work to maintain stability, provide accountability and promote staff morale, according to Darling-Hammond et al. (1983). An administrator does not want to spend an inordinate amount of time on evaluations and would prefer an objective process. An objective process is evidence based, uses numbers and is less biased by the opinion of the evaluator than a subjective process (Alicias, 2005; van Schooten, 1998). Administrators are interested in both formative and summative evaluations, according to Peterson and Kauchak (1982). 
Another group of stakeholders, teachers, are concerned with keeping their jobs, their efficacy and maintaining self-respect. If a teacher must be evaluated, the teacher wants an evaluation process providing constructive criticism and encouraging selfimprovement while affording due process (Darling-Hammond et al., 1983). According to Peterson and Kauchak (1982), "there is increasing evidence that teacher satisfaction with the profession can be strengthened by availability of reassuring and respected feedback about effectiveness" (p. 10).

A third group of stakeholders, parents, are concerned with a teacher's effect on students. They want a process that indicates the relationship between teacher performance and effectiveness, and one that addresses the appropriate treatment of students by the classroom teacher (Darling-Hammond et al., 1983) According to Nolan and Hoover (2008), parents want to make sure "that their children receive high-quality instruction" (p. 169).

An additional group of stakeholders in the evaluation process, school board members, have a triad of concerns (Nolan \& Hoover, 2007). First, they are concerned that the district implementation of teacher evaluation adheres to evaluation policy requirements. Second, school board members want professional staff members held accountable and third, they are concerned with the provision of resources required to be committed to the teacher evaluation process.

All four groups of stakeholders: administrators, teachers, parents and school board members, may share at least one perspective about the purpose of teacher evaluation, providing data to indicate the quality of a district's schools. This purpose may become important when seeking financial support from the public. According to Peterson (2001), 
we live in a consumer oriented society where our schools are in competition with other public entities (e.g., prisons, health and welfare) seeking a share of financial resources. "Educators who expect support for public education have a burden to make their case" (Peterson, 2001, p. 5).

\section{The Evaluation Process}

Teacher evaluation is a process that has been described by scholars as being ritualistic (Hazi \& Arredondo Rucinski, 2009), cursory (Goldrick, 2002), an administrative burden (Halverson et al., 2004) and a bureaucratic necessity (Wise \& Darling-Hammond, 1984).

\section{Process Similarities}

Although the evaluation process differs from state to state and district to district due to differences in law, similarities have been noted. The process generally consists of: the principal as the evaluator, pre- and/or post-observation conferences, one or two classroom observations to gather data, an observation instrument, and a formal evaluation document with an evaluation judgment housed in the teacher's personnel folder (Danielson \& McGreal, 2000).

"Just about every important decision about teacher utilization - whether the teacher is certified as competent, hired, receives tenure, is recognized as meritorious depends on someone's judgment of how well that teacher performs in the classroom" (Medley \& Coker, 1987, p. 242). That someone is most often the principal, the first similarity among current evaluation processes. In most districts, the principal is primarily responsible for teacher evaluation (Marshall, 2005). "Educational audiences such as 
school boards, teachers, parents, legislators, and superintendents likewise consider the principal to be the key teacher evaluator" (Peterson, 2001, p. 72).

The second similarity, an observation conference between the administrator and the teacher, may occur before and after a classroom observation. Pre-observation conferencing is used as a means to identify the expectations of the upcoming classroom observation (Darling-Hammond et al., 1983). The post-observation conference is used to provide constructive feedback, to enhance the teacher's reflection of her own performance (Danielson \& McGreal, 2000; Darling-Hammond et al., 1983) and to communicate "performance appraisals to a practicing teacher" (Darling-Hammond et al., 1983, p. 304).

The third similarity, one or two classroom observations to gather data, grants the evaluator access to the teacher during interaction with students. According to Duke and Stiggins (1986), the goal of classroom observations "is to obtain a representative sample of teacher performance from which to draw conclusions about teacher competence" ( $p$. 28). A classroom observation is generally completed by a principal or administrator and can be formal or informal. Formal observations are planned and usually preceded and followed by a conference between the administrator and teacher. The observation may last for an entire class period and might occur once or twice in a school year (Duke \& Stiggins, 1986). Informal observations occur more frequently, are usually unannounced and may last for only a few moments, according to Duke and Stiggins (1986). The teacher's subject knowledge and pedagogical skills can be assessed first-hand during the observations. 
The fourth similarity with current teacher evaluation processes is the use of an observation instrument to collect data during the classroom observation. The observation instrument may involve scripting, providing a written record and timeline of verbal interactions (Nolan \& Hoover, 2007); anecdotal note taking, a summary of what occurred in the classroom (Nolan \& Hoover, 2007); a coding system to provide a visual representation of data (i.e., time on task, verbal flow, teacher movement; Nolan \& Hoover, 2007); or checking off observable behaviors from a list (Danielson \& McGreal, 2000). The completed observation instrument provides documentation of the performance data to be considered when making the evaluation judgment.

The fifth similarity in teacher evaluation processes is the use of a formal evaluation document with an evaluation judgment housed in the teacher's personnel folder. The judgment may be summed up in one word, such as "satisfactory," or may be given a numerical value, such as "3" to represent "needs improvement" (Danielson \& McGreal, 2000).

\section{Designing the Process}

In order to structure an effective process for teacher evaluation, it is important for the school district's decision makers to understand the multiple perspectives of the stakeholders (Darling-Hammond et al., 1983). Identification of the underlying assumptions from each perspective assists in creating a successful evaluation process, according to Darling-Hammond et al. (1983). When deciding the evaluation process to use, each perspective about the purpose for evaluating teachers should be recognized to help ensure well-suited choices (Darling-Hammond et al., 1983). 
The evaluation process should be based upon the needs of the school district, be aligned to the criteria the district notes as "essential to good practice" (Danielson \& McGreal, 2000, p. 55) and be highly individualized for each teacher (Duke \& Stiggins, 1986). The evaluation process is likened to a "personal journey" (Duke \& Stiggins, 1986, p. 14) in which travel is accomplished "via different modes and routes with or without company" (p. 14). According to Duke and Stiggins (1986), a teacher's level of experience assists in determining the routes (e.g., formal classroom observation, setting professional goals) and the type of resources needed (e.g., technical assistance from district experts, attending workshops, a mentor, observation of peers).

Traditional teacher evaluation has not been individualized but instead has been a single route for all teachers to travel dooming school systems to "inefficient evaluation at best and inadequate teaching at worst" (Duke \& Stiggins, 1986, p. 14). This uniformity has been legally required, as will be shown in the section on legal requirements. Five keys to individualized, effective teacher evaluation processes are: the teacher, the evaluator, the performance data, the feedback and the context (Duke \& Stiggins, 1986). Important attributes of the teacher and the evaluator, and the collection of appropriate performance data summarized and relayed back to the teacher in a context focused on teacher growth will promote teacher improvement, according to Duke and Stiggins (1986).

The most critical factor in an effective teacher evaluation process is the teacher (Duke \& Stiggins, 1986). There are at least six teacher attributes exerting an influence on whether an evaluation process is effective, according to Duke and Stiggins (1986). First, the teacher must possess instructional competence, the ability to deliver subject content 
using sound instructional strategies. Second, teachers must have high expectations of theirselves and third, be open to constructive suggestions. Fourth, teachers must be open to change and be willing to experiment and take risks while seeking alternative instructional approaches to teaching. Fifth, the teacher must have knowledge of the subject being taught and knowledge of how the subject fits into the district's curriculum plan. Finally, the teacher's professional experience (e.g., success with students, reputation for classroom management, relationships with supervisors, seniority) will impact the evaluation process. In the opinion of Duke and Stiggins (1986), "a probationary teacher is apt to deal with the evaluation process differently from a tenured teacher" (p. 18).

The second key to an effective evaluation process is the evaluator. According to Duke and Stiggins (1986), there are at least six attributes of the evaluator contributing to an effective evaluation process. First, the evaluator must be credible. Credibility can be determined by possessing knowledge of both the subject and pedagogy, amount of personal experience in the classroom and district, recentness of classroom experience and familiarity with the evaluatee's classroom and students. Second, the evaluator must be persuasive in convincing a teacher to try a new instructional strategy. Third, the evaluator needs patience to devote the time needed for proper teacher evaluation. Fourth, the evaluator must have the ability to inspire trust before suggesting change and delivering critical feedback. Trust may be inspired by maintaining confidentiality, and demonstrating consistency, honesty and sincerity. Fifth, the past history of the evaluator in that role is important (i.e., providing successful suggestions, not having an answer for everything, willingness to collaborate with the evaluatee in researching a solution to a 
problem). Sixth, the evaluator needs to be able to model desirable attitudes, and new ideas or techniques for the evaluatee.

The third key to an effective evaluation process is the data gathered on teacher performance. According to Duke and Stiggins (1986), the observation instrument can contain performance criteria and performance standards. "Performance criteria define the dimensions of teacher performance to be evaluated. Performance standards represent required levels of performance with respect to the criteria" (Duke \& Stiggins, 1986, p. 27). Both the criteria and the standards vary with purpose of the evaluation. When the purpose is to ensure minimum competency, the criteria and standards must be uniform for all teachers and legally defensible. When the purpose of the evaluation is promotion of professional development, the criteria and standards need to be tailored to the individual context and capability of the teacher, endorsed by the teacher and related to the teacher's attainment of professional goals. Data should be gathered from various sources (e.g., classroom observation, classroom records, measurement of student achievement, peer review, student input) and on multiple occasions during the school year.

The fourth key to effective teacher evaluation is feedback attributes. There are at least eight feedback attributes, according to Duke and Stiggins (1986). Feedback must be discussed with a level of formality and communicated in a way that makes sense to the teacher. The amount of feedback given at one time must not be overwhelming and must be timed to have maximum impact. The feedback must relate to performance standards and be specific to suggestions to promote teacher growth or improvement. Effective feedback must be frequent in order to encourage continued development. Feedback 
should "convey either descriptive information on teacher performance or evaluative judgments regarding that performance" (Duke \& Stiggins, 1986, p. 32).

The fifth key to effective teacher evaluation is context attributes (Duke \& Stiggins, 1986). The evaluation process is occurring in an organizational context and according to Duke and Stiggins (1986), there are six influential contextual factors: district policy, state laws, contractual obligations from collective bargaining agreements and contracts, history of labor relations within the district, time spent on evaluation (i.e., is it a high priority or are shortcuts taken) and resources available for growth (e.g., release time for visiting other classrooms or attending workshops, technical assistance from indistrict experts or consultants, staff development).

The five keys to an effective teacher evaluation process will lead to growthoriented teacher evaluation, according to Duke and Stiggins (1986). As states and districts work to develop a teacher evaluation process, the influence each key factor impacts effective evaluation practice should be considered.

\section{Beginning v. Veteran Teachers}

In addition to the consideration of the five key factors that influence effective evaluation processes, the evaluation process should be developed with teacher experience as a consideration. Teaching is the lone profession making the same demands on beginning teachers as on experienced practitioners (Danielson \& McGreal, 2000). Novice teachers are judged "to the same standard and subjected to the same procedures as their more experienced colleagues" (Danielson \& McGreal, 2000, p. 5). The evaluation instrument used for evaluating the beginning teacher is identical to the instrument used for evaluating the veteran teacher. 
The evaluation process needs to be different for beginning teachers and veteran teachers (Danielson \& McGreal, 2000; Duke \& Stiggins, 1986). Procedures chosen to evaluate the beginning teacher should serve to provide evidence of essential teaching skills (McColskey \& Egelson, 1993). Essential teaching skills may include: a commitment to students and their learning, knowledge of the subject matter being taught and how to teach that subject, an understanding of how children learn, the ability to selfevaluate reflectively on a regular basis and the ability to work as a member of a learning community (National Board for Professional Teaching Standards [NBPTS], 1987).

Procedures for the evaluation of experienced teachers should be conducive to professional growth (Danielson \& McGreal, 2000; McColskey \& Egelson, 1993). There are two presumptions of a veteran teacher: competency and continued professional growth, according to Danielson and McGreal (2000). Veteran teachers are presumed to perform at least at a satisfactory level and are presumed responsible for continuing to grow professionally in order to prevent stagnation in their professional knowledge. Continuing professional growth may involve learning to use new instructional strategies. School reform efforts and increased achievement standards for students continue to compel teachers to take risks and experiment with instructional methods (McColskey \& Egelson, 1993). Teachers need to "know that, even during a formal, evaluation observation, they can try a new strategy and receive feedback on it...in an environment safe for professional risk-taking” (Danielson \& McGreal, 2000, p. 30).

The timelines of the evaluation process may also differ for beginning and veteran teachers. According to McColskey and Egelson (1993), beginning teachers need to be evaluated annually until tenure is received. Tenure is usually received after two to three 
years of teaching. The annual summative review should address remediation, if needed (McColskey \& Egelson, 1993). Experienced teachers may be formally evaluated less frequently than beginning teachers and may collect additional information themselves during the years between their formal evaluations (Danielson \& McGreal, 2000). Documentation of continuing education and verification of professional development activities, self-assessment and reflective activities, preparation of a portfolio, and student and parent surveys may be used to collect information during the time between formal evaluations (Darling-Hammond et al., 1983).

\section{Summary}

The evaluation process has been studied and, due to its importance, constructively criticized by several scholars in the field. Traditional evaluation processes recognize the principal as the evaluator, use classroom observations to gather data, provide pre- and post-observation conferences, and require the completion of both an observation instrument and an evaluation document. Although some scholars suggest individualizing a teacher's evaluation, most districts use the same process for all teachers.

\section{The Politics of Teacher Evaluation}

The evaluation process may be influenced by politics. "Politics shapes the character of personnel evaluation" (Bridges \& Groves, 1999, p. 321). Politics can be defined as the power relationships between people and groups of people in a field such as education (Encarta, 2007). Power refers to the capacity to do something, to exert control and influence over the actions of others, and the authority to act (Encarta, 2007). The political power of personnel evaluations lies in the possibility of influencing another's 
behavior to get them to do something they may otherwise not do and to possibly change a course of events (Bridges \& Groves, 1999).

To understand the dynamics of politics in personnel evaluation, numerous factors needs to be considered. Factors to consider include: "types of personnel evaluation decisions, the actors, their access to these decisions, their interests, their sources of power, their goals, their strategies, their coalitions, their conflict and their outcomes" (Bridges \& Groves, 1999, p. 322).

There are three major types of decisions: ground rules, procedures and evaluations (Bridges \& Groves, 1999). Ground rule decisions involve granting tenure, providing due process, determining dismissal based upon a reason in state statute and collective bargaining conditions. Procedures refer to how the evaluation is conducted, what data is used and who does the evaluation. Procedural decisions may be made at the state-level, locally or through collective bargaining. Evaluation decisions are the summary judgments rating an employee's performance and any actions taken that are based on these judgments.

There are seven categories of actors, according to Bridges and Groves (1999). The actors include:

1. Architects - politicians setting the ground rules (e.g., governor, legislatures) and local school board members.

2. Evaluators - those conducting the evaluation.

3. Evaluatees - those who are being evaluated.

4. Referees - hearing officers, arbitrators, court judges or anyone advising the actors on the legal aspects of evaluations. 
5. Prime beneficiaries - those who gain or lose from the education providers, usually students and their parents.

6. Employee organizations - groups representing employees such as unions and statewide organizations.

7. Superintendents - the chief executive officer of the local board of education responsible for implementing state and local policies.

8. Miscellaneous - those lacking direct access to the decision-making process but having an interest in the outcome (e.g., business people, professors; Bridges \& Groves, 1999).

The amount of access actors have to the different types of decisions varies, according to Bridges and Groves (1999). The examples that follow are of actors with the highest level of access to each major type of decision. Governors, state legislatures, and employee organizations have a high level of access to ground rules decisions. Local school boards, superintendents and employee organizations have a high level of access to procedure decisions. Principals, employees, employee organizations, superintendents and local school boards have a high level of access to employee evaluation decisions.

Actors may have various interests which represent their concerns, preferences and wants, according to Bridges and Groves (1999). The usual dominant interests include: job security, unfair treatment, educational quality, educational reform and conflict avoidance.

Each actor pursues their own interests in personnel evaluation, translating them into specific goals (Bridges \& Groves, 1999). The translation of interests into goals causes an action to take place. "For example, employee organizations in their quest for 
job security may attempt to initiate legislation that provides employees with tenure" (Bridges \& Groves, 1999, p. 325).

Conflict may occur when the interests and goals of the actors are in disagreement. Actors may use their power in an attempt to influence the outcomes, according to Bridges and Groves (1999). Actors with greater power, more resources and the most effective strategies are those that are more likely to attain their goals. "The level of power that actors possess is relative to how much power other actors have in a particular situation" (Bridges \& Groves, 1999, p. 326).

Actors with common interests may bond together to concentrate their power toward the achievement of a particular goal (Bridges \& Groves, 1999). The actors form a coalition. Coalitions may be temporary or sustained over a period of time but they generally are issue specific, according to Bridges and Groves (1999). Coalitions may result because an actor issues a threat of reprisal to another actor, promises a trade-off or provides emotional satisfaction.

Peterson (2001) discussed the implications of political viewpoints on teacher evaluation. Changes in evaluation policy and procedures are indicative of the national opinion of teacher quality, explained Peterson (2001). A declining opinion of teacher quality results in evaluation policies aimed at identifying deficient teachers and improving their performance. In contrast, the opinion that teacher quality is stable or improving results in evaluation aimed at highlighting best practices and giving teachers increased choice in data collection. Therefore, evaluation policy is often the subject of reform. 


\section{Legal Requirements of Teacher Evaluations}

When designing an evaluation system, care must be given that all essential elements for the process are present. "Experience has shown that personnel evaluations often lead to legal proceedings" (Joint Committee on Standards for Education Evaluation [Joint Committee], 1988, p. 151). Teacher evaluation policies produce numerous questions of fairness and judgment resulting in educators seeking the settlement of educational controversies (e.g., revocation of license, suspension from duties, dismissal, nonrenewal) from the courts (Peterson \& Kauchak, 1982). "Although courts do not enact laws as legislative bodies do, they significantly influence educational policies and practices by interpreting constitutional and statutory provisions" (Cambron-McCabe et al., 2004, p. 499).

To satisfy constitutional provisions, federal laws, state laws, case law findings, employment contracts and collective bargaining agreements, teacher evaluation policies need to follow legal guidelines and incorporate specific requirements to create both a professionally sound and legally defensible performance evaluation system (Stufflebeam \& Pullin, 1998). The development of legally sound teacher evaluation policies should address the Uniform Guidelines on Employee Selection Procedures [Uniform Guidelines]

of 1978, due process requirements (Peterson \& Kauchak, 1982; Scriven, 1980; Stronge \& Tucker, 2003), open-records laws (Scriven, 1980; Sullivan \& Zirkel, 1998) and collective bargaining.

\section{Uniform Guidelines}

Legally sound teacher evaluation policies must adhere to the Uniform Guidelines (1978). The purpose of the Uniform Guidelines was to create a consistent set of 
principles to be used in employee selection decisions (e.g., hiring, promotion, demotion, retention. The Uniform Guidelines (1978) assist “employers, labor organizations, employment agencies, and licensing and certification boards to comply with requirements of Federal law prohibiting employment practices which discriminate on grounds of race, color, religion, sex, and national origin" (p. 120).

Following the adoption of the Civil Rights Act of 1964 by Congress, four federal agencies (i.e., the Equal Employment Opportunity Commission (EEOC), the U.S. Department of Justice (DOJ), the U. S. Department of Labor (DOL), and the Civil Service Commission) each created their own set of guidelines for hiring minorities. The independently created sets of guidelines were not consistent and sometimes conflicted with each other. In 1978, the four agencies jointly developed the Uniform Guidelines basing them upon "court decisions, the previously issued guidelines of the agencies, and the practical experience of the agencies, as well as the standards of the psychological profession" (p. 120).

The EEOC applies the Uniform Guidelines (1978) in the enforcement of Title VII of the Civil Rights Act of 1964. Title VII prohibits an employer from discriminating against an employee on the basis of race, color, religion, sex or national origin. According to the EEOC (2008b), the Uniform Guidelines apply to federal government employments and to all private employers, state and local governments, and educational institutes that employ 15 or more individuals. Private and public employment agencies, labor organizations and apprenticeship committees are also covered by the guidelines (1978). 
Adverse Impact. The principles addressed by the Uniform Guidelines (1978) include: adverse impact, validity and disparate treatment. Adverse impact is defined as "a substantially different rate of selection in hiring, promotion, or other employment decision which works to the disadvantage of members of a race, sex, or ethnic group" (Uniform Guidelines, 1978, p. 140). Under the guidelines, the employee selection procedure, "any measure, combination of measures, or procedure used as a basis for any employment decision" (1978, p. 141) must not demonstrate an adverse impact unless the procedure is justified through a validation process.

To determine adverse impact, the Uniform Guidelines (1978) require that employment records and other information pertinent to selection procedures and employment opportunities be available for inspection. The records, or a sampling if there are large numbers, must be maintained by sex, applicable race and ethnic group. An employer can then calculate if adverse impact exists by first calculating the selection rate for each group and second, dividing the highest selection rate into each of the other groups. If any group is $80 \%$ less than the selection rate for the highest group, adverse impact is usually indicated (EEOC, 2008b).

If adverse impact is evident in the employer's total selection process, then the Uniform Guidelines (1978) require an evaluation of the individual components of the selection process. If adverse impact is not evident, the employer is not usually expected to evaluate the individual components of the total selection process. There are two exceptions when adverse impact is not evident of the total selection process but the employer may be required to evaluate the individual components: when the selection process is a key factor in continuing assignment patterns of incumbent employees based 
on prior discriminatory employment practices and when the weight of court decisions or administrative interpretations insist that a job requirement is not job related (e.g., height, weight). Job related refers to "critical or important job duties, work behaviors or work outcomes as developed from the review of job information" during a job analysis (Uniform Guidelines, 1978, p. 128).

Validity. For any part of the selection process that indicates evidence of adverse impact, evidence of a validity study is required (Uniform Guidelines, 1978). A validity study demonstrates the job relatedness of a particular selection procedure. The validity study must be based upon a review of information about the job for which the selection procedure was used. The information review should include a job analysis, "a detailed statement of work behaviors and other information relevant to the job" (Uniform Guidelines, 1978, p. 141).

There are three types of validity studies outlined by the Uniform Guidelines (1978) that may be used to satisfy this requirement: criterion-related validity, content validity and construct validity. Criterion-related validity studies "consist of empirical data demonstrating that the selection procedure is predictive of or significantly correlated with important elements of job performance" (Uniform Guidelines, 1978, p. 123). Using criterion-related validity studies involves completing a job analysis to identify relevant work behaviors. The work behaviors, defined as activities that are performed to meet the objectives of the job, become the criterion measures.

The second type of validation procedure that can be used is a content validity study. "A content validity study should consist of data showing that the content of the selection procedure is representative of important aspects of performance on the job for 
which the candidates are to be evaluated" (Uniform Guidelines, 1978, p. 123). Employers can justify the knowledge, skills and abilities of a job by content validity by operationally defining each and showing that each is a necessary prerequisite to successfully performing the job.

The third type of validity study is construct validity. A construct validity study "should consist of data showing that the procedure measures the degree to which candidates have identifiable characteristics which have been determined to be important in successful performance in the job for which the candidates are to be evaluated" (Uniform Guidelines, 1978, p. 123). Completion of the job analysis is used to identify work behaviors and the underlying construct for successful performance. Each construct should be named and defined.

Disparate Treatment. In addition to adverse impact and validity, the Uniform Guidelines (1978) addressed the issue of disparate treatment. Disparate treatment is the unequal treatment of a group. "Disparate treatment occurs when members of a race, sex or ethnic group have been denied the same employment, promotion, membership, or other employment opportunities as have been available to other employees or applicants" (Uniform Guidelines, 1978, p. 127). Selection procedures, even though they are validated, may not be imposed upon one group when other employees, applicants, or members have not been subjected to that standard also.

Employees or applicants that have been denied equal treatment in the past because of prior discriminatory practices or policies must be afforded the same opportunities that existed for other employees or applicants during the period of discrimination, according to the Uniform Guidelines (1978). The persons discriminated against in the past "should 
be allowed the opportunity to qualify under less stringent selection procedures previously followed, unless the user demonstrates that the increased standards are required by business necessity" (Uniform Guidelines, 1978, p. 127). An opportunity for retesting and reconsideration should be provided to persons discriminated against in the past, according to the guidelines.

Protection from discrimination is guaranteed by the $14^{\text {th }}$ Amendment and federal legislation (e.g., Title I, Title V). According to the EEOC (2008a), Title I of the Americans with Disabilities Act of 1990 (ADA) prohibits employers with 15 or more employees from discriminating against qualified individuals with disabilities "in job application procedures, hiring, firing, advancement, compensation, job training, and other terms, conditions, and privileges of employment" (n.p.). Title V, like Title VII, prohibits an employer from discriminating against an employee on the basis of race, color, religion, sex or national origin. The EEOC (2008a) further explains that a disabled person "has a physical or mental impairment that substantially limits one or more major life activities; has a record of such an impairment; or is regarded as having such an impairment" (p. 1). If the applicant or employee has a disability but can perform the important functions of a job, with or without reasonable accommodations (e.g., modifying work schedules, making facilities handicap accessible), they are considered qualified, according to the $\operatorname{EEOC~(2008a).~}$

Affirmative Action. Federal enforcement agencies may require employers to develop affirmative action plans to assure equal employment opportunities when there is evidence of past discriminatory practices. Affirmative action programs must include "the use of lawful selection procedures which assist in remedying the effects of prior 
discriminatory practices, or the achievement of affirmative action objectives" (Uniform Guidelines, 1978, p. 127). An affirmative action program may be designed for race, color, sex, or ethnic consciousness. Selection procedures used in affirmative action programs must "be based upon the ability or relative ability to do the work" (Uniform Guidelines, 1978, p. 123). Employers who are not obligated by Federal enforcement agencies to implement an affirmative action program are encouraged to adopt voluntary affirmative action programs, according to the guidelines.

An employer's use of an affirmative action program will be considered by Federal enforcement agencies when the selection process is examined for adverse impact. Consideration will be given to the goals and timetables of the program and to the progress the employer has made in both carrying out the program and in meeting the goals and timetables.

The Uniform Guidelines (1978) stipulated requirements that addressed adverse impact, validity and disparate treatment. The requirements were intended to justify the legality of assessment procedures used in employee selection and for all procedures (e.g., performance appraisals) used as a basis for making employee promotion decisions (Kleiman \& Durham, 1981). Legally sound teacher evaluation policies should incorporate the requirements of the Uniform Guidelines.

\section{Due Process}

Another legal requirement of teacher evaluation policies is due process, guaranteed by the 14th Amendment of the United States Constitution. The Due Process Clause "prohibits states from depriving citizens of life, liberty, or property without due process of law" (Cambron-McCabe et al., 2004, p. 13). Due process is “a citizen's right 
to justice, the entitlement of a citizen to proper legal procedures and natural justice" (Encarta, 2007, n.p.). The intention of due process is to ensure an individual's fair treatment when charged with legal violations (Taylor, Tracy, Renard, Harrison \& Carroll, 1995).

Adequate notice. The three basic principles of due process are: adequate notice, fair hearing and judgment based on evidence (Erdogan, Kraimer \& Liden, 2001). The first principle, adequate notice, must be timely, provide the nature of the specific charges and allow sufficient time for a response to be prepared (Cambron-McCabe et al., 2004). The employer must provide sufficient time between issuing the notice and the date of the hearing to ensure the employee has ample time to prepare a defense. State laws and local policies usually add very specific requirements relating to form, timeliness and content of the notice, according to Cambron-McCabe et al. (2004). If the timeline is not specified it must be considered reasonable.

In the context of teacher evaluation, adequate notice requires that the evaluatee be provided the "objectives and standards of the performance appraisal system before the performance appraisal period starts" (Erdogan et al., 2001, p. 210). The objectives and standards have to be published, distributed and explained to the evaluatee, according to Taylor et al. (1995).

Fair hearing. The second principle of due process, fair hearing, provides the opportunity for all parties to appear before an impartial tribunal ( e.g., the Board of Education in the context of teacher evaluations) to state their views and present all relevant evidence that might affect the employment decision (Cambron-McCabe et al., 2004). The initial hearing entails ensuring the procedure was correct and "determining if 
there are reasonable grounds to believe that the charges are true and that they support the dismissal" (Cambron-McCabe et al., 2004, p. 406). The employee must be given the opportunity to provide commentary before the decision is made (Taylor et al., 1995). The commentary may include the employee's explanation of certain events, a self-appraisal intended to challenge the performance evaluation and other input to be considered during the decision making process (Erdogan et al., 2001; Taylor et al., 1995).

"Fair hearing requires that employees receive training in the appraisal process to ensure that they possess the knowledge needed to challenge assessments perceived to be unfair" (Taylor et al, 1995, p. 496). Although fair hearing is a basic element of due process, an employee can waive this right and decide not to proceed with a challenge. The employee may not request a hearing, refuse to attend it or in some cases choose an alternative hearing procedure, according to Cambron-McCabe et al. (2004). An alternate hearing procedure (e.g., a grievance mechanism, an impartial referee) may be offered via state laws or regulations (Cambron-McCabe et al., 2004).

Judgment based on evidence. The third principle of due process is judgment based on evidence. A preponderance of evidence or substantial evidence must be produced (Cambron-McCabe et al., 2004). Proof by a preponderance of evidence means that the majority of the evidence presented supported the decision and that any reasonable mind might accept the evidence as being adequate to support the conclusion of the hearing (Cambron-McCabe, 2004).

In the context of performance appraisals, in order for the judgment to be based on evidence, the validity of the evaluation must be ensured (Erdogan et al., 2001). One way validity of the performance evaluation process can be ensured is the uniform application 
of nondiscriminatory performance standards to all employees "without yielding to external pressure, corruption, or personal prejudice" (Taylor et al., 1995, p. 497).

Procedural due process. There are two components of due process: procedural and substantive. The three principles just discussed (i.e., adequate notice, fair hearing, judgment based on evidence) are the requirements of one component of due process, procedural. Procedural due process guarantees basic fairness in instances when the government threatens one's life, liberty or property interests, according to CambronMcCabe et al. (2004). "Most teacher termination cases have focused on procedural due process requirement" (Cambron-McCabe et al., 2004, p. 393).

Substantive due process. The other component of due process is substantive. Substantive due process protects a person from arbitrary government action that could impair life, liberty, or property interests. Substantive due process requires that a state action is based on a valid objective and that the means related to attaining that objective are reasonable (Cambron-McCabe et al., 2004).

Liberty rights refer to concerns about one's reputation, the fundamental rights relative to marriage, family matters and personal privacy, and the personal freedoms embodied in the Bill of Rights (e.g., religious freedom, freedom of speech, freedom of press), according to Cambron-McCabe et al. (2004). Liberty claims to due process can be established if the actions of the employer compromises constitutionally protected rights, causes damage to the employee's reputation or prevents the opportunity for the employee to obtain other employment (Cambron-McCabe et al., 2004). A liberty interest is involved when a teacher is dismissed for allegedly assisting students to cheat on a state 
test because the teacher's professional integrity and reputation are impugned (CambronMcCabe et al., 2004).

Property rights are expectations of entitlement established by state laws, regulations and contracts, according to Cambron-McCabe et al. (2004). "The granting of tenure gives teachers a property entitlement to continued employment" (CambronMcCabe et al., 2004, p. 13) as long as the teacher's performance is judged to be satisfactory. Property claims to due process can be established by tenure status, contractual agreement and actions of the school board that create a valid expectation of reemployment (Cambron-McCabe et al., 2004). When a tenured teacher is dismissed, it must be for a statutory cause (e.g., incompetence, insubordination, immorality) or a property interest may be implicated (Cambron-McCabe et al., 2004).

In addition to the constitutional requirements of due process, state and local laws may stipulate further conditions. Progressive discipline and remediation plans are processes used to demonstrate the use of affirmative steps toward improvement of employee performance (Falcone 1997; Nolan \& Hoover, 2007). As a part of due process, the employer may have to show that positive steps were taken to provide employees the opportunity to improve (Falcone, 1997).

\section{Progressive Discipline}

Progressive discipline is often a legal requirement of teacher evaluation policies, especially policies developed in states with collective bargaining (Stone, 1981). In the 1930s, "unions demanded that companies eliminate summary terminations and instead develop a progressive system of penalties" (Grote, 2006, p. 6) providing employees with protection against job loss without first being aware that their job was at risk. Progressive 
discipline is the application of increased levels of discipline to employees repeatedly violating workplace rules (Bernardi, 2003) or performing unsatisfactorily (Stone, 1981).

Progressive discipline serves multiple purposes. First, according to McDaniel (2007), progressive discipline protects employers against claims of discrimination and, second, provides the opportunity to notify employees when performance standards are not being met or when standards of conduct are being violated. Third, progressive discipline provides an opportunity for performance improvement and, fourth, enables employers to terminate ineffective employees (Heathfield, 2007).

The goal of progressive discipline is to assist in creating a better employee (Bernardi, 2003), "not to threaten or punish, but to collaborate and be fair" (DelPo \& Guerin, 2007). Collaboration between the employer and employee (e.g., the administrator and the teacher) can, according to DelPo and Guerin (2007):

1. Allow early intervention and correction of unwanted behaviors,

2. increase communication between employer and employee,

3. improve morale and employee retention,

4. ensure consistency and fairness, and

5. provide the groundwork for fair, legally defensible termination for employees who do not improve.

The graduated range of disciplinary responses in progressive discipline is from mild to severe (DelPo \& Guerin, 2007). The discipline level chosen depends on the nature and the frequency of the infraction. For a minor infraction, the mildest level of discipline is implemented. Progressively more severe penalties can be imposed on employees each time they repeat an offense (Sherman, 2005). For a severe infraction, the 
severest level of discipline may be the first level to be implemented, according to DelPo and Guerin (2007). The "disciplinary response should be appropriate and proportionate to the employee's conduct" (DelPo \& Guerin, 2007, p. 106).

The discipline levels in progressive discipline often include: verbal warning, written reprimand, suspension and termination (Bernardi, 2003). Counseling (Heathfield, 2007) or "a nonadversarial inquiry" (Scriven, 1997, p. 130) is sometimes added as a precursor to the verbal warning. Both counseling and nonadversarial inquiries are conversations concerning the problematic behavior and offers of support while seeking solutions to solve the performance problem.

Verbal warning. A verbal warning provides notice to the teacher that there are deficiencies (i.e., actions and performance that are not acceptable). The verbal warning must fully indicate the performance that is deemed unsatisfactory, the time allowed for remediation and the next disciplinary step if the performance remains unsatisfactory (Scriven, 1997). It may be advisable for the administrator to recommend to the teacher to contact the teacher union for legal advice, according to Scriven (1997).

Written reprimand. The written reprimand is more structured than the verbal warning. According to Scriven (1997), the formal, written notification of reprimand must involve six elements:

1. The notice must state all grounds of concern. During the ensuing remediation period no new concerns or complaints can be addressed that were not on the original notice. This prevents the employee from being in a position of “defending blind" (p. 132), attempting to improve without having knowledge of the total concerns. 
2. The notice must relate to job-related performance only.

3. The notice must indicate why the behavior of concern is a violation of duty or a justification for disciplinary action.

4. The notice must specify a reasonable amount of time for a remediation period.

5. The notice must specify what constitutes adequate remediation, how the remediation period will be judged and who will determine if the remediation was adequate.

6. The notice must provide a timeline that includes: a reasonable time for a reply and rebuttal from the employee, time for the remediation period, time for reevaluation, time for a second rebuttal, time for consideration of the rebuttal and time for a decision to proceed or not.

Suspension. In progressive discipline, the step following the written reprimand is suspension, according to Bernardi (2003). A suspension prohibits an employee from working for a specified time period. Suspensions are used for major infractions of policy or for repeated offenders who have already received a written reprimand, and may be with or without pay (Bernardi, 2003; Scriven, 1997). Suspensions with pay may occur when the charges are being disputed and resolution is pending. Otherwise, the suspension would be without pay (Scriven, 1997).

Termination. Termination is the severest form of discipline and the final level of progressive discipline. Termination may be used in cases of continued unsatisfactory performance or for offenses that can no longer be tolerated. "If the employee does not respond to discipline, the last violation becomes the culminating incident - the point at which you no longer need to tolerate the misconduct and may terminate the employee for 
just cause" (Bernardi, 2003, p. 2). The decision to terminate and the specific reasons must be explained to the employee in person, and should be documented in a letter (Stone, 1981). Information concerning the appeals process should be included.

Termination of a teacher can be classified as a dismissal or a nonrenewal, according to Cambron-McCabe et al. (2004). The termination classification will impact the teacher's due process (i.e., procedural) rights (Cambron-McCabe et al., 2004).

The first classification, dismissal, "refers to the termination for cause of any tenured teacher or a probationary teacher within the contract period" (Cambron-McCabe et al., 2004, p. 394). The teacher has a property entitlement due to both tenure and an employment contract and is guaranteed full procedural protection, according to CambronMcCabe et al. (2004). Justifiable cause (e.g., immorality, incompetence, insubordination, willful neglect of duty) is identified in state law as a requirement for the dismissal of a teacher and must be indicated on the notice of discharge (Cambron-McCabe et al., 2004). Justifiable cause is an assurance to employees that dismissal will occur only for reasons “that are arguable before an arbitrator or court of law" (Stone, 1981, p. 407). If dismissal does not relate to justifiable cause, as outlined in state statute, the termination can be invalidated by the courts. "Procedural safeguards ensure not only that a teacher is informed of the specific reasons and grounds for dismissal, but also that the school board bases its decision on evidence substantiating those grounds" (Cambron-McCabe et al., 2004, p. 394).

The second classification of teacher termination is nonrenewal, the employment contract of a probationary teacher is not renewed. Some states do not grant procedural protection for nonrenewal termination, according to Cambron-McCabe et al. (2004). A 
probationary teacher "can be terminated for any or no reason, as long as the reason is not constitutionally impermissible" (e.g., denial of protected speech; Cambron-McCabe et al., 2004, p. 395). Most state statutes provide a specific timeline for nonrenewal terminations that require the nonrenewal notice be issued to the probationary teacher on or before a specific date that is prior to the end of the employment contract (Cambron-McCabe et al., 2004). Other states may require a written reason for nonrenewal and may provide a hearing if requested by the teacher (Cambron-McCabe et al., 2004). At the hearing, the teacher is provided with the reason for nonrenewal and is given the opportunity to address the school board.

\section{Remediation Plans}

In addition to progressive discipline, the use of remediation plans is another process used to demonstrate the use of positive steps toward improvement of employee performance. Remediation, educational assistance to improve skills (Encarta, 2007), may be required by state law to be included in teacher evaluation policy. Veir and Dagley's (2002) research identified fifteen states with statutory reference to remediating teachers. Courts have invalidated teacher dismissals when administrators have failed to provide legally required remediation plans and periods, according to Sullivan and Zirkel (1998). In states where remediation is not a requirement, "the courts exhibited considerable reluctance to impose such procedures" (Sullivan \& Zirkel, 1998, p. 170).

Before a remediation plan is developed the administrator must first understand the cause of the specific unsatisfactory behavior and determine if the behavior is remediable (Bridges \& Groves, 1984; Stronge \& Tucker, 2003). Remediable behavior generally refers to teaching responsibilities (e.g., classroom instruction, classroom management; 
Stronge \& Tucker, 2003). Irremediable behavior (e.g., physical or psychological abuse of students, embezzlement of school funds), as defined by case law, is behavior that "has seriously damaging effect on students or the school community or that could not have been corrected even with prior warning" (Stronge \& Tucker, 2003, p. 81).

There are three major causes of unsatisfactory performance that may be addressed with a remediation plan: managerial and/or organizational shortcomings, a problem with the employee and outside, non-job-related influences (Steinmetz, 1969). Managerial and/or organizational shortcomings that may contribute to unsatisfactory behavior include: the criteria used to evaluate the teacher, lack of communication between the administrator and the teacher about the criteria used in evaluation, the teacher's teaching assignment (e.g., too many preparations), the teacher's lack of resources and the lack of opportunity for teacher professional development (Bridges \& Groves, 1984).

The second major cause of unsatisfactory teacher performance is a problem with the employee. According to Bridges and Groves (1984), the teacher may lack the motivation to perform satisfactorily and will not exert the effort needed for competent teaching or the teacher may be motivated but lacks the necessary skills or ability to perform satisfactorily. The teacher may have one or more "personal pathologies" (Bridges \& Groves, 1984, p. 31): alcoholism, drug addiction, mental illness or emotional distress.

The third major cause of a teacher's unsatisfactory performance is a result of an outside influence. According to Bridges and Groves (1984), problems in the classroom may arise from problems outside the workplace. Marital difficulties, conflicts with 
children and financial problems may affect a teacher's performance (Bridges \& Groves, 1984).

If the unsatisfactory behavior has been determined to be remediable, a remediation plan may be developed. The remediation plan provides an opportunity for the teacher to improve, demonstrates administrative support and is necessary for due process, according to Nolan and Hoover (2007).

Open Records

Another legal requirement that needs to be addressed in teacher evaluation policy is the open-records law (i.e., freedom of information; Scriven, 1980; Sullivan \& Zirkel, 1998). The United States Freedom of Information Act [FOA] (2002) ensures public access to U.S. government records. All records are presumed open or public unless the government can substantiate a reason for not releasing specific information. Agencies of the U.S. government are required to disclose their records upon written request unless the information is lawfully exempt from disclosure.

One of the nine categories of exemptions for nondisclosure of information is "personnel and medical files and similar files" (FOA, 2002, p. 10). Disclosure of these files constitutes "a clearly unwarranted invasion of personal privacy" (FOA, 2002, p. 10). Without statutory guidance, courts usually grant access to teacher evaluations and other personnel records (e.g., disciplinary records, job references), according to Sullivan and Zirkel (1998). "When the statutes fail to provide specific guidelines, courts continue to interpret the applicability of such statutes to school personnel records by weighing the potential benefits to the public interest against potential harm" (Sullivan \& Zirkel, 1998, 
p. 375). There are a minority of states providing statutory exclusion from the public disclosure of teacher evaluations, according to Sullivan and Zirkel (1998).

State statute may not always protect information pertaining to educational personnel from being disclosed (Fossey, 1998). State statutes and local policies regarding confidential settlement agreements are often not upheld by the courts as valid exemptions from public disclosure, according to Fossey (1998). Confidential settlement agreements are sometimes used by school districts to allow an employee to resign in lieu of entering into a dismissal action (Fossey, 1998). Teachers with poor teaching skills and unprofessional behavior, and the buy-out of a superintendent's contract are examples cited by Fossey (1998) that may involve confidential settlement agreements. According to Fossey (1998), courts “have struck down school districts' confidential settlement agreements on the grounds that such agreements violate state open-records laws" (p. 62). Most courts will require a school district to disclose a confidential settlement agreement if a legal suit is filed under the jurisdiction's open-records statute, according to Fossey (1998).

\section{Collective Bargaining}

In addition to state statutes regarding open records, states may have laws permitting or prohibiting collective bargaining. "To bargain collectively is the performance of the mutual obligation of the employer and the representative of the employees to meet at reasonable times and confer in good faith with respect to wage, hours and other terms and conditions of employment" (National Labor Relations Board [NLRB] 2008, p. 6). 
There are three legal categories of collective bargaining topics: mandatory, permissive and prohibited (Munk, 1998). Mandatory topics are those subjects that employers are obligated to bargain with employees' representatives (e.g., pay rate, work rules, seniority, grievance procedures; Munk, 1998). Permissive topics are neither obligated nor prohibited subjects of bargaining (e.g., formulation of new positions recruiting standards, code of ethics, teacher evaluation; Bridges \& Groves, 1999; Munk, 1998). Prohibited topics are those subjects that are unenforceable as a matter of law and cannot be bargained away in an agreement (e.g., establishment of the starting day for the school year, authorization of charter school contracts; Munk, 1998).

Collective bargaining was a result of the National Labor Relations Act (NLRA) established by Congress in 1935. The NLRA was enacted "to protect the rights of employees and employers, to encourage collective bargaining, and to curtail certain private sector labor and management practices, which can harm the general welfare of workers, businesses and the U. S. economy" (NLRB, 2008, p. 1). The NLRA granted employees the right to self-organize, to create and participate in labor organizations and to collectively bargain. "Employers were prohibited from engaging in certain anti-union practices...designated as unfair labor practices" (Saidens, 1980, p. 6).

\section{Summary}

Dismissals of teachers as a result of teacher evaluation ratings have led to controversy and many times to legal proceedings. To withstand judicial scrutiny, evaluation practices and policies should provide evidence of satisfying constitutional provisions, federal and state laws, previous case law findings, employment contracts, and collective bargaining agreements. Legal requirements for teacher evaluation policies to 
include elements outlined in the Uniform Guidelines, due process, progressive discipline, remediation and open records. Evaluation policies complying with these legal requirements will be professionally sound and legally defensible.

\section{Personnel Standards}

Although the adoption of personnel standards is not a legal requirement, doing so may also produce an evaluation system that is more professionally sound and legally defensible. Their adoption is also suggested by researchers interested in improving the professional standing of teachers (Stronge \& Tucker, 2003). "The foundation for an effective teacher evaluation system...is the identification of well-defined job performance standards" (Stronge \& Tucker, 2003, p. 30). Standards, a uniform level of quality against which others are measured, serve as an established model and have a fixed value (Allee, 1984). They are described by Danielson and McGreal (2000) as being the cornerstone of an evaluation system.

Personnel standards should have clarity, be unambiguous and represent the criteria that defines good teaching (Danielson \& McGreal, 2000). The use of personnel standards will assist in providing consistency to the process teacher evaluation. The function of standards for teachers is to present a shared view of the principles that can be used for acceptable personnel evaluation procedures so that deficiencies in practice may be corrected (Joint Committee, 1988). The standards for teachers must specify the capabilities that educators are expected to possess and that can be applied in a variety of contexts (Nolan \& Hoover, 2007). They must be clearly and accurately described to ensure performance evaluations are fair and comprehensive (Danielson \& McGreal, 2000). 
Descriptions of standards should be three-tiered (Stronge \& Tucker, 2003). Tier one should address the domain (i.e., area of responsibility). Tier two should address performance standards (i.e., job responsibilities). Tier three should address performance indicators (i.e., sample behaviors).

Domains are the categories of teachers' job responsibilities and may be used to cluster performance standards, according to Stronge and Tucker (2003). The domains of a classroom teacher may include: instruction, assessment, learning environment, communication and community relations, and professionalism (Stronge \& Tucker, 2003). These would differ from a resource teacher's domains that may include: program management, assessment, direct services/instruction, collaboration and professionalism. The domains must define the educator's work (Stronge \& Tucker, 2003).

Performance standards, organized under the appropriate domain, are the responsibilities and duties of the teacher's job, according to Stronge and Tucker (2003). The performance standards form the basis for the creation of job descriptions and should be the basis for performance evaluation. The performance standards provide clarity on the job responsibilities in each domain and are broader in nature than the performance indicators (Stronge \& Tucker, 2003).

Performance indicators are examples of behavior and the most specific units of performance (Stronge \& Tucker, 2003). They are important for the actual documentation of the teacher's accomplishments “A performance indicator is a typical behavior that can be observed or documented to determine the degree to which an employee is fulfilling a given performance standard" in a specified domain (Stronge \& Tucker, 2003, p. 35). 
This section will discuss The Joint Committee Standards, Charlotte Danielson's system of standards and rubrics, and The National Board for Professional Teachers Standards. A brief history about the development of the three sets of standards and a description of each will be provided.

\section{The Joint Committee Standards}

Twelve professional organizations concerned with improving education established the Joint Committee in 1975 with the goal of developing, reviewing and improving teaching standards that could be used in teacher evaluation systems (Stufflebeam \& Pullin, 1998). The sixteen member committee used five major assumptions to guide their work. The assumptions included:

1. The fundamental purpose of personnel evaluation must be to provide effective services to students and society,

2. personnel evaluation practices should be constructive and free of unnecessarily threatening or demoralizing characteristics,

3. personnel evaluations are vital for planning sound professional development experiences,

4. disagreements about what constitutes good teaching, good administration, and good research may complicate personnel evaluation, but such disagreements are warranted, and

5. personnel evaluations vary in complexity and importance; consequently, applications of the standards may be crucial in some circumstances but out of place or even counterproductive in others. (p. 8-9) 
The result was the creation of The Personnel Evaluation Standards (Joint Commission, 1988), 21 standards to assist with the assessment of systems used for the evaluation of educators.

The domain and the nature of the Joint Committee's (1988) standards are broad and general. The domain is described as focusing on systems that evaluate both the performance and the qualifications of personnel and are intended to have an extensive range of techniques (e.g., interviews, observation, portfolio development). The standards can be used in educational agencies that deal with student growth and development. They cover multiple professional jobs in educational systems. The nature of the standards are “at the level of elaborated general principles" (Joint Committee, 1988, p. 10) without differentiating sharply between acceptable and unacceptable reliability.

There are four categories of Joint Committee (1988) standards corresponding to four basic attributes of sound evaluation. The categories include: propriety, utility, feasibility and accuracy.

The "Propriety Standards reflect the fact that personnel evaluations may violate or fail to address certain ethical and legal principles" (Joint Committee, 1988, p. 11). The primary principle of the Propriety Standards is based on the belief that since schools exist to serve students the personnel evaluations must concentrate on how effectively educators meet the needs of all students. The aim of the Propriety Standards is to protect the rights of students, instructors, counselors, administrators, evaluators, and any person affected by an evaluation. These five standards require that the conduction of evaluations be legal, ethical, and with due regard for the evaluatee and anyone involved in the evaluation. 
The "Utility Standards are intended to guide evaluations so that they will be informative, timely, and influential" (Joint Committee, 1988, p. 11). This set of standards requires that information provided through the evaluation be used in improving the performance of the educator, the evaluator has expertise and credibility, and that the use of the evaluation be predetermined. The aim of the Utility Standards is to assist systems with the recruitment of quality staff and to provide relevant feedback during their employment so they deliver "high quality service" (Joint Committee, 1988, p.13).

The "Feasibility Standards promote evaluations that are efficient, easy to use, viable in the face of social, political, and governmental forces and constraints, and that will be adequately funded" (Joint Committee, 1988, p. 13). This set of standards includes practical procedures, political viability and fiscal viability.

The "Accuracy Standards aim at determining whether an evaluation has produced sound information about an educator's qualifications or performance" (Joint Committee, 1988, p. 13). By comparing the Accuracy Standards to the overall rating of a personnel evaluation, the evaluation's validity is assessed.

The standards are intended to be reviewed, revised and expanded, according to the Joint Committee (1988). Scriven (1997) suggested the addition of a legal standard noting that "The Personnel Evaluation Standards is almost entirely silent on the subject of due process" (p. 136). Stufflebeam and Pullin (1998) were of the same opinion and stated that “while The Personnel Evaluation Standards include standards of practical viability, political viability, and fiscal viability, they lack the obvious companion section on legal viability" (p. 215). The second edition of The Personnel Evaluation Standards (Joint Committee, 2007) has a new standard, P7, Legal Viability. The standard states: 
Personnel evaluations should meet the requirements of all federal, state, and local laws, as well as case law, contracts, collective bargaining agreements, affirmative action policies, and local board policies and regulations or institutional statutes or bylaws, so that evaluators can successfully conduct fair, efficient, and responsible personnel evaluations. (p. 29)

\section{Danielson's System of Standards}

In the early 1990s while working on the Praxis III, an assessment to measure the classroom skills of novice teachers, for the Educational Testing Service (ETS), Charlotte Danielson created a system for training evaluators to judge the strengths and weaknesses of teachers. Danielson received positive feedback from evaluators she was training and urged ETS to adapt and use the Praxis III for veteran teachers as well. When ETS declined, Danielson received permission to pursue the project herself. Danielson published Enhancing Professional Practice: A Framework for Teaching, consisting of standards and rubrics for evaluating teachers, in 1996.

According to Toch and Rothman (2008), Danielson's system of standards and rubrics are used or adapted by many to create comprehensive evaluation systems. The Teacher Advancement Program, Connecticut's Beginning Educator Support and Training Program, the evaluation models for schools in Cincinnati and Toledo, Ohio, and the National Board for Professional Teaching Standards are examples cited by Toch and Rothman (2008).

Danielson used four major categories to illustrate the components of teaching. The categories include: 
1. Domain 1: Planning and Preparation includes comprehensive understanding of the content to be taught, knowledge of the students' backgrounds, and designing instruction and assessment. It has six components.

2. Domain 2: The Classroom Environment addresses the teacher's skill in establishing an environment conducive to learning, including both the physical and interpersonal aspects of the environment. It has five components.

3. Domain 3: Instruction is concerned with the teacher's skill in engaging students in learning the content, and includes the wide range of instructional strategies that enable students to learn. It has five components.

4. Domain 4: Professional Responsibilities addresses a teacher's additional professional responsibilities, including self-assessment and reflection, communication with parents, participating in ongoing professional development, and contributing to the school and district environment. It has six components. (Danielson \& McGreal, 2000, p. 23)

In addition to the standards, Danielson created scoring rubrics for evaluators. The rubrics describe what teachers need to do to earn the rating of unsatisfactory, basic, proficient and distinguished. Rubrics are designed for each component of the four domains and address each of these three elements: knowledge of content, knowledge of prerequisite relationships and knowledge of content-related pedagogy (Danielson \& McGreal, 2000, p. 98).

National Board for Professional Teaching Standards

In 1987, an independent, nonprofit, nonpartisan organization, the NBPTS, was created. Their mission was three-fold: 
1. to establish high and rigorous standards for what accomplished teachers should know and be able to do,

2. to develop and operate a national voluntary system to assess and certify teachers who meet these standards, and

3. to advance related education reforms for the purpose of improving student learning. (Linquanti \& Peterson, 2001, p. 6)

The governing board was comprised of 63 members that included educators, elected officials and leaders of business and community particular to each certification area. The majority of the members were classroom teachers. The standards for each of the 25 certificates in 15 content areas were created by separate standards committees of educators in that specific discipline. The committee members represented a national cross-section of professionals. The contractor for the NBPTS was the Educational Testing Service (Linquanti \& Peterson, 2001).

The NBPTS believes that students learn be building on prior understanding, and that good teachers reflect on the interaction of student strengths and needs along with learning contexts and content (Weiss \& Weiss, 1998). There are five core propositions that frame these beliefs and characterize National Board Certified Teachers. The propositions include:

1. Teachers are committed to students and learning,

2. teachers know the subjects they teach and how to teach those subjects to students,

3. teachers are responsible for managing and monitoring student learning, 
4. teachers think systematically about their practice and learn from experience, and

5. teachers are members of learning communities.(np)

National Board certification is voluntary and open to pre-K-12 teachers.

Candidates must have a baccalaureate degree and three years or more of experience.

Teachers must have a state teaching license or teach in an accredited school (Linquanti \& Peterson, 2001).

Earning National Board certification is a rigorous process. The candidate has three years from initial application to complete the process. During the first year, the portfolio must be completed and the assessments completed. The candidate is allotted five months to assemble a portfolio providing evidence of their teaching practice.

"Evidence includes unedited videotapes of classroom teaching, student work samples and written commentaries analyzing how the evidence provided meets the teaching standards for the certificate" (Linquanti \& Peterson, 2001, p. 3). The candidate must also complete six thirty-minute assessments of their subject-matter knowledge within a three-week time period.

The applicant must be willing to spend between 200 and 400 hours demonstrating teaching proficiency. The five areas of proficiency include: “commitment to students' learning, knowledge of subject and of how to teach it, monitoring of student learning, ability to think systematically and strategically about instruction, and professional growth" (Toch \& Rothman, 2008, p. 7).

The portfolio and assessments are scored by teachers who have already qualified for National Board certification (Linquanti \& Peterson, 2001). If the scores of the 
assessment and the portfolio do not meet the performance standard, the candidate may retain scores from successful portfolio entries and assessments. The candidate may redo unsuccessful portfolio entries and retake any part of the assessment that is needed to raise their overall score (Linquanti \& Peterson, 2001).

Although some scholars in the field of teacher evaluation advocate the adoption of personnel standards, several versions exist. The decision to include one set of standards over another in an evaluation system may be controversial. Inclusion of any of the three discussed here, The Joint Committee Standards, Danielson's System of Standards and the National Board for Professional Teaching Standards, would be beneficial to an evaluation system by making it more professionally sound and judicially defensible.

\section{Relevant Court Cases}

"The relationship between pubic schools and their employees is one of the most frequently litigated aspects of American education" (Beckham \& Zirkel, 1983, p. v). This relationship has been influenced by landmark decisions of the United States Supreme Court and the United States Court of Appeals. According to Zirkel (2001, 2002), several court decisions have had a major impact on both educational practice and educational law but school law experts differ in their opinions of the most significant cases. The following cases are often noted for their importance: Pickering v. Board of Education of Township High School District 205 (1968), Griggs v. Duke Power Co. (1971), Perry v. Sindermann (1972), Board of Regents v. Roth (1972), Brito v. Zia Company (1973), Chance v. Board of Examiners (1974) and Mount Healthy City School District v. Doyle (1977). These seven cases are presented chronologically to show how case law relative to teacher evaluation has evolved. 
Pickering v. Board of Education of Township High School District 205 (1968)

"Public educators have a First Amendment right to express their views on issues of public concern: dismissal or other retaliatory personnel action - such as transfers, demotions, or written reprimands - cannot be predicated solely on protected speech" (Cambron-McCabe et al., 2004, p. 344). Teacher Marvin Pickering was dismissed for writing a letter to the local newspaper criticizing the school board's fiscal policies. The letter contained some false statements and was critical about the manner in which certain board of education members and the superintendent had previously allocated revenues. The Board chose to dismiss Pickering after a full hearing stating that the teacher's comments were detrimental to district's operation of the school. The Court applied a balancing test and concluded that as a teacher Pickering was offering an "informed and definite opinion" (Pickering, 1968, p. 5), adding to public debate, and a detrimental effect to the operation of the school did not exist as a result of his letter (i.e., his relationship with his immediate supervisor was not jeopardized and his classroom performance was not negatively effected; Cambron-McCabe et al., 2004).

Griggs v. Duke Power Company (1971)

Evaluation must be job-related as a result of the Griggs (1971) case. The U. S. Supreme Court ruled against the Duke Power Company for requiring a high-school education and satisfactory scores on both the Wonderlic Personnel Test and the Bennett Mechanical Comprehension Test when selecting employees for transfer and promotion. A group of African-American employees, who were less likely to have a high-school diploma and were more likely to have lower scores on the general aptitude tests, brought the suit against their employer because they were selected at a much lower rate for 
transfers and promotions than their white counterparts. The Court decided that since the company's transfer and promotion requirements were adversely impacting the AfricanAmerican employees, the Duke Power Company could use the selection process only if it was a reasonable measure of job performance or if the employer could prove it was a business necessity. The Court held that the requirements were not directly related to the jobs being performed and were not a business necessity (Griggs, 1972).

Perry v. Sindermann (1972)

A nontenured employee having an expectancy of reemployment due to continuing employment under numerous one-year contracts and the employer's policies and practices is guaranteed procedural due process and therefore must be supplied with cause when not rehired. The U. S. Supreme Court's decision in Perry v. Sindermann (1972) held that a teacher's public criticism of superiors did not constitute a basis for termination of employment regardless of the teacher's tenure. A junior college professor, Mr. Sindermann, worked for the state college system for ten years under one-year contracts. After public disagreements with the Board of Regents, Sindermann's employment was not renewed for the next school year. He was given neither a reason for the termination nor a hearing. Sindermann alleged the non-renewal was due to the disagreements with the regents and therefore infringed upon both his rights to free speech and de facto (i.e., informal) tenure. The court decided that Sindermann did have an objective expectation of reemployment and was entitled to procedural due process before his employment was terminated. Nonrenewal denied Sinderman procedural safeguards and violated his freedom of speech right (Perry, 1972). 


\section{Board of Regents v. Roth (1972)}

Unlike Perry, Mr. Roth, who was also a nontenured teacher on a one-year contract, was not guaranteed procedural due process (i.e., provided cause and a hearing) because he could not show an expectancy of reemployment contingent upon his employer's policies and practices. In Roth, the U. S. Supreme Court decided that nonrenewal of a nontenured teacher "did not require procedural protection unless impairment of a protected liberty or property interest could be shown" (CambronMcCabe et al., 2004, p. 396). Mr. Roth, a college teacher with a one-year contract, was not rehired for the next school year and was not given a reason or a hearing that addressed the termination. Roth believed he had been denied due process. Because Wisconsin statute required completion of four continuous years of employment for tenure status, the regents would only be required to provide due process if Roth could show that the termination damaged his reputation and community standing or that it imposed a stigma against someone else hiring him, according to the Court. Because Roth could not prove either of these he was not entitled to procedural due process.

Brito v. Zia Company (1973)

"Ill-defined and subjectively based evaluation criteria" (Allen \& Jarvis, 1983, abstract) is prohibited as a result of Brito v. Zia Company (1973). A group of Zia Company employees claimed that the performance evaluation test used by their employer was not valid according to the requirements of the EEOC and Title VII of the Civil Rights Act of 1964. Both the EEOC and Title VII forbid the intentional discrimination of individuals on the basis of race, sex, color, religion or national origin. Zia's performance evaluation test included the following content areas: volume of work, quality of work, job 
knowledge, dependability and cooperation. The evaluation was conducted by supervisors and foremen while the employees were working. Employees with low scores were laid off when the Zia Company reduced their work force. According to Brito v. Zia Co. (1973), the court found that Zia's performance evaluation test was

1. invalid and resulted in a discriminatory employment practice,

2. based on judgments and opinions instead of definite identifiable criteria supported by record,

3. based on subjective observations instead of Zia's own guidelines, and

4. not administered and scored under controlled and standardized conditions.

Chance v. Board of Examiners (1974)

Evaluation criteria must demonstrate content validity as a result of Chance $v$. Board of Examiners (1974). Content validity consists of data showing that the content of the selection procedure represents important aspects of job performance (Uniform Guidelines, 1978). In this court case, the New York City Schools were found to have used unconstitutional examinations for supervisory positions that discriminated against black and Puerto Rican applicants. The court decided that the appointment of supervisors must be based on factors correlated with job relatedness, fairness and performance evaluation.

Mount Healthy City School District v. Doyle (1977)

"The exercise of protected speech will not invalidate a dismissal action if the school board can show by a preponderance of evidence that it would have reached the same decision had the protected speech not occurred" (Cambron-McCabe et al., 2004, p. 344). A three-step test for causation must be applied when a public employee believes an 
adverse personnel decision is in retaliation for constitutionally protected behavior (e.g., freedom of expression; Zirkel, 2001/2002). A principal's memo about the teacher's dress code was read by teacher Doyle during a radio station's call-in show. Doyle had prior altercations with teachers, staff and students. Doyle was dismissed due to lack of professionalism, obscene gestures and the memo incident. According to Zirkel (2001/2002), the three-step test states that:

First, the employee must prove that the expression concerns a public, not intramural, issue and that the right to speak outweighs the employer's responsibility to provide effective public services. Second the employee must show that the expression was a substantial factor in the adverse action being challenged. Third, the employer must prove that it would have taken the adverse action regardless of the employee's protected expression. (p. 9-10)

\section{Summary}

Personnel evaluation policies and statutes have been and will continue to be affected by judicial resolutions. It is reasonable to expect teacher evaluation statutes to continue to evolve based upon decisions rendered by our Courts. Repeated challenges to personnel practices make it imperative for educators to become knowledgeable of constitutional provisions and personnel statutes.

\section{Problems with Teacher Evaluation}

There exists a negative perception of teacher evaluation by some. Described as inadequate (Danielson \& McGreal, 2000), ineffective (Marshall, 2005) and superficial (Toch \& Rothman, 2008), traditional teacher evaluation has sometimes been viewed as a 
"protective mechanism" for incompetent teachers (Scriven, 1980, p.1). The negative perception may be a result of the problems associated with teacher evaluation.

Some researchers feel that traditional teacher evaluation is not adequate for assessing the performance of today's teachers. The role of the educator has expanded in the twenty-first century adding additional teacher responsibilities (Danielson \& McGreal, 2000; Kyriakides, Demetriou \& Charalambous, 2006). The expanded role of a teacher may include assisting with curriculum development, planning action research, serving as a team leader, facilitating staff development, and monitoring the progress of students. The changes in teacher evaluation have not paralleled those role changes. Today's evaluation still portrays the perception of teachers, their duties and responsibilities of the early 1900s (Danielson \& McGreal, 2000).

Writers in the field of performance-based teacher evaluations cite numerous problems related to teacher evaluation. For this proposed research, I am using Allee's (1984) definition of problem: "a matter proposed for solution" ( $p$ 293). The problems of teacher evaluation can be placed into three categories:

1. Principal: the lack of, limited or inadequate training; the lack of subject matter expertise; the use of personal impressions instead of data to rate a teacher; the lack of time to conduct evaluations; the failure to give a negative evaluation; and, the responsibility of performing conflicting dual roles (i.e., summative $\mathrm{v}$ formative).

2. Teacher: a lack of trust in the principal and the lack of participation in the design of the evaluation process. 
3. Process: the atypical lessons observed; the absence of one, perfect evaluation instrument; the use of one data source; the lack of or inadequate feedback; the lack of central office support; and, the infrequent evaluation of tenured teachers.

\section{The Principal}

Most teacher evaluation systems use one evaluator, the teacher's immediate supervisor (i.e., the principal). Problems associated with the use of principals as evaluators include: the lack of, limited or inadequate training; the lack of subject matter expertise; the use of personal impressions to formulate an evaluation rating instead of data; the lack of time to conduct evaluations; the failure to rate a teacher negatively; and, the responsibility of performing conflicting dual roles (i.e., summative $v$ formative).

Training issues. The first problem of using principals as evaluators is the lack of, limited or inadequate training. Training is the instruction that provides the skills necessary for a person to engage in an intended practice (Halverson et al., 2004) and must be ongoing during the evaluator's career. As a result of proper evaluator training, the accuracy and consistency of evaluations will be increased, according to Goldrick (2002), and the perceived evaluator credibility of the principal will be enhanced (Tucker, 1997).

Evaluator training is needed to ensure the effectiveness of an evaluation system (Tucker, 1997; Wise et al., 1984). Some researchers believe that effectiveness depends upon producing evaluation ratings that are consistent between evaluators (Goldrick, 2002; Toch \& Rothman, 2008). This requires evaluators to be trained specific to the evaluation system they will be using (e.g., TAP; Toch \& Rothman, 2008). A system may employ well-designed evaluation instruments but "an apparently thorough checklist of 
behaviors, competencies, or duties is of little use in inexpert hands" (Peterson, 2001, p. 61). The value lies in knowing when a particular component of the checklist should or should not be performed. Training can provide this knowledge (Peterson, 2001).

Evaluator training is also helpful for the identification of incompetent teachers, when needed. Teacher evaluation was one of the three issues "of fundamental importance in the identification and response to incompetent teachers" (Tucker, 1997, p. 116). Incompetence is often one of the grounds listed as a reason for dismissal that is found in state statute. Dismissals due to incompetence are frequently appealed. Scriven (1988) used this fact to stress the importance of evaluator training. "If you use judges, you have to validate them or face the skepticism of the kind of judges you run into in court" (Scriven, 1988, p. 21). One way evaluators can be validated is by the type and amount of training they are provided.

Subject matter expertise. Another problem in this category is the evaluator's lack of subject matter expertise. According to Wise et al (1984), the evaluator's level of expertise should at least equal that of the teacher being evaluated. In middle and high schools where teachers may teach only one subject, it is usually impossible for the evaluator to have the same subject matter expertise (Toch \& Rothman, 2008). Still, the evaluator is expected to comment on: accuracy of the information presented, relevance to student concerns, appropriateness for the level of student ability and appropriateness for course objectives (Duke \& Stiggins, 1986).

In the absence of subject matter expertise, the evaluation will often focus on how the teacher is teaching instead of what is being taught. This can lead to the loss of evaluator credibility, in the opinion of Duke and Stiggins (1986). In the 2004 study by 
Halverson et al, evaluators lacking subject matter expertise "were not perceived as having the ability to evaluate instructional content decisions or pedagogical content knowledge" by some teachers ( $\mathrm{p} 12)$.

Using impressions instead of data. Some principals tend to base evaluation ratings on their assumptions or overall impressions of teachers instead of using data. An impression is a psychological effect or an influence on the mind (Allee, 1984) and is not data based. Using impressions to evaluate teachers can produce the halo effect which ensures that the teachers believed by the principal to be most effective will receive the highest evaluation ratings (Medley \& Coker, 1987). Producing the halo effect is considered to be a rating error that affects the accuracy of the evaluation by minimizing its authority, according to Kleiman and Durham (1981).

Time issues. Lack of time to complete evaluations is another problem with principals as evaluators. Although some principals listed evaluating teachers as their "single most desired role" (Peterson, 2001, p. 11), it was often left undone and replaced with other administrative tasks. Meetings and supervising extracurricular activities were two tasks rated as low priority that ended up consuming large amounts of time, greater than projected by administrators (Peterson, 2001). Principals must also devote a great amount of time to disciplining students and the operational duties of the school leaving them with little time to evaluate (Marshall, 2005).

Avoid giving negative evaluations. Another problem with principals as evaluators may be their reluctance to negatively evaluate a teacher (Tucker, 1997). Administrators may avoid giving a negative evaluation and decide to tolerate the situation and protect the 
teacher. According to Bridges (1993), administrators may tolerate the poor performing teacher due to one or more of these three reasons:

1. The tenured teacher's job security. The rights afforded to the tenured teacher may cause some administrators to hesitate giving a negative evaluation. The administrator may be concerned about the possibility that the court will protect the tenured teacher's rights by ruling against the school (Bridges, 1993; Tucker, 1997).

2. The ambiguity of terms associated with teacher evaluation. Terminology such as incompetent teacher has no precise meaning. Without a specific definition, evaluators may lack the confidence that their judgment of teacher incompetence will be upheld in court (Bridges, 1993).

3. The principal's personal discomfort with confrontation. Evaluators may desire to avoid the conflict and discomfort associated with negative evaluations. Concerns about their working relationship with teachers, and being perceived as the bad guy may cause the evaluator to remain silent (Bridges, 1993).

Conflicting dual roles: Formative versus summative. The conflicting dual roles of a principal, being responsible for both formative and summative evaluations, may also be a problem. Formative evaluations offer feedback and information focusing on teacher improvement while summative evaluations offer an interpretation of the data collected at the end of a specified time period. It can be difficult for the principal to perform as both the person seeking to collaborate and help the teacher to improve and the person responsible for issuing the final judgment of that teacher's performance (Peterson, 2001, Scriven, 1988). "The mutual trust, open communication, and collegial relations needed in 
the formative evaluation relationship are seriously jeopardized by the critical, judgmental role required of the evaluator in the summative evaluation setting" (Hazard, 1993, p. 7). The Teacher

The next category of problems pertains to the teacher being evaluated. The lack of trust the teacher has with the principal and the lack of involvement in the design of the evaluation are two problems facing the evaluatee.

Lack of trust. Mutual trust between the principal and the teacher is "the first casualty in the summative evaluation process," according to Hazard (1993, p. 7). Trust is difficult to attain in an evaluation system featuring the principal as both the judge and the confidante (McColskey \& Egelson, 1993). Trust must be present for the teacher to confide in the principal about any difficulties being experienced, and to feel comfortable enough to take risks and attempt new strategies in the classroom. If the teacher feels the principal will use the information negatively in an evaluative rating, such information and risk-taking might be withheld (McColskey \& Egelson, 1993). Teachers are unlikely to be open and forthright if they are accompanied by a feeling of vulnerability, according to Hazard (1993).

Lack of teacher involvement in evaluation design. The lack of involvement in the design of the evaluation process is also a problem for the teacher. Teacher involvement in the design process, not being the norm, is advocated by several scholars (Conley \& Glasman, 2008; Peterson, 1987; Ponticell \& Zepeda, 2004; Trenta et al., 2004). Teachers need to be involved in the development of evaluation criteria and the instrument, in validating the criteria and the instrument, and in analyzing and interpreting the data (Trenta et al., 2004). Involvement provides teachers with opportunities for reflection 
about their teaching, adds credibility to the evaluation process, and increases opportunities for collegial interactions with administrators and other teachers (Peterson, 2001).

\section{The Evaluation Process}

Another category of problems with teacher evaluations is the evaluation process. Described as flawed (Danielson \& McGreal, 2000) and fatally invalid (Scriven, 1988), the current evaluation process does not promote improvement in teacher performance (Peterson, 1987). Problems in this category include the atypical lessons observed, the lack of one perfect evaluation instrument, the use of one data source, the lack of or inadequate feedback, the lack of central office support and the infrequent evaluation of tenured teachers.

The atypical lesson observed. The lessons observed by principals can be a problem with the evaluation process. The observed lesson is atypical due to the advanced notice of the observation providing the teacher the opportunity to present a glamorized lesson for the benefit of the principal. The observed lesson is only an isolated part of a teacher's instruction because it represents only "a small part of a teacher's effort to inspire students and convey knowledge and skills" (Marshall, 2005, p. 729). This isolated lesson may not be a true sampling of the teacher's performance but "a stage, polished presentation" (Bridges, 1993, p. 8) that is not indicative of the teacher's true behavior.

Poor evaluation instruments. Another problem with the evaluation process is the absence of one perfect evaluation instrument. The evaluation instrument is used to document the data collected and to provide the evaluator's judgment about a teacher's 
performance (Danielson \& McGreal, 2000). Problems with evaluation instruments include:

1. The content - excessive items (Peterson \& Kauchak, 1982), and the inclusion or exclusion of evidence of student achievement due to the tenuous link between student learning and teacher quality (Peterson, 1987; Peterson \& Kauchak, 1982), Scriven, 1988; Soar \& Soar, 1975; Toch \& Rothman, 2008).

2. The lack of consensual criteria defining quality teaching (Bridges, 1993; Danielson \& McGreal, 2000, Scriven, 1988; Wise et al., 1984).

3. The use - formative (i.e., teacher improvement) versus summative (i.e., personnel decisions; Duke \& Stiggins, 1986; Kyriakides et al., 2006; McColsky \& Egelson, 1993).

4. The design - indicating only the general status of exemplary, satisfactory or unsatisfactory (Marshall, 2005); and, local development of the evaluation instrument without adequate resources and skilled personnel (Veir \& Dagley, 2002).

Use of one data source. Another problem with the evaluation process is the use of one data source. Data is a collection of information from which inferences may be deduced, according to Allee (1984). Traditional evaluation uses an inadequate number of classroom observations as the main source of evaluation data (Duke \& Stiggins, 1986; Peterson \& Kauchak, 1982; Scriven, 1988; Wise \& Darling-Hammond, 1984). Additional sources of data are needed (Peterson, 1987; Peterson \& Kauchak, 1982, Stronge \& Tucker, 2003; Toch \& Rothman, 2008). Multiple data sources provide documentation of a variety of performance indicators. They may depict a greater depth of the teacher's 
abilities and facilitate the measurement of additional teaching goals. Examples of multiple data sources include: student and parent surveys, peer review, documentation of professional activities, student achievement and teacher test scores (Peterson, 2001).

Failure to provide adequate feedback. Failure of the principal to provide adequate feedback to the teacher is another problem with the evaluation process. Feedback is the constructive criticism offered by the evaluator as a response to what has been learned about the teacher during the evaluation process (Encarta, 2007). Feedback is the most important part of the evaluation process because without it the teacher's behavior will not change (Duke \& Stiggins, 1986).

Principals may offer limited or poor feedback or they may not offer any feedback at all (Halverson et al., 2004; Toch \& Rothman, 2008). Examples of poor feedback are ceremonial congratulations and double-talk (Bridges, 1993). Ceremonial congratulations refer to generalities that do not contain a specific reference to what was actually observed (e.g., I really enjoyed the class). Double-talk is a language that masks the evaluator's criticisms. The criticism may be embedded in compliments, constructive suggestions and in words of encouragement (Bridges, 1993).

The lack of central office support. Another problem with the evaluation process may be the lack of support from the central office. "No plan for evaluating teachers is going to work without the total commitment and support of the Superintendent and the Board" (Bridges, 1993, p. 154). The central office may lack in their show of support by:

1. Portraying the task as one of low importance and priority (Kyriakides et al., 2006; Marshall, 2005; Toch \& Rothman, 2008,), 
2. failing to form evaluation committees dedicated to the gathering of evaluation data (Peterson et al., 2001),

3. failing to provide ample time in school schedules for the principal to conduct evaluations (Tucker, 1997),

4. failing to provide principals access to legal counsel for advice (Tucker, 1997),

5. failing to provide resources for remedial assistance (Tucker, 1997),

6. failing to provide opportunities for professional conversations between administrators and teachers using a common language (Danielson \& McGreal, 2000),

7. failing to provide professional development to teachers and administrators in the evaluation process (Danielson \& McGreal, 2000),

8. failing to model the practice of evaluation by evaluating principals (Scriven, 1988),

9. failing to hold administrators responsible for their evaluation ratings of teachers (Scriven, 1988), and

10. failing to follow through with the dismissal of poor performing teachers (Bridges, 1993).

Infrequent evaluation. The infrequent evaluation of tenured teachers is another problem with teacher evaluation. Teachers need to be evaluated annually because competence is relative and cannot be assumed to exist year after year (Scriven, 1988). According to studies by Hazi and Arredondo Rucinski (2009) and the NCTQ (2007), the majority of states do not evaluate tenured teachers on an annual basis. Some are 
evaluated on cycles of three or five years while other states do not require the evaluation of tenured teachers. This is contrary to the norm of most professions.

\section{Summary}

Multiple problems exist with teacher evaluation, according to writers in this field. Problems written about the principal as the evaluator are in the areas of training, subject matter expertise, personal impressions, daily schedule, personal conflicts and their roles within the school. Writers mention trust and participation issues as problems with teachers. Problems noted about the evaluation process include the lesson, evaluation instrument, data sources, feedback, central office and the frequency of evaluations. The existence of these various problems may decrease the effectiveness of the evaluation process and increase judicial proceedings.

\section{National Trends in Teacher Evaluation}

Reform movements sometimes create trends. Trends are tendencies or inclinations (i.e., favoring one thing over another), according to Allee (1984).Trends can be slow to develop and may be short-lived or long lasting. Trends in teacher evaluation develop as the search continues to create a better, more efficient evaluation system, one that is not as flawed in its attempt to monitor teacher quality as the traditional system (Danielson \& McGreal, 2000). This section of literature review provides an overview of the national trends in teacher evaluation as educators seek more productive means of rating teaching performance. Various types of teacher evaluation processes will be defined and their criteria examined. Peer Assistance and Review, teacher portfolios and performance-based pay programs represent trends or alternatives designed contrary to traditional teacher evaluation systems. 


\section{Peer Assistance and Review}

Peer Assistance and Review (PAR) is an alternative process to traditional teacher evaluation and has been used in various districts (e.g., Cincinnati, Columbus and Toledo, OH; Dade County, FL; Rochester, NY; Salt Lake City, UT) over the last two decades. PAR enables “deeper structural changes" (Weiss \& Weiss, 1998, p. 3) of teacher responsibilities by providing greater opportunities for teachers to engage in the decision making process, the evaluation process and collaboration with colleagues. The PAR process uses consulting teachers, teachers that were identified for their excellence and then released from their teaching duties for two to three years (Goldstein, 2007). The consulting teachers function as mentors to new teachers and provide interventions for veteran teachers having difficulty (i.e., a veteran teacher receiving an unsatisfactory evaluation; Goldstein, 2007). Both new and veteran teachers working with consulting teachers are referred to as participating teachers.

Consulting teachers have greater opportunities than principals have to interact with participating teachers, according to Goldstein (2007). The classrooms of participating teachers are observed weekly by the consulting teachers. In addition, participating teachers have the opportunity for daily contact with the consulting teacher, if needed.

Besides observing the participating teacher, the consulting teacher formally evaluates the participating teacher three times per year. The consulting teacher reports the participating teacher's progress to the PAR panel which is usually comprised of teachers, administrators, the union president and the district personnel director. The consulting teacher also offers the panel employment recommendations for the participating teacher. 
The panel, basing its recommendation on the consulting teacher's recommendation, may elect to remove a participating teacher from the classroom or recommend employment to the superintendent (Goldstein, 2007).

There is evidence of six key factors distinguishing PAR from traditional evaluation, according to Goldstein (2007). The key factors include: time devoted to the task of evaluation, evaluation's link to professional development, transparency of the evaluation process, the role of the teacher union, confidence of the evaluator when making evaluative decisions and teacher's performance accountability. Each factor will be discussed briefly.

The first factor distinguishing PAR from traditional evaluation is the difficulty principals had allocating adequate time for teacher evaluation. Sometimes principals completed fewer evaluations than expected or required, according to Goldstein (2007). Principals agreed that their "lack of time allowed teachers not meeting standards to slip through the cracks with the traditional evaluation process" (Goldstein, 2007, p. 485). Releasing consulting teachers from their full-time teaching positions enabled them to focus on their participating teacher caseloads (Goldstein, 2007). The consulting teachers were able to visit each participating teacher on an average of once per week and complete multiple formal evaluations per year. The consulting teachers were easily accessible to the participating teacher and "on call to meet participating teacher needs as they arose" (Goldstein, 2007, p. 486). The consulting teacher demonstrated a higher level of involvement in the participating teacher's daily schedule and responsibilities that principals could not match while tending to day to day school operations (Goldstein, 2007). The consulting teachers provided a level of support not available from principals. 
Evaluation's link to professional development is the second factor differentiating PAR from traditional teacher evaluation. Teacher evaluation has traditionally been summative in nature and less often formative. Both summative and formative evaluations were found to be compatible with PAR, according to Goldstein (2007). In districts where evaluations were both summative and formative, the summative review may have been the responsibility of an administrator while the professional development may have been the responsibility of a support provider. In other districts, one person may have functioned in both capacities (Goldstein, 2007). The arguments of several authors (Costa and Garmston, 1994; Nolan, 1997; Popham, 1988) in reference to the use of both summative and formative evaluations were cited by Goldstein (2007). The arguments included: the incompatibility of summative and formative evaluations, the same person functioning as the evaluator and the support provider, and the lack of communication between the evaluator and the support provider.

Traditional summative evaluations by administrators have been based upon little data and infrequent, announced classroom visits. Administrators often lack expertise as an evaluator and expertise in the content area or grade level of the evaluatee. As a result, the evaluation process "is uneducative for teachers," according to Goldstein (2007, p. 87). Consulting teachers focused on formative evaluations and provided support to participating teachers so that the summative evaluations were based on ongoing classroom observations and personal knowledge of the participating teacher in their classrooms. The needs identified through the evaluation process were then linked to professional development activities. The linkage assisted in: building trust, establishing 
rapport, providing instructional feedback, individualized support, evaluations grounded in performance standards, and evaluator training (Goldstein, 2007).

The third factor distinguishing PAR from traditional teacher evaluation was transparency of the evaluation process. Greater transparency or clarity of both a teacher's performance in the classroom and the evaluation process existed with PAR than with traditional teacher evaluation, according to Goldstein (2007). Teachers work in isolation behind closed classroom doors minimizing both interaction with the principal and data to be used in the evaluation process. According to Goldstein (2007), minimal data has been cited as one reason principals have given inflated teacher evaluation ratings.

A second reason was the desire to minimize or avoid conflict possibly due to a personal connection or lack of support from the district. Principals' evaluative decisions typically have been made in isolation without presentation of a defense of the decision, according to Goldstein (2007). Principals were not held accountable for their evaluative decisions (Goldstein, 2007).

PAR “opens the door to practice” (Goldstein, 2007, p. 491) by placing a consulting teacher in a participating teacher's classroom on a regular basis. Consulting teachers had ongoing access to teachers in their classrooms throughout the school year which generated a great amount of data for formulating the evaluative decision, according to Goldstein (2007). Consulting teachers were utilized district-wide for specific grade and content areas, broadening their perspective to evaluation and disallowing personal connections (Goldstein, 2007). Consulting teachers presented their evaluation findings to the PAR panel, defended their decision and ensured they were accountable for their evaluative decisions (Goldstein, 2007). 
The role of teachers' unions was the fourth factor distinguishing PAR from traditional teacher evaluation. Teachers' unions have been confrontational in teacher dismissal cases and have caused increased spending of both cost and time during the dismissal process (Goldstein, 2007). Viewed by some as an unbeatable adversary, the union may have prompted hesitation of principals contemplating teacher dismissal. Alternatives to dismissal (e.g., transfer to another school, resignation, retirement) were often sought by principals. The PAR process required "that the union sign off on a district's proposal for the creation of a PAR program" (Goldstein, 2007, p. 494) and that the union president be the co-leader of the PAR panel. PAR has enabled the union to become a defender of the teaching profession instead of individual teachers, according to Goldstein (2007).

Confidence of the evaluator when making personnel decisions was the fifth factor that separated PAR from traditional teacher evaluation. Principals routinely doubt themselves as they make evaluative decisions because of the lack of time available for evaluations, their lack of involvement in professional development activities, nonspecific standards used for evaluation, the isolation of both the evaluation and decision making processes, and the traditional role of teachers' unions (Goldstein, 2007).

The sixth key factor is teacher's performance accountability. Prior to the use of consulting teachers as evaluators, incompetent teachers were rarely terminated, according to Goldstein (2007). Of the teachers being evaluated under the PAR method, twelve and one-half percent of the new teachers were not recommended for reemployment and onehundred percent of the veteran teachers were encouraged to retire (Goldstein, 2007). "This constituted a major change in accountability when compared to prior dismissal 
rates in the district" (Goldstein, 2007, p. 496). During the school year immediately preceding the use of PAR, 0.1 percent of the teachers were nonrenewed, and none of those were for performance problems (Goldstein, 2007).

\section{Portfolios for Teacher Evaluation}

Portfolios provide documentation of information and activities relative to a teacher's practice. Wolf, Lichtenstein and Stevenson (1997) identified four key features of a teacher's portfolio:

1. Structured around teaching standards, individual goals and school goals;

2. contained examples of student work and teacher practice;

3. included captions and explanations that are reflective of the portfolio's contents; and,

4. used for ongoing professional dialogue between the teacher and other teachers and supervisors.

The chief concerns about portfolios used for evaluation are structure and fairness, according to Wolf et al. (1997). The portfolio requirements must be consistent. "Ensuring that the evaluation process is manageable and fair requires putting several pieces into place in advance, including sound content and performance standards for teachers, specifying the requirements for constructing the portfolio, and designing an efficient evaluation system" (Wolf et al., 1997, p. 7).

School districts may find portfolios beneficial to use for evaluations. Portfolios are considered by some to be authentic (i.e., representative of real-life tasks), complex, flexible and adaptable as they support accountability and performance improvement goals (Tucker, Stronge, Gareis \& Beers, 2003). Completing a portfolio encourages reflection 
and self-assessment while providing evidence that teaching responsibilities have been met (Tucker et al., 2003). They can be a part of both formative and summative evaluations, according to Tucker et al. (2003).

There are three disadvantages of using portfolios for evaluative purposes, according to Wolf et al. (1997). Portfolio construction is time consuming and diminishes the feasibility of their use (Tucker et al., 2003; Wolf et al., 1997). The second disadvantage is the difficulty in scoring a portfolio. Evaluation of a portfolio must be based upon clear content standards and specific performance standards, and must include feedback to the teacher (Wolf et al., 1997). The final concern is that the size of the portfolio makes storage cumbersome, according to Wolf et al. (1997).

According to the research of Tucker et al. (2003), portfolios can fulfill the documentation of teaching responsibilities for an evaluation system. "Fully $90 \%$ of all artifacts selected and included by teachers had content validity" (Tucker et al., 2003, p. 583). One of the artifacts used most frequently to provide evidence of instructional responsibilities was the lesson plan.

Another finding by Tucker et al. (2003) was that using portfolios with the associated training provided greater differentiation in evaluation ratings. Prior to their use, $96 \%$ of the staff was rated above average compared to $43 \%$ when using portfolios. Significant differences appeared in each of the four rating categories.

A third finding by Tucker et al. (2003) was that both teachers and administrators had moderate levels of confidence with the use of portfolio evaluation. Nontenured teachers viewed the portfolio evaluation more favorably, according to Tucker et al. (2003). This was possibly due to the increased use of portfolios in preservice programs. 
Administrators believed that the portfolios were beneficial due to the broader perspective presented of the teacher's work. Both groups rated the process high on fairness and accuracy.

The final finding reported by Tucker et al. (2003) was that the impact of portfolios on professional development was "least definitive" (p. 591). Teachers realized that they had increased the use of self-reflection but were not aware of an impact on their teaching performance.

Tucker et al. (2003) concluded that the use of teacher portfolios as a mechanism of evaluation enhanced both accountability and purposes of professional development. Areas of quality instruction and professional growth were evidenced in the portfolio. Samples of units of study reflected the processes of teaching, student work samples were evidence of the products of teaching, and reflections or annotations about artifacts provided the teacher's beliefs about teaching. The researchers, believing that portfolios improved teacher self-evaluation and professionalism, commended the use of portfolios as being a significant source of information in evaluating teachers.

\section{Performance-Based Pay Programs}

School districts began experimenting again with performance-based pay programs following the report, A Nation at Risk (NCEE, 1983). Prior attempts at developing performance-based pay programs occurred in the early 1900s, the 1920s and the 1960s (DeSander, 2000). The programs were designed to encourage pay bonuses for a teacher that would be issued on an individual basis as the teacher's performance strengthened.

Most of the programs were short-lived, according to Podgursky and Springer (2007). Complaints were voiced by administrators that found performance-based pay 
programs "unduly burdensome and time consuming" (DeSander, 2000, p. 307). Others objected about the difficulty in devising a performance monitoring system that would measure the value of an individual teacher, and the belief that a performance-base pay program would reduce incentives for teachers to collaborate as a team (Podgursdy \& Springer, 2007).

Performance-based pay programs have become more reliable over the last twenty years, according to Podgursky and Sringer (2007). Longitudinal student databases permitting more precise estimates of a teacher's value-added effect are now used in many states. This may permit the use of more dependable payment for output programs (Podgursky \& Springer, 2007).

The Teacher Incentive Fund enacted by Congress, initially provided “ $\$ 100$ million annually on a competitive basis to school districts, charter schools, and states to fund experiments and pilot performance-based pay projects" (Podgursky \& Springer, 2007, p. 554) and stimulated both a renewed interest in performance pay and the development of several state-level performance-based compensation programs. The amount of funding was reduced in 2007 to $\$ 200,000$ but several states are still experimenting with performance-based pay programs.

Performance-based pay programs differ from state to state. Florida has implemented E-Comp which provides bonuses to the top $10 \%$ of their teachers based on their value-added estimates. Denver's program, ProComp, provides annual pay increases for their teachers based on performance measures that include student test scores. Minnesota legislature has created Q-Comp, providing \$260 per student to be used in 
incentive pay systems. Texas introduced a pay program called Governor's Educator Excellence Awards that is based in part on student scores.

A model performance-based pay program, the Teacher Advancement Program (TAP), has been developed by the Milken Family Foundation and is "attracting attention in many states" (Podgursky \& Springer, 2007, p. 554). TAP restructures the teaching profession by:

1. Recruiting high-quality teachers - advertise statewide, offer competitive salaries, establish a career continuum and provide teacher-led professional development.

2. Providing teachers with a career continuum - organize staff into inductee teacher, teacher, specialist teacher, mentor teacher, and master teacher. Each role has additional responsibilities, authority and salary.

3. Implementing teacher-led professional development - teachers network for approximately two hours per week organized by grade level, content area or both. Master and mentor teachers facilitate the identification of student learning needs. Individualized teacher coaching is provided. Once per week teachers team teach and evaluate each other's instruction.

4. Establishing a rigorous teacher accountability system - each teacher's skills, knowledge and responsibilities are assessed and evaluated six times a year. The teacher-level value-added affect is assessed. The school-level value-added effect is assessed.

5. Granting commensurate compensation based on position, skills, knowledge, and performance - teachers can be compensated differently based on their position and their performance. (Schacter \& Thum, 2005, p 328) 
The four elements of TAP were created to counter "many of the traditional drawbacks that plague the teaching profession: ineffective professional development, lack of career advancement, unsupported accountability demands and low, undifferentiated compensation" (National Institute for Excellence in Teaching [NIET], 2008, n.p.).

The first element, multiple career paths, enables the advancement of teachers up a career ladder based on several performance evaluations. The evaluations are based on both classroom observations and student achievement gains. An example of a career ladder is from career teacher to mentor to master teacher. There is a recommended difference of at least $\$ 15,000$ in the salary between career and master teachers (Podgursky \& Springer, 2007). This allows teachers to advance while remaining in the classroom.

The second element of TAP is ongoing applied professional growth. Mentoring and collaboration time are scheduled during the school day. The focus is based on needs that have been identified and are data based. The goal is to increase student achievement by increasing teacher quality (NIET, 2008).

The third element of TAP is instructionally focused accountability. To evaluate teachers, the TAP process uses rubrics identifying standards for teaching skills, knowledge and responsibility (NIET, 2008). Evaluations are completed at least four times per year by evaluators that have been trained and certified. The evaluators may be master teachers, mentors, and principals.

The final element of TAP is performance based compensation. Teacher compensation is awarded based on the role and responsibilities, classroom performance 
and student performance. A teacher in a subject area or school that is difficult to staff also receives additional compensation.

TAP adapted Charlotte Danielson's system of standards and rubrics, according to Toch and Rothman (2008). The categories of standards were reduced from four to three. The three major categories of teaching standards for TAP include: designing and planning instruction, the learning environment, and instruction. The three categories are broken into 19 subgroups targeting specific teacher behaviors (Toch \& Rothman, 2008). The "Danielson-like rubric" (Toch \& Rothman, 2008, p. 6) rates a teacher's performance as unsatisfactory, proficient or exemplary.

There may be problems associated with performance-based pay programs. One problem is teacher opposition (Ballou \& Podgursky, 1993; DeSander, 2000). To counteract the opposition, teachers must be part of the program design and implementation, according to Ballou and Podgursky (1993). Teachers are often concerned about the fairness of performance assessments, the negative effect competition places on relationships with other teachers and the low pay scale prior to the implementation of performance pay (Ballou \& Podgursky, 1993).

A second problem with performance-based pay programs is inadequate funding. The predicted cost of a performance-based pay program is much more difficult to estimate compared to a salary pay schedule (DeSander, 2000). In order not to create limits on incentives, states and local school districts must be willing to commit adequate funding with the supposition that all teachers may earn a performance-based pay increase. 


\section{Summary}

As more districts incorporate trends such as PAR, portfolios and performancebased pay programs into their evaluation processes, determinations can be made about their effectiveness and their worth for assisting in the creation of a more productive means of rating teaching performance. Some trends may lose that label and become a permanent part of an evaluation system. Evaluation systems will continue to change until an efficient and fair process is established that will provide accountability for teachers and assurance of teacher quality.

\section{Related Dissertations}

Four searches of the Dissertation Abstract Online Database were conducted to obtain previous research on teacher evaluation that was done during the time period of 1980 to 2008 and available in English. Search number one was completed using the keywords teacher, dismissal and legal, and yielded seventy-seven studies. Search number two with keywords teacher, dismissal and evaluation netted fifty-four studies. The third search using keywords teacher, evaluation and legal yielded thirty-seven studies while the final search with keywords teacher, evaluation and problems yielded nine.

One hundred seventy-seven dissertation titles were read. Forty-one titles were duplicated, appearing on more than one list, and were deleted. The remaining 136 titles were reread to determine if they appeared relevant to my proposed research. Ninety-three titles were deleted. The 43 remaining titles were read again to determine if the title indicated the following two factors:

1. The span of the research based on the number of states involved in the study, and 2. the cause for dismissal. 
The results from those 44 titles are contained in Table 1.

Table 1

Titles Indicating Research Span and Dismissal Cause

\begin{tabular}{ll}
\hline \multicolumn{1}{c}{ Factor } & Number of Titles Identifying Factor \\
\hline Research in one state & 23 \\
Research in multiple states & 0 \\
Research location not specified & 20 \\
Dismissal reason not specified & 16 \\
Dismissal due to incompetence & 11 \\
Dismissal due to immorality & 6 \\
Dismissal due to insubordination & 4 \\
Dismissal and due process concerns & 4 \\
Dismissal due to unsatisfactory & 1 \\
performance & \\
\hline
\end{tabular}

The abstracts for those 44 dissertations were retrieved and read to determine the relevance of their purpose to my proposed research and the method used. Five studies had a relevant purpose. Forty-one of the studies employed qualitative methods while three used quantitative.

Two studies with purposes similar to mine were selected for review. A study by Batagiannis (1984) reviewed teacher dismissal cases due to incompetency and to reduction in force that were based on evaluation ratings. The second study by Metcalf (1992) investigated the historical interpretations of teacher dismissals in Arizona from 
1912 to 1973 and from 1974 to 1990 that were due to the inadequacy of classroom performance. This allowed for a comparison to be made before and after enactment of laws in 1974 addressing the definition of classroom inadequacy.

\section{Batagiannis Dissertation}

Gaining insight into the position of the courts on teacher dismissal due to incompetency and to reduction in force based on evaluation was the purpose of the study by Batagiannis (1984). The researcher sought information on the function of court roles relative to teacher evaluation; court rulings; the importance of teacher tenure, remediation and seniority; and the position of teacher organizations. The historical and legal research reviewed teacher evaluation, incompetency, remediation, teacher organizations, collective bargaining, tenure and reduction in force. The data included 60 cases litigated during the 1972 to 1983 time period.

The conclusions of the research included:

1. Generally, the courts will not substitute their judgment for that of school administrators provided the decisions of the latter are not arbitrary or capricious.

2. Each case is assessed on its own facts due to a lack of objective evaluation criteria.

3. Written standards, sufficient documentation, and evidence of the teacher's performance being compared to the performance of others is expected by the courts.

4. Administrators have the prerogative to determine the provision of remediation.

5. A lone evaluation or a remediation period insufficient in length is usually deemed inadequate. 
6. Remediable offenses may become irremediable over a substantial period of time or in combination with other offenses.

7. Tenure provides teacher with more extensive rights in reduction-in-force cases.

8. Tenure does not provide teachers immunity from dismissal if there is evidence of performance deficiencies.

9. Following legal procedure is of the courts' concern when hearing reduction-inforce cases.

10. There are no consistent court definitions of qualified and certified.

11. Teacher organizations are more frequently involved in reduction-in-force cases than teacher dismissal.

\section{Metcalf Dissertation}

The second study involving the investigation of the historical interpretations of Arizona courts from 1912 to 1990 for teacher dismissals due to inadequacy of classroom performance was completed by Metcalf (1992). A nonreactive study was the method of choice. The primary sources of data were AZ legislative history, AZ case law and opinions of the AZ attorney general.

Metcalf's (1992) conclusions were:

1. Prior to 1974 , school districts had minimal guidance as to what defined inadequate classroom performance, cases were decided on a one-by-one basis, and school districts were inconsistent in stating the cause for teacher dismissal. This led to the enactment of the Laws of 1974. 
2. In 1974, laws requiring the establishment of criteria for teaching performance and for teacher evaluation were enacted. Teachers began appealing for reasons of due process.

3. In 1977, incompetency and competent were replaced in statute with inadequacy of classroom performance and teachers were to be provided with a 90-day period to correct inadequacies. School districts were remiss in adapting to the new statutes.

\section{Chapter Two Summary}

Performance evaluation of teachers has received much attention in the last two decades. It has been studied as a means to ensure teacher quality and improve schools. Teacher evaluation has often been the subject of reform efforts. No Child Left Behind and The American Recovery and Reinvestment Act are two reform efforts currently in place in America's public schools.

Traditional teacher evaluation is often characterized by its principles and its problems. The principles of traditional teacher evaluation include: using the principal as the evaluator, conducting one or two classroom observations to gather data, conducting pre- and post-observation conferences, and using an evaluation instrument to record data and the evaluation judgment. There are three broad categories of problems: the principal, the teacher, and the process.

Administrators are anxious to find a more professionally sound evaluation system and may experiment with trends to do so. Trends currently being tested by many school districts include: peer assistance and review, teacher portfolios and performance-based pay programs. 
As administrators work to improve teacher evaluation systems, certain policy requirements must be maintained. Legal requirements include elements of the Uniform Guidelines, due process, progressive discipline and the open records law. Collective bargaining agreements and remediation plans may also need to be included depending upon the state. The adoption of personnel standards, though not a requirement for evaluation, is recommended to produce professionally sound and legally defensible evaluation policies.

Teachers often challenge dismissals resulting from evaluation ratings in the Courts and "there is a reasonable expectation that the legal issues related to performance evaluation will multiply" (Hazard, 1993, p. 7). Seven cases decided by the U.S. Supreme Court or State Court of Appeals that have impacted teacher evaluation were discussed.

Prior research was reviewed for studies with a similar purpose to this proposed research. Two relevant dissertations were mentioned. A listing of the problems with teacher evaluation that were identified in the literature by source is provided as Appendix B. A matrix was created based on these problems and is provided as Appendix C. 


\section{CHAPTER THREE}

\section{Research Method}

The purpose of chapter three is to explain the research design, rationale, methods and procedures that address the research questions: (1) What are the problems of teacher evaluation as found in selected teacher dismissal cases of the states in the Southern Regional Education Board (SREB) between 1980 and 2008 and what is the frequency of each? (2) Which of these problems are documented in the literature of teacher evaluation? And, (3) Which of these problems are not documented in the literature of teacher evaluation?

This research was a content analysis providing an interpretation of legal text. Case law of teacher dismissals based on evaluation and appealed to the Supreme Court or the Court of Appeals in the 16 states of the SREB was analyzed. There were five criteria for case law selection: retrieved from one of the sixteen SREB states, occurred within the timeframe 1980 to 2008, based upon teacher evaluation, teacher evaluation referenced in the context of the judgment, and it involved a classroom teacher at the time of dismissal.

\section{Research Theoretic for Education Law Inquiry}

\section{The Three Paradigms of Research}

There are three paradigms in legal research: positivism, constructivism, and critical theory (Hazi, 1995). A paradigm is a set of basic beliefs representing a worldview that defines the nature of the world, an individual's place in it, and the possible relationships to that world and its parts (Guba \& Lincoln, 1994). Paradigms answer three basic questions that guide the researcher. Garman (1994) described the questions as:

1. The ontological question - what is the nature of social and educational reality? 
2. The epistemological question - how is truth to be defined?

3. The axiology question - what values are embedded in the approach? Each paradigm is associated with a type of inquiry: "empirical (i.e., objective), interpretive (i.e., deals with human inter subjective and subjective meaning), and critical (i.e., brings operative ideologies to conscious awareness and makes action-value decisions), respectively (Hazi, 1995, p. 3).

Empirical research is similar to natural science research (Hazi, 1995). Positivism is the philosophy of empirical researchers. The researchers believe that law-like regularities or variables structure the world. The identified variables can be manipulated. The researchers are concerned about neutrality and objectivity (i.e., a detachment from those they study; Hazi, 1995) in attempting to control their bias.

Constructivism is the philosophy of interpretive researchers and one of the competing paradigms of qualitative inquiry (Guba \& Lincoln, 1994). Interpretive researchers seek to understand the perspective of the participants as they characterize the event being studied instead of searching for variables (Hazi, 1995). Interpretivists maintain that "human beings construct their perceptions of the world, that no one perception is 'right' or more 'real' than another, and that these realities must be seen as wholes" (Glesne, 2003, p. 7). The reality is constructed within an interpretive community (i.e., a group sharing common ideologies and judging each others work; Garman, 1994). The work of constructivists often has a hermeneutic orientation that is based on interpretation and a search for deeper understanding (Garman, 1994).

Critical theory is a term used to indicate a set of several alternative paradigms (e.g., neoMarxism, feminism, materialism, participatory inquiry; Guba \& Lincoln, 1994). 
Criticalists may be poststructuralists, postmodernists or a blend of the two, according to Guba and Lincoln (1994). Criticalists "reject the idea of value-free research into human social, political, and educational phenomena as a myth and stress the need for inquiry that takes into account the historical-ideological moment we live in and the influence it has on us" (Soltis, 1984, p. 7).

Each paradigm offers its own answers to the three questions that guide the researcher. The answers are not entirely agreed upon by writers in the field (Guba \& Lincoln, 1994). Generally, for a positivist the ontological belief is naïve realism (i.e., "an apprehendable reality is assumed to exist, driven by immutable natural laws and mechanisms;" Guba \& Lincoln, 1994, p. 109). The epistemological beliefs are dualist and objectivist (i.e., both the investigator and the object investigated are independent entities, and the investigator can study the object without influencing it or being influenced by it; (Guba \& Lincoln, 1994). The axiological belief is experimental and manipulative in nature. A hypothesis is stated as a proposal and then tested to verify. The researcher must manipulate conditions so that the outcome is not influenced by outside variables (Guba \& Lincoln, 1994).

For a constructivist, the ontological belief is that the reality of the world is socially constructed, complex and constantly changing (Glesne, 2003). The law is an example of a social construction (Lee \& Adler, 2006). The epistemological belief is that the findings of the study are created as the investigation proceeds and are based on the explorations of the research (Glesne, 2003; Guba \& Lincoln, 1994). The axiological belief is that hermeneutical techniques are best used to interpret the construct (Guba \& Lincoln, 1994). 
The ontological belief for criticalists is historical realism (i.e., there is a virtual reality that is shaped by social, political, cultural, economic, ethic, and gender values that come together over time; Guba \& Lincoln, 1994). The epistemological belief is transactional subjectivist (i.e., both the investigator and the investigated are interactively linked, exchanging values and influencing the inquiry; Guba \& Lincoln, 1994). The axiological belief is dialogic and dialectical (i.e., the inquiry requires a dialogue between the researcher and the participants that may be a debate to resolve conflict by establishing truths for each side; Guba \& Lincoln, 1994).

\section{Qualitative Research}

Qualitative research is one of the two modes of inquiry (Glesne, 2003). It is a "careful and diligent search" (Glesne, 2003, p. 3) and may include the "researcher gathering words by...collecting a variety of documents" (p. 4). Much qualitative research uses an inductive approach and is generally named interpretive research. It involves using systematic strategies to gather information that is then reflected upon and evaluated in order to develop an interpretation (Marshall \& Rossman, 1999). Qualitative research "provides interpretive insight into legal issues concerning education that other research methods cannot" (Lee \& Adler, 2006, p. 25).

Qualitative research has broad purposes that center around the promotion of a deep, complex understanding of an incident (Gay, Mills \& Airasian, 2006). The object is to produce findings that can be analyzed, interpreted and presented (Patton, 1990). "The challenge is to make sense of massive amounts of data, reduce the volume of information, identify significant patterns, and construct a framework for communicating the essence of what the data reveal" (Patton, 1990, p. 371-2). "Qualitative research has the potential to 
enlighten, supplement, reinterpret, and validate our perspectives about legal issues pertaining to federal, state, and local legislative decisions concerning education" (Lee \& Adler, 2006, p. 26).

Qualitative researchers. Qualitative researchers become the research instruments for a qualitative study. Their personal interests, talents and skills may impact both the research process and outcomes as the researcher seeks to understand and interpret how the participants construct their world (Glesne, 2003). Known as subjectivity, this "quality" (Peshkin, 1988, p 17) affects all of the investigation's results and should be disclosed to the reader.

My role as researcher. I have long held an interest in teacher evaluation as a tool to dismiss poor performing teachers. The interest originated early in my teaching career when I became aware of teachers that were justifiably the focus of many student complaints. Just as every faculty is aware of their dynamic teachers, they are equally aware of their inadequate teachers. I believed then as I do now that the most marginal performer in the classroom sets the standard of acceptable behavior. Principals who allowed poor performing teachers to continue their bad classroom practices year after year frustrated me.

I have been a rule-follower all of my life. Because I value laws, regulations, and rules, I expect them to be followed. I found it hard to accept that poor performing teachers were not addressed and either remediated or dismissed. When I became an assistant principal, I vowed that I would not look the other way when a teacher's performance was inadequate. I believed that meaningful evaluations could make a difference and I took on the responsibility of overseeing the evaluation of 94 faculty 
members. I found some teachers receptive to honest evaluations, in my perception, while other teachers appeared resentful.

In my two years as an assistant principal, I worked with four teachers on improvement plans with four different outcomes:

1. Teacher number one did not improve at the end of a 90 day improvement period and I was directed by the central office to give her an additional 90-days. At the end of the second 90 day period the deficiencies still existed. Central office administrators decided not to act on the recommendation of dismissal due to the teacher's twenty-three years of experience.

2. Teacher number two transferred to another school in the district. All of the personnel files were forwarded to the central office to be given to the teacher's new administrator. The improvement plan was not acted upon at the second school.

3. Teacher number three chose to resign four weeks into the improvement period.

4. Teacher number four showed improvement and received a successful evaluation at the end of the improvement period.

I was frustrated about the lack of belief teachers and fellow administrators had in the evaluation process as a tool to improve teaching, the poor attitude of teachers who refused to believe they were anything less than perfect, the glowing evaluations penned by my predecessors that were basically carbon copies of one another, the amount of time spent on improvement plans, and the lack of support from the central office. I didn't realize many of these feelings were shared by other educators until I began researching the literature for this proposed research. 
After two years as an assistant principal, I made a career move that I believe will eventually afford me greater input into our district's evaluation process. My goal is to provide our students with teachers who exhibit quality classroom performances. I believe that achievement of that goal can be assisted by a restructured performance-based evaluation process for teachers.

\section{Traditional Legal Research}

Legal research is a form of historical research that is "a systematic investigation involving the interpretation and explanation of the law" (Russo, 2006, p. 6). Legal research uses a timeline to examine the law in the past, the present and in the future. Research of the past will locate authorities on the law topic. The legal system is "grounded in the principle of precedent or stare decisis (to abide by), the notion that an authoritative ruling of the highest court in a given jurisdiction is binding on lower courts within its purview" (Russo, 2006, p. 7). Research of the present helps to inform policymakers and practitioners about the meaning and status of the law. Research of the future will assist in forming questions that may need additional study.

Typically, legal research is completed from a historical perspective and seeks to describe a body of law and how it applies (Dobinson \& Johns, 2007). The research is often conducted in one particular state because states may differ in their statutory interpretations. An example is the Burton (2003) dissertation that was conducted in Georgia. The purpose of the study was to identify and analyze Georgia State Board of Education dismissal appeal decisions of tenured teachers between 1991 and 2001. The data for that study included: historical documents, constitutional provisions, statutes, regulations, and case law. A second example is the dissertation by Van Dyke (1984). The 
purpose of that study was to examine the effects of a policy change on teacher dismissal in New York. Public documents from teacher dismissal cases provided the data. Thirty documents in the time period before the policy change were compared to thirty documents after the policy change.

According to Russo (2006), there are three sources of information that need to be considered when researching a legal issue: primary sources, secondary sources and research tools. The primary sources of law are constitutions, statutes, regulations and case law:

1. Constitutions are the most basic form of law and create the governmental framework within a jurisdiction. The rights and obligations of the government and the citizens are outlined within constitutions.

2. Statutes are laws that provide broad directives and are made by the legislative branch of the government. A statute initially appears as a bill and then becomes a law. A law is first published individually, then as a session law and finally as part of code.

3. Regulations help the public carry out statute and provide details of a law. They are made by the executive branch of the government.

4. Case law or common law tests a statute and "refers to judicial interpretations of issues that may have been overlooked in the legislative or regulatory process or that may not have been anticipated when a statute was enacted" (Russo, 2006, p 10). It is grounded in the concept of precedence, the idea that "a majority of ruling of the highest court in a given jurisdiction, or geographic area over which a court has authority, is binding on all lower courts within its jurisdiction" (Russo, 2006, 
P. 10). Case law provides clear meaning of a statute through the interpretation of a judge.

This research used the primary source of case law. Case law is recognized for its importance in providing meaning to legal research that may not be clear in constitutions, statutes and regulations (Russo, 2006). The ordinary person often does not comprehend the judicial construction of these three primary sources of law. Context clarity frequently requires the interpretation of judges. This is provided when using case law.

The secondary sources of law are periodicals, encyclopedias and dictionaries, restatements of the law, and books and treatises (Russo, 2006, p. 17-18). This research used dictionaries as secondary sources of law:

1. Periodicals include peer-reviewed journals for educators that provide "accurate, concise, and up-to-date analyses of current and emerging legal topics for academicians and practitioners" (Russo, 2006, p. 17). Law reviews are another type of periodical. They are edited by law students and provide a more comprehensive and well-referenced analysis of a specific issue.

2. Encyclopedias and dictionaries provide a quick and general overview of a topic. Their depth is usually not sufficient enough for a researcher.

The dictionaries were used as information became revealed through case law. The secondary sources were searched for definitions to aid in the interpretations of some of the findings on teacher evaluation.

The research tools of law are electronic databases, case digests, annotated reports and descriptive word searches. Of the four research tools, this research used electronic databases: 
1. Electronic databases are accessed free of charge. They provide a topic analysis with a listing of cases and secondary materials that could be used to assist in further research. Electronic databases provide wide access to legislative, administrative, and judicial materials.

The electronic databases (e.g., LexisNexis, LexisOne) were used with the following keyword identifiers: teacher dismissal, teacher and unsatisfactory performance, teacher termination, teacher discharge and the statute or policy regulating teacher evaluation for each state.

This was an atypical legal research in that it encompassed case law related to teacher dismissal that was based on evaluation in a defined region of states, the SREB. Each state has its own judicial system to hear the appeals from lower courts. In addition, the 16 states are serviced by 7 federal circuit courts of appeal for rulings on constitutional matters. Federal circuit court decisions are only binding in the states within their jurisdiction. The circuit courts may offer judicial interpretations to the lower courts within their circuit that differ from interpretations made by a neighboring circuit (Cambron-McCabe et al., 2004).

\section{Education Law Inquiry}

Hazi (1992) writes of the interaction of law and practice. According to Hazi, "we should realize that educational practice is embedded within and shaped by a legal context" (1992, p. 251). Teacher evaluation and teacher dismissal are two practices the author mentioned as being impacted by and the subject of legal interpretation and legislative action. Studying about the interaction of law and practice can be accomplished through a type of interpretive research named education law inquiry. 
Education law inquiry is a type of research involving the interpretation and clarification of law and legal-based incidents of practice (Hazi, 1992). Legal-based incidents are defined by Hazi (1992) as "incidents of educational practice that are connected to law by virtue of some binding document such as a collective bargaining contract, school board policy, or state law" (p. 253). Legal-based incidents of practice may appear in the form of a strike, grievance, legislation or litigation (Hazi, 1992).

The goal of education law inquiry is to provide information about the interaction of law and educational practice to both policymakers and practitioners, according to Hazi (1992). The information from the inquiry may help to further explain concepts of the practice in relation to the law and to elicit questions about the practice being studied.

There are four characteristics guiding education law inquiry (Hazi, 1992). First, the law is dynamic and subject to continual change. Second, the law has stability due to the search for authorities in past records of the law. Third, the law provides for unique and idiosyncratic cases by establishing precedence, and fourth, the law is fundamentally related to social issues.

The practice of teacher evaluation is a subject that can be found in all three of the document types Hazi (1992) mentioned: collective bargaining contracts, school board policies and state law. Teacher dismissals are often the issues of grievances and litigation. Therefore, education law inquiry would be a relevant way to study case law of teacher dismissals based upon evaluation. 


\section{Review of Research Method}

\section{Content Analysis}

Content analysis is used to identify, code and categorize the patterns in data (Patton, 1990) and is often the specialized approach in qualitative research when using document review (Marshall \& Rossman, 1995). The amount of data initially selected for a study may be massive. With reference to the purpose of the study and conceptual lens of the researcher, the data that is essential to the research must be retrieved (Miles \& Huberman, 1994).

The process of retrieving the data begins with coding. Coding involves assigning "units of meaning" (Miles \& Huberman, 1994, p. 56) called tags or labels to phrases, sentences or paragraphs of data. Codes are usually written in the margin of the text along with the researcher's reflections and other remarks.

There are three types of codes that are often used: descriptive, interpretive and pattern. A descriptive code describes the data's meaning (e.g., MOT for motivation; Miles \& Huberman, 1994). An interpretive code explains the meaning of the data (e.g., PUB-MOT for public motivation, PRI-MOT for private motivation; Miles \& Huberman, 1994, p. 57). A pattern code can be used to show themes in the data (e.g., PATT-TEAMS for educators exhibiting support for or resistance to a special project; Miles \& Huberman, 1994, p. 57).

Codes can be used to separate the data and organize it into categories that relate to a specific research question or theme. The organization or clustering of the data assists the researcher in analysis. A cluster of data can be reviewed for similar terminology, relationships, patterns, themes, differences and commonalities (Miles \& Huberman, 
1994). Often the data from the review are visually displayed in a "format that presents information systematically, so the user can draw valid conclusions" (Miles \& Huberman, 1994, p. 91). One format is the data matrix. Data displayed in a matrix enables the viewing of the condensed data in a systematic arrangement and in one location so that the research questions can be answered.

\section{Document Review}

One of the four fundamental methods qualitative researchers rely upon for gathering information is document review (Marshall \& Rossman, 1995). Documents that contain information relevant to the research questions and that can be practically acquired can serve as a data source by yielding "excerpts, quotations or entire passages" (Patton, 1990, p. 10). Data mined from documents "can furnish descriptive information, verify emerging hypotheses, advance new categories and hypotheses, offer historical understanding, [and] track change and development" (Merriam, 1988, p. 108). The following are strengths of document review:

1. It is unobtrusive and nonreactive (i.e., the researcher can conduct the gathering of information without disturbing the setting; Marshall \& Rossman, 1995).

2. Facts can be checked by readers of the research (Marshall \& Rossman, 1995).

3. Values and beliefs of participants can be revealed without requiring their participation or cooperation (Marshall \& Rossman, 1995; Merriam, 1988).

4. There is minimal utilization cost (Merriam, 1988).

5. There is a conservation of investigative time (Merriam, 1988).

6. The mode of acquisition is practical and systematic (Marshall \& Rossman, 1995; Merriam, 1988). 
7. The data can be easily manipulated and categorized (Marshall \& Rossman, 1995). Qualitatively, document data is good for grounding "an investigation in the context of the problem being investigated" (Merriam, 1988, p. 109). Document data from public records, one of the three major types of documents available to the researcher for analysis, are useful for qualitative research (Merriam, 1988). Court records and case law are examples of public records (Merriam, 1988).

Case law is considered a primary source when examining a legal issue (Russo, 2006). Case law can be located using an electronic database (e.g., LexisNexis), free websites (LexisOne) or manually (e.g., Education Law Reporter; Russo, 2006). Documents such as case law allows for "the accidental uncovering of valuable data" (Merriam, 1988, p. 115). The purpose of this research was to determine if the problems of teacher evaluation that appeared in the literature were those manifested in case law. Reviewing case law uncovered problems not previously written about by scholars in the field.

\section{Research Procedures}

Rationale for Examining Case Law of the SREB

The evidence gathered emerged from the content analysis of case law of teacher dismissals based on evaluation and appealed to courts in the 16 states of the SREB: Alabama (AL), Arkansas (AR), Delaware (DE), Florida (FL), Georgia (GA), Kentucky (KY), Louisiana (LA), Maryland (MD), Mississippi (MS), North Carolina (NC),

Oklahoma (OK), South Carolina (SC), Tennessee (TN), Texas (TX), Virginia (VA) and West Virginia (WV) that occurred within the last twenty-eight years. Prior studies with a 
similar purpose have been completed using individual states, a group of two or four states, or all fifty states. This research involved a defined region of states.

The SREB was the first interstate compact developed in the U.S for education. Created in 1948, the organization is nonprofit and nonpartisan, and was a collaboration between government and educational leaders from the 16 member states. The central focus of the SREB was to assist each member state with meeting the 12 Challenge to Lead Goals for Education (SREB, n.d.). Goal ten ensured that each child was taught by a highly qualified teacher. The 16 member states share: information compiled and provided by the SREB, demonstration programs, coordination of shared state resources, access to SREB publications, representation on the SREB Governing Board, regional databases for K-12 schools and for higher education, and access to SREB-sponsored meetings (SREB, n.d.).

The SREB contains states differing in their level of state control over teacher evaluation practices, as defined by Hazi and Arredondo Rucinski's (2009) research. The researchers reviewed state evaluation statutes, regulations and policies, and an analysis was completed to determine the extent to which teacher evaluation procedures and practices have become embedded with statute. Hazi and Arredondo Rucinski (2009) characterized the level of state control over teacher evaluation depending upon the amount of oversight the state sought at the local level from the least to the most prescriptive.

Four types of activity were found to be occurring in states. First, states were adopting new evaluation strategies. Second, states were no longer leaving the evaluation of teachers to local discretion. Third, most states were not annually evaluating veteran 
teachers, and fourth, most changes in teacher evaluation focused on data. In the opinion of Hazi and Arredondo Rucinski (2009), these changes may further complicate teacher evaluation and increase its ritualism. In addition, increased complications have the potential to cause an increase in litigation The scholars' concerns included:

1. Many of the associated terms (e.g., classroom walkthrough, multiple measures) were undefined and ambiguous in state policy and consequently "can be misused to control teachers and...ultimately contribute to the dysfunctional nature of the evaluation" (Hazi \& Arredondo Rucinski, 2009, p. 26).

2. The increased use of technology "promotes surveillance, restricts access, and perpetuates the illusion of objectivity” (Hazi \& Arredondo Rucinski, 2009, p. 27).

3. The increased use of data promoted a false confidence that the use of numbers could replace judgment about teaching.

The SREB contained states that were very active in reform (Hazi, 2008).

Examples cited by the researcher included:

1. SC was the most involved state with results of teacher evaluation. The state received reports on the results and made them available to colleges, approved remediation plans and had a state committee for oversight.

2. TX adopted the most extensive training requirements for evaluators, requiring 36 hours in Instructional Leadership and 20 hours of instrument training (Hazi, 2008).

3. AL required a week-long training for administrators to receive certification that allowed them to evaluate teachers. The training included performance demonstrations. 
4. NC required teachers in low-performing schools to be evaluated more frequently (i.e., annually) than other state teachers (i.e., once in three years).

5. DE, FL, GA, MD, TN, TX and VA were among the twelve states currently using student performance data in some way for teacher evaluation.

6. States participating on the vanguard of change may be more likely to experience litigation. In addition, five of the SREB states have collective bargaining: DE, FL, MD, OK and TN. The anticipation of litigation may be increased in states with collective bargaining.

\section{Rationale for Timeline}

The use of 1980 as the beginning of the time frame for case selection was chosen for the following reasons:

1. During the 1960 s and 1970 s case law began impacting employment decisions resulting in the development of the Uniform Guidelines in 1978. The Uniform Guidelines were based upon judicial interpretations, previously used personnel guidelines, psychological standards and practical experience.

2. Prior to the 1980 s relatively little legislation directly addressed teacher evaluation and the practice was left to local discretion (Veir \& Dagley, 2002). A move toward state control of teacher evaluation began in 1983 with the release of the report $A$ Nation at Risk (NCEE). The report targeted teacher evaluation as a reform strategy by recommending the creation of effective teacher evaluation systems.

3. During the 1980s, increased membership in both the National Education Association and the American Federation of Teachers resulted in the two unions 
becoming two of the largest in the United States (Cohen-Vogel \& OsborneLampkin, 2007). As membership increases, so may power and occurrences of litigation.

4. During the late 1970s collective bargaining agreements and provisions increased (Darling-Hammond et al., 1983). The legal requirements for teacher evaluation policies increased.

5. Sixteen relevant cases involving the dismissal of a teacher based on evaluation from 1980 to 2008 were found in the pilot study. A second sweep of cases was done for this research to ensure no relevant cases were missed and to include newly added cases.

\section{Criteria for Selecting Case Law}

Case law was selected from 16 SREB states between 1980 and 2008 based upon five criteria. Criterion sampling is defined as the selection of cases meeting some set of criteria or having some characteristic necessary to answer questions about a certain matter (Gay et al., 2006). The criteria included: a dismissal case, occurred in an SREB state, involved a classroom teacher, based on evaluation, and within the time period of 1980 and 2008.

\section{Pilot Study}

"Pilot studies offer a wealth of information with the potential to improve the conduct of later studies" (Beebe, 2007, p. 214). A small version of a proposed study, pilot studies assist researchers by uncovering design flaws, determining protocols, and developing methods for collecting and analyzing data (van Teijlingen \& Hundley, 2002; 
Yin, 1984). The pilot study may assist the researcher with developing relevancy and conceptual clarification, in the opinion of Yin (1984).

For the pilot study, public school teacher dismissals based on evaluation that were appealed during 1980 and 2008 were retrieved and examined. The keywords to search the electronic database were teacher dismissal, teacher and unsatisfactory performance, and teacher termination. The pilot was a trial run to mine existing Supreme Court and Court of Appeals cases in the 16 states of the SREB from 1980 to 2008 for the selection of criteria in the identification of potential problems that teacher evaluation revealed (Appendix B).

Forty-five cases were produced from the electronic searches. Kentucky had the most cases with 13, West Virginia had 6 and Arkansas had 5. Four cases were found in Oklahoma, South Carolina and Tennessee. The remainder of the SREB states each contributed one case. The cases were read to verify the five criteria for inclusion. Sixteen cases were identified for use in the pilot study. Dr. Hazi read three cases to corroborate their selection.

The problems manifested in case law were grouped into the three categories of problems as determined by the literature review: problems with the principal, problems with the teacher, and problems with the evaluation process. There were four problems with the principal: the first administrator to find a teacher unsatisfactory, a strained relationship between the administrator and the teacher, poor communication (a training issue) and differing opinions of evaluators (perhaps an additional training issue). There was one problem with the teacher: poor relationship with the administrator. There were 
24 problems with process: eleven problems with data, three problems with the evaluation instrument, and ten problems with procedure.

A first draft matrix of teacher evaluation problems was developed. The matrix was used to assist in organization of the data. The row headings on the matrix represented the features that belonged to one category while the column headings represented the features that belonged to the second category. Each cell in the matrix represented an item characterized by the features in the corresponding row and column.

The matrix for this pilot study was entitled Problems with Teacher Evaluation and crossed the categories of problems with teacher evaluation with the sources providing the information about the problems (Appendix C). The row headings represented the categories of problems with teacher evaluation as revealed in the literature and manifested in case law and included subheadings for each specific problem within that group (e.g. the category titled Problems with Principals had subheadings of Lack of Training, Lack of Time...). The column headings were entitled Sources of Information Presenting the Problem and had subheadings of Appears in Literature by Author and Appears in Case Law by Name and Number, and Frequency of Occurrence with the subheading of Number of Times Manifested in Case Law. The cells under Sources would contain the related authors and case law reference. When a problem was not found in the literature but found in case law, the author cell was empty. For a problem not found in case law but found in the literature, the name and case number cell was empty.

Each case name and number of every case coded to indicate the principal as the evaluator was the problem was entered into the matrix under the appropriate subheading. 
Additional rows were available to add problems which were not identified in the literature review and did not appear in the matrix originally.

Each case name and number of every case coded to indicate that the teacher was the problem was entered into the matrix under the appropriate subheading. Additional rows were available to add problems which were not identified in the literature review and did not appear in the matrix originally.

Each case name and number of every case coded to indicate that the evaluation process was the problem was entered into the matrix under the appropriate subheading. Additional rows were available to add problems which were not identified in the literature review and did not appear in the matrix originally.

Each case name and number of every case coded to indicate that the problem did not appear in the literature was entered into the matrix in an empty cell and labeled with the appropriate subheading.

\section{Data Collection Method}

The data sources for this research were electronically accessed case law. The procedure used to collect the data followed the procedure that was used for the pilot study. Multiple websites were used to search for relevant case law. The initial set of searches was done using LexisOne. LexisOne provided access to cases appealed within the last ten years.

LexisOne was searched five times for case law, each time using a new set of keywords: teacher dismissal, teacher and unsatisfactory performance, teacher termination, teacher discharge and the policy number or statute code for teacher evaluation in that state. The researcher began with keywords "teacher dismissal" 
followed by "teacher and unsatisfactory performance" and then "teacher termination." Multiple keywords were used because states may differ in their key legal terms. As the pilot study case from Florida was reviewed, the researcher noticed the term "teacher discharge" was used frequently. Another search was done using that keyword. When reviewing a pilot case from Kentucky, the researcher noticed the policy number for teacher evaluation was often referenced. The final search used the policy number specific to each of the 16 states.

The second set of searches used the highest court of appeals website for each of the sixteen states. Case law for each state was searched for five times, once with each set of the previously listed keywords. The third set of searches utilized LexisNexis and the same process as the previous two searches. The use of LexisNexis was needed to access case law from the 1980 s to 1999.

Cases produced from the searches were read to determine if the five criteria for inclusion were met. The five inclusion criteria included: retrieved from one of the sixteen states of the SREB, occurred during the time frame of 1980 to 2008, based on teacher evaluation, included a reference to teacher evaluation, and involved a classroom teacher at the time of the dismissal.

\section{Procedure for Data Analysis}

This research used a coding method and the development of a matrix to assist in analyzing the data. "The coding method is a procedure for organizing the text ... and discovering patterns within that organization structure" (Auerbach \& Silverstein, 2003, p. 31). A matrix is an arrangement of items placed into labeled rows and columns within a 
table in order to show the relationship between the two categories of features that are relevant to the items within the matrix (Loos, Anderson, Day, Jordan \& Wingate, 2003).

First, each case was read in its entirety to familiarize the researcher with the facts of the case. A second reading was completed for the purpose of highlighting and coding the text. A coding process was used to reduce the amount of text that was referenced (Merriam, 1988). "Codes are tags or labels for assigning units of meaning to the descriptive or inferential information compiled during a study" (Miles \& Huberman, 1994, p. 56). The initial set of codes used for this research included: principal, teacher, and process. The codes enabled the researcher to retrieve and organize the passages later in the study.

The raw text of each case was read and analyzed separately. Inductive content analysis was the primary method used for the analysis of the data. Inductive refers to the logic used to produce a general claim or principle from observed examples (Encarta, 2007). Content analysis is a systematic procedure used to describe the contents of the data (Merriam, 1988). Using a systematic process, the researcher is challenged to make sense of very large amounts of data by reducing the volume of information, identifying significant patterns, and constructing a framework for communicating what the data reveals (Patton, 1990). "The patterns, themes and categories of analysis come from the data" (Patton, 1990, p. 390).

The relevant text, text that was related to the research concern (i.e., teacher dismissal based on teacher evaluation) was separated out by the use of highlighting. The relevant text was chosen based upon the researcher's theoretical framework, constructivism. Law is socially constructed. 
The relevant text was coded using electronic highlighting: green highlights to indicate problems related to the principal as evaluator, pink highlights to indicate problems related to the teacher as evaluatee, and yellow highlights to indicate problems with the evaluation process. These three broad categories were determined after a careful and exhaustive search of the literature (Appendix A). Problems not appearing in the literature were initially coded with blue highlights. The codes were typed in the margin next to the highlighted passage using insert comment feature in Microsoft Word.

The case law passages were then copied into electronic folders based upon the color of the highlights and the code: principal problems, teacher problems, process problems and other problems not appearing in the literature. The case law name was noted prior to each passage in the electronic folder.

When all passages had been separated into electronic folders, the passages were read again to be separated into subcategories. The first passage in the principal folder was reread and a determination was made whether the passage belonged in a previously identified subcategory (e.g., the lack of, limited or inadequate training; the lack of subject matter expertise; the use of personal impressions instead of data to rate a teacher; the lack of time to conduct evaluations; the failure to give a negative evaluation; the responsibility of performing conflicting dual roles). When the passage did not fit into one of the previously identified subcategories a new subcategory was created. The name of the subcategory (e.g., new principal) was added in the margin as the second code. The second code, known as a "descriptive code" (Miles \& Huberman, 1994, p. 57), allowed for greater differentiation. This process continued until all passages of relevant text on principal problems had been placed in the appropriate subcategory. 
A new subcategory was named based upon the language used in the passage currently being examined for sorting. These names were referred to as "in vivo codes" (Strauss \& Corbin, 1990, p. 69). Words from the passage were sometimes defined first to aid in the creation of the new subcategory and to ensure that the relevant text did not best fit in a previously established subcategory. The definitions were derived from the context of the case, the literature, a legal dictionary and the Oxford English dictionary.

Next, the folder of passages on teacher problems was opened and the relevant text was reread one passage at a time and placed into a previously identified subcategory (e.g., lack of trust in the principal, lack of participation in the design of the evaluation) when possible. New subcategories were created as needed until all passages had been categorized.

This process was repeated with the passages relating to evaluation process problems. One passage at a time was reread and placed in a previously identified subcategory (e.g., atypical lesson observed, absence of one perfect evaluation instrument, use of one data source, lack of or inadequate feedback, lack of central office support, infrequent evaluation of tenured teachers) when appropriate. New subcategories were created as needed until all the relevant text had been sorted.

The final folder of passages, those not fitting into the original three categories, was reread and sorted. The first passage of relevant text was read. All existing subcategories were checked for possible placement. When the relevant text did not fit into an existing subcategory a new one was created. The second passage was reread and checked for placement into an existing subcategory. When the relevant text did not fit 
into a subcategory already identified then another new one was created. This process continued until all passages had been read and sorted appropriately.

A review of the categories revealed that some subcategories needed further division to identify the full range of problems that were reflected in the cases. A third code, known as a "pattern code" (Miles \& Huberman, 1994, p. 57) was used to subdivide the subcategories of Instrument and Evaluator. The pattern code was more inferential and explanatory.

It now became apparent to the researcher that the original matrix was less useful than originally believed. The matrix was revised several times. The original matrix listed the three categories: Principal, Teacher, and Process. As subcategories were added to each, the researcher, with the advisor's guidance, decided to change the names of the categories to ensure exclusivity. Policy and data were removed from the category Process and were named as two new categories. Principal was changed to Evaluator and placed in the category Process as a subcategory. Teacher was eliminated and replaced with Attitude and Communication. The second revision of the matrix removed Remediation as a subcategory of Process and became the sixth category. The third revision was needed because of two excerpts that did not fit into any existing category. Emerging Issues was created as the seventh category (see Appendix D).

The matrix retained the title, Problems with Teacher Evaluation. The categories were listed as headings of a section and were followed by their definition. In each section column one identified the subcategory, column two presented the definition of the subcategory and column three illustrated the type of problem with examples of relevant text retrieved from case law. The sequence of the category titles and the subcategory 
titles was from general to the more specific. The definitions for the categories and the subcategories came from the literature, case law, a legal dictionary and the Oxford English dictionary. The definitions were compared to ensure that each subcategory was mutually exclusive.

There were three criteria used to place an illustration into column three of the matrix. First, the excerpt was reread to determine if the illustration fit the type of problem listed in the subcategory. Next the illustration was checked to see if it fit the definition of the subcategory. Third, the illustration was checked to ensure it fit within the category. When these three criteria were met, the illustration was entered into the matrix. When the criteria were not met, the illustration was set aside for later review. The illustration was copied as a direct quote into the matrix with the text citation of the case (i.e., Name $v$. Name and the date; APA, 2001, p. 401). This process was repeated for each passage of relevant text.

The matrix allowed for text coordination which was important for the content analysis (Auerback \& Siverstein, 2003). Using a matrix enabled the researcher to be sensitive to the range of conditions present and to the range of potential consequences, while relating the conditions to the consequences (Strauss \& Corbin, 1990).

The frequency that each subcategory of problems appeared in case law was determined. A problem counted once per case regardless of the number of times it was mentioned in the case. The frequency count resulted in a rank order of problems from most frequent to least frequent and the construction of a Appendix E. In addition, a table was created that provided the number of cases per category and the number of cases per type of problem (see Table 3). Column one listed the category, column two the number of 
cases with problems in the category, column three the type of problems in the category and column four the number of cases with evidence of each type of problem.

\section{Interpretation of the Data}

\section{Research Question One}

What are the problems of teacher evaluation as found in selected teacher dismissal cases of the states in the Southern Regional Education Board (SREB) between 1980 and 2008 and what is the frequency of each? This question is answered by developing a data matrix. The data matrix is divided into seven sections, one for each category. The first row in each section contains the category name and its definition. Column one in the section lists the types of problems in the category, and column two contains the definitions of the problems. Column three has the illustrations of the problems that are extracted from the case law (see Appendix D). The goal of the matrix is to show the full range of teacher problems as manifested in case law.

In addition, a narrative that is based upon the matrix is presented. The goal of the narrative is to present each problem, its definition, and one or two cases that best illustrate each problem. An exemplar case that has evidence of the types of problems revealed in case law is presented and discussed.

\section{Research Question Two}

Which of these problems are documented in the literature of teacher evaluation? This question is answered by combining the information found in the completed matrix (Appendix D) with the information provided in Appendix B, Teacher Evaluation Problems as Found in Literature by Source. The goal of using the matrix and Appendix B is to combine the data on types of problems in case law with the types of problems 
revealed in the literature to create Appendix F, Problems of Teacher Evaluation Found in the Literature and in Case Law. Column one is entitled The Types of Problems of Teacher Evaluation by Category, column two, Found in the Literature, and column three, Found in Case Law.

To begin filling column one, the types of problems by category as identified on the revised data matrix are listed. Across from each type of problem an $\mathrm{X}$ is placed in column three to indicate these problems are those identified from case law. Next, an $\mathrm{X}$ is placed in column two, Found In Literature, for each type of problem listed in column one that also appears in Appendix B. When the type of problem does not appear in column one then it is added in the appropriate category and an $\mathrm{X}$ is placed in column two.

The completed table is visually analyzed. A determination of the problems manifested in case law and appearing in the literature is apparent when there are Xs in both column two and column three. A problem in column one that does not have an $\mathrm{X}$ in both column two and column three is not included in the answer to this research question.

\section{Research Question Three}

Which of these problems are not documented in the literature of teacher evaluation? This question is answered by using the table created as Appendix F for research question two. The table is visually analyzed to find those problems lacking an $\mathrm{X}$ in column two, Found in Literature. An empty cell in column two indicates that the problem is not found in the literature. Any problem in column one that has an $\mathrm{X}$ in column two is not included in the answer.

In addition, an EBSCO academic search is conducted for each type of problem shown by the matrix as not being documented in the literature of the field. A search of 
legal websites is conducted, as well. The goal of the searches is to produce literature on the types of problems with teacher evaluation that may not have been identified earlier.

\section{Ensuring Quality of the Research}

Selected criteria have been used to describe and assess the quality of qualitative research. Criteria selection must be judged within the context of the community of scholars the work represents, according to Garman (1994). The following three criteria were selected from the eight Garman (1994) suggested using to judge the quality of qualitative research: integrity, rigor and utility.

Integrity

Integrity refers to the work being structurally sound with a logical and appropriate research rationale. Content analysis, the qualitative approach used for this research, "provides interpretive insight into legal issues concerning education that other research methods cannot" (Lee \& Adler, 2006, p. 25). In addition, qualitative research methods have the power and potential to enlighten our understanding of the legal issues in education (Lee \& Adler, 2006).

The integrity of the research was confirmed by a cohort member who is a coordinator with the West Virginia Department of Education. The case, Belcher $v$. Jefferson Co. BOE (1985), and an amended copy of the data matrix were provided to the cohort member. The first two columns of the data matrix (i.e., subcategory and definition) were left intact but the illustrations from column three were removed.

Using three guiding questions, the cohort member was asked to read, highlight, and code the relevant text. The guiding questions were: (1) what are the problems of teacher evaluation in Belcher v. Jefferson Co. BOE (1985), (2) where do the problems of 
this case fit into the matrix and, (3) is there a problem that does not fit into an existing category?

She was then asked to complete the matrix by copying and pasting the passages of relevant text that she had highlighted into the appropriate categories and subcategories. She was instructed to add additional categories and subcategories as needed. The completed data matrix, and the highlighted and coded case were emailed to the researcher.

The highlighting and coding completed by the cohort member corresponded to that of the researcher's with one exception. Due to faulty directions, the cohort member also included illustrations from the cases cited in the Standard of Review. The Standard of Review is the section of the document where resolved cases are cited as precedence. In responding to the integrity of the data matrix, the cohort member stated that the categories of the matrix were well-thought out and enabled placement of the identified problems. She stated that the matrix design was beneficial. It was beneficial, in her opinion, because of the subcategories and the definitions that were provided.

\section{Rigor}

Rigor implies that the work has a sufficient depth of intellect. The rigor of this study included auditability (i.e., providing a detailed record of the process used in the research; Hazi, 1992) and confirmability (i.e., the matrix was supplied to a national scholar to evaluate the problem list). The data matrix and an excerpt from chapter three explaining the data analysis was sent to Dr. James Stronge. Dr. Stronge is the Heritage Professor in the School of Education at William and Mary College, VA in the 
Educational Policy, Planning and Leadership Area. Dr. Stronge has authored numerous articles and fourteen books, including Qualities of Effective Principals in 2007.

Dr. Stronge volunteered to evaluate the matrix and comment on the rigor. The three guiding questions provided to Dr. Stronge included: (1) does the illustration fit the type of problem listed in the subcategory, (2) does the definition fit the illustration, and (3) does the illustration fit within the category?

Dr. Stronge commented that "overall, I think you have coded and categorized the problems accurately" (personal communication, April 21, 2009). He evaluated each of the 99 illustrations using a three letter abbreviation that indicated his responses to the three guiding questions. $\mathrm{Y}$ was used for yes, $\mathrm{N}$ was used for no, and $\mathrm{P}$ was used for partial in referring to his level of agreement with the use of each illustration. The first letter of the threesome was the answer to question number one, the second letter was the answer to question number two and the third letter was the answer to question number three. Ninety illustrations were evaluated as YYY indicating Dr. Stronge was in complete agreement with the researcher. Five illustrations received at least one P, meaning Dr. Stronge was in partial agreement with the researcher. Three illustrations were evaluated as NNN indicating that Dr. Stronge was in complete disagreement with the researcher. One illustration was unclear to Dr. Stronge and not evaluated.

Each of the nine illustrations not evaluated as YYY were reviewed. All three illustrations evaluated as NNN were removed from the matrix. One had been erroneously placed by the researcher and the placements of the other two were slightly confusing when read out of context, in the researcher's opinion. The remaining six were kept as illustrations in their original placement. An example of an illustration that Dr. Stronge 
partially agreed with was "the claimant refused to sign because she disagreed with the process and did not feel that was fair" (St. Tammany v. Hearty, 2002). Dr. Stronge rated the illustration as YPP. In Dr. Stronge's opinion, the illustration fit the type of problem, Toward Negative Evaluations, and partially fit both the definition (i.e., the expression of a negative attitude about issuing or receiving a poor evaluation rating) and the category, Attitude.

One type of problem was renamed in the matrix. Dr. Stronge questioned the problem labeled as "Negative Results of Poor Evaluations." He asked "do you mean poorly conducted evaluation or unsatisfactory evaluation of the teacher? (J.H. Stronge, personal communication, April 21, 2009). The researcher reviewed the definition of the subcategory and decided to relabel the problem as "Repercussions from a Teacher's Unsatisfactory Evaluation.”

Utility

When a work is useful and relevant to the profession it has utility. The utility of this research included: (a) A review of literature did not produce a prior dissertation addressing the research questions. This study may have provided the first attempt at identifying case law problems that did and did not appear in teacher evaluation literature. (b) By identifying teacher evaluation problems that were manifested in case law, writers may become aware of the problems that need to be written about, and (c) administrators may be provided a training tool for principals concerning problematic areas of teacher evaluation that lead to appeals.

The utility was confirmed by requesting central office administrators and RESA directors to evaluate the usefulness of the matrix as a training tool. The researcher 
initially sought to have principals respond to the matrix but decided to seek responses from those responsible for ensuring principals were trained as evaluators instead. To comment on the utility, each was asked to review the matrix with reference to the following guiding questions: (1) could you use the matrix in thinking about problems with teacher evaluation and, (2) how could you use this matrix?

Comments received from five central office administrators varied with position. Two superintendents responded that the matrix would be useful in decision making. Should a grievance be appealed? "Can history be prevented from repeating itself?" (S.L. Smith, personal communication, April 19, 2009). Two assistant superintendents believed the matrix would be especially valuable for the training of new principals. The cases used to illustrate the types of problems with teacher evaluation provided a "real world application" (W. Neely, personal communication, April 19, 2009) for the training of evaluators. A director responsible for professional development stated that the value of the matrix would be evident when training principals on Policy 5310 and when referenced at the county's monthly principal meeting when discussing evaluation issues. In addition, she felt it would be useful for her county "as we review and update our policies" (T.H. Wells, personal communication, April 16, 2009).

One RESA director responded. He believed the matrix to be "an excellent tool to assist principals and asst. principals in their evaluations" (N. Zervos, personal communication, April 27, 2009). He stated that the legal references made the tool useful. In addition, the director commented that "the matrix could be used to prevent bad decisions on part of the principals' comments" (N. Zervos, personal communication, 
April 27, 2009). He further stated that it may be useful for justifying and supporting necessary recommendations.

\section{Chapter Three Summary}

The purpose of chapter three was to explain the research design, rationale, methods and procedures that were used to address the three research questions of this study. The research is a content analysis of legal text. Case law of teacher dismissals based on evaluation and appealed to the Supreme Court or the Court of Appeals in the 16 states of the SREB provides the legal text. There are five criteria for case law selection: retrieved from one of the sixteen SREB states, occurred within the timeframe 1980 to 2008, based upon teacher evaluation, teacher evaluation referenced in the context of the judgment, and it involved a classroom teacher at the time of dismissal.

The three paradigms in legal research were presented and discussed. The paradigms included: positivism, constructivism, and critical theory. A paradigm provides answers to ontological, epistemological and axiology questions to guide the researcher. A constructivist paradigm was used by this researcher.

The use of qualitative research as an inquiry type was discussed. The discussion included the characteristics of qualitative researchers and the role of the researcher in the study. The researcher provided information of her background that was relevant to the study.

Traditional legal research was defined and its use was described. Examples of two dissertations using traditional legal research were included. The three sources of information used in legal research: primary, secondary and resources were defined. 
Examples of each type of source were provided. This research utilized case law as the primary source, dictionaries as secondary sources, and electronic databases as resources. Information on education law inquiry, a type of research involving the interpretation and clarification of law and legal-based incidents of practice, was presented. In educational practice legal based incidents have a connection to law through a binding document. The document may be a contract, a policy or a state law. Reference to teacher dismissals can be found in all three types of documents. A legal based incident of practice appears in the form of a strike, grievance, legislation or litigation. This research discussed litigation pertaining to teacher dismissals that were due to problems in the practice of teacher evaluation.

Document review and content analysis were explained as the research methods of this study. Case law were the research documents used. They were electronically accessed using LexisOne, LexisNexis and judicial websites in each of the 16 SREB states. The section on research procedures provided the rationale for examining case law of the SREB, criteria for selecting case law, a brief explanation of a pilot study, and data collection methods.

Data analysis was completed using a coding method and the development of a matrix. Three levels of codes provided meaning to the descriptive or inferential information found in the case law while reducing the amount of relevant text the researcher referenced for interpretation. The first code indicated the broad category where the data was placed. The names of the categories were determined by the careful and exhaustive search of the literature. The second code (i.e., descriptive code) allowed for 
greater differentiation and the third code (i.e., pattern code) was inferential and explanatory.

A matrix was constructed for use in organizing the study's data. The matrix listed the category with its definition, the subcategories with their definitions, and illustrations of each type of problem from case law. The coded passages were copied and pasted into the matrix as illustrations of the types of problems that had been revealed in case law. The illustrations met three criteria: it fit the type of problem listed in the subcategory, the definition of the subcategory fit the illustration, and the illustration fit into the category identified.

Integrity, rigor and utility were discussed and confirmed to determine the quality of the study. A cohort member commented on the integrity. A national scholar, Dr. James Stronge, evaluated the matrix to confirm the rigor. Five central office administrators commented on the utility of the matrix. 


\section{CHAPTER FOUR}

The Case Law and its Interpretation

The purpose of the study was to identify teacher evaluation problems that were manifested in case law and to determine if these problems were documented in the literature of the field or not. Case law of teacher dismissals that were based on evaluation and occurred between 1980 and 2008 in the 16 states of the SREB was analyzed to provide an interpretation of the legal text. The cases were retrieved electronically from LexisOne, LexisNexis and the judicial web-sites of the 16 states. The electronic searches were conducted using the keywords teacher dismissal, teacher and unsatisfactory performance, teacher termination, teacher discharge and the number of the policy or the state statute governing teacher evaluation in each state.

This chapter is divided into four sections. The first section is the presentation of findings. There are seven categories of problems of teacher evaluation that are manifested in case law. There are 31 types of problems distributed among the 7 categories that are identified in narrative and table form.

The second section presents each type of teacher evaluation problem and its definition. Each type of problem is illustrated with examples from case text. The third section is an exemplar case that is presented in narrative form to reveal the types of problems that occur in case law. The exemplar case, Maxey v. McDowell Co. (2002), has evidence of 17 types of problems with teacher evaluation. The problems are presented in table form, also. Following the facts of the case, the court's decision is presented. The researcher's interpretation of the problems is next. The final section of the chapter is a 
summary. The explanations of how both the problems are identified and the matrix created are found in chapter three.

\section{Presentation of Findings}

\section{Case Selection}

One hundred thirty-five cases were produced from electronic searches to determine the problems associated with teacher evaluation as manifested in case law. Five criteria determined case law selection for the study: retrieved from one of the sixteen SREB states, occurred within the timeframe 1980 to 2008, dismissed based upon teacher evaluation, teacher evaluation referenced in the context of the judgment, and the dismissal involved a classroom teacher. Thirty-seven cases met the criteria and were selected for this research.

The 37 cases with teacher evaluation problems are located in 14 of the 16 SREB states. The range of cases is 1-7 per state. Table 2 illustrates the distribution of cases among the states. 
Table 2: The Number of Court Cases Found by State

\begin{tabular}{cc}
\hline State $(\mathbf{N}=\mathbf{1 6})$ & Number of Cases $(\mathbf{N}=\mathbf{3 7})$ \\
\hline Alabama & 2 \\
Arkansas & 1 \\
Delaware & 4 \\
Florida & 1 \\
Georgia & 4 \\
Kentucky & 4 \\
Louisiana & 3 \\
Maryland & 0 \\
Mississippi & 2 \\
North Carolina & 7 \\
Oklahoma & 2 \\
South Carolina & 1 \\
Tennessee & 2 \\
Texas & 0 \\
Virginia & 2 \\
West Virginia & \\
\hline
\end{tabular}

The states in the table are arranged alphabetically. Oklahoma has the most cases with teacher evaluation problems and that is seven. Florida, Kentucky and Louisiana have four cases each. Maryland has three cases. Alabama, Arkansas, North Carolina, South Carolina, Texas and West Virginia each have two cases. Delaware, Georgia, and 
Tennessee each have one case. No cases meeting the criteria are located in Mississippi or in Virginia. A list of the 37 cases appears in Appendix G.

Categories and Subcategories of Problems

There are 31 types of problems with teacher evaluation distributed within 7 categories that emerged from the content analysis of the 37 cases. The seven categories of problems include: attitude, communication, policy, data, process, remediation and emerging issues. The categories are arranged from general to specific. The types of problems by category include:

I. Attitude
A. Toward Job
B. Toward Others in the School/District
C. Toward Negative Evaluation
D. Attributed to Conflicting Personalities
E. Lack of Trust

II. Communication
A. Unwillingness
B. Limited Skill
C. Inadequate Feedback

III. Policy
A. Insufficient
B. Inconsistent Language
C. Failure to Follow

IV. Data 

A. Insufficient
B. Conflicting
C. Misused
D. Ignored
E. Using Impressions Instead of Data

V. Process
A. Observations Not Open and Honest
B. Instrument

1. Incorrect Form

2. Ambiguity

C. Failure to Abide by Time Requirements

D. Failure to Provide Each Component

E. Inadequate Component

F. Evaluator

1. Multiple Evaluators Lacking Agreement

2. Novice Evaluators

3. Attitude Toward Job

G. Repercussions from a Teacher's Unsatisfactory Evaluation

VI. Remediation
A. Failure to Determine Need
B. Failure to Provide an Adequate Plan
C. Failure for Teacher to Participate
D. Failure for Teacher to Comply 
VII. Emerging Issues
A. Teacher's Lack of Training Prior to Evaluation
B. Teacher Singled Out as an Example

The definitions and illustrations for each of these are presented in a subsequent section. Frequency of Problems

The 31 types of problems with teacher evaluation are grouped into 7 categories. The types of problems in each category are counted to determine the frequency of the subcategories. Next, the cases that illustrate each type of problem (i.e., subcategory) are counted to determine the frequency of the problem. A problem is counted once per case regardless of the frequency in which it is mentioned in an individual case. The range of cases per category is $2-31$. Table 3 shows the number of subcategories in each category and the number of cases for each type of problem. The categories in the table are sequenced by frequency from highest to lowest. 
Table 3: Number of Cases by Category and by Type of Teacher Evaluation Problem

\begin{tabular}{|c|c|c|c|}
\hline \multirow{3}{*}{$\begin{array}{c}\text { Category of } \\
\text { Problems }\end{array}$} & \multirow{3}{*}{$\begin{array}{l}\text { No. of } \\
\text { Cases }\end{array}$} & \multirow{3}{*}{ Types of Teacher Evaluation Problems } & \multirow{3}{*}{$\begin{array}{c}\text { No. of Cases } \\
\text { Illustrating } \\
\text { Each }\end{array}$} \\
\hline & & & \\
\hline & & & \\
\hline \multirow[t]{11}{*}{ Process } & 31 & Evaluators Lack Agreement - 4 & 9 \\
\hline & & Novice Evaluators - 1 & \\
\hline & & Evaluator's Attitude Toward the Job -4 & \\
\hline & & Failure to Provide Components & 8 \\
\hline & & Inadequate Components & 4 \\
\hline & & Repercussions from a Teacher's & 4 \\
\hline & & Unsatisfactory Evaluation & \\
\hline & & Incorrect Instrument -2 & 3 \\
\hline & & Instrument Ambiguity - 1 & \\
\hline & & Failure to Abide by Time Requirements & 2 \\
\hline & & Observations not Open and Honest & 1 \\
\hline \multirow[t]{5}{*}{ Data } & 18 & Ignored & 6 \\
\hline & & Insufficient & 4 \\
\hline & & Conflicting & 3 \\
\hline & & Misused & 3 \\
\hline & & Using Impressions Instead of Data & 2 \\
\hline \multirow[t]{3}{*}{ Attitude } & 16 & Toward Negative Evaluations & 7 \\
\hline & & Toward Others in the School/District & 6 \\
\hline & & Attributed to Conflicting Personalities & 2 \\
\hline
\end{tabular}


Lack of Trust 1

$\begin{array}{llll}\text { Communication } & 11 & \text { Inadequate Feedback } & 9\end{array}$

Lack of Skill 1

Unwillingness 1

$\begin{array}{lll}\text { Remediation } & 11 \quad \text { Failure for Teacher to Comply }\end{array}$

Failure to Provide an Adequate Plan 4

Failure for Teacher to Participate $\quad 1$

Failure to Determine Need $\quad 1$

$\begin{array}{llll}\text { Policy } & 10 & \text { Failure to Follow } & 6\end{array}$

Insufficient 3

Inconsistent Language $\quad 1$

Emerging Issues $\quad 2 \quad$ Teacher's Lack of Training Prior to 1

Evaluation

Teacher Single out as an Example $\quad 1$

The category with the highest frequency of problems is process. There are 31 cases in this category. Process problems include: observations not open and honest, instrument, failure to abide by time requirements, failure to provide each component, inadequate components, multiple evaluators lacking agreement, novice evaluators, evaluator's attitude toward the job, and repercussions from unsatisfactory evaluations. The most frequent problems are evaluators (9) and failure to provide components (8).

The category with the second highest frequency of problems is data. There are 17 cases with data problems. Data problems include: insufficient, conflicting, misused, 
ignored, and the use of impressions instead of data. The most frequent data problems are ignored (6) and insufficient (4).

The category with the third highest frequency is attitude. Attitude problems occur in 16 cases. Problems with attitude include: toward others in the school/district, toward negative evaluations, attributed to personality conflicts, and lack of trust. The most frequent attitude problems are toward negative evaluations (7) and toward others in the school/district (6).

Two categories are the fourth most frequent. Communication and remediation each are problems in 11 cases. Communication problems include: unwillingness to communicate, lack of skill and inadequate feedback. The most frequent type of communication problem is inadequate feedback (9). Remediation problems include: failure to determine need, failure to provide an adequate plan, failure for teacher to participate and failure for teacher to comply. The most frequent types of problems with remediation are failure for the teacher to comply (5) and failure to provide an adequate plan (4).

The least frequent categories are policy and emerging issues. Policy has ten problems. Policy problems are: insufficient, inconsistent language and failure to follow. The most frequent policy problem is failure to follow (6). Emerging issues has problems in two cases. Emerging issues include: teacher's lack of training prior to evaluation and teacher singled out as an example. The problems occur in one case each.

The 31 types of problems distributed within the 7 categories are found in 37 cases. The range of problems per case is from $1-17$. The average number of problems 
per case is 2.7. The complete frequency ranking of the types of problems appears in Appendix E.

Inadequate feedback is the most frequently appearing problem and is present in nine cases. Failure to provide each component is the next most frequent and appears in eight cases. Attitude toward negative evaluations is apparent in seven cases. Attitude toward others in the school/district, failure to follow policy and ignored data are the next most frequent problems and appear in six cases each.

Failure for the teacher to comply with the remediation plan is the next most frequent and is evidenced in five cases. Insufficient data, inadequate components of the evaluation process, multiple evaluators lacking agreement, evaluators' attitudes toward the job, repercussions from unsatisfactory evaluations and failure to provide an adequate remediation plan are the next most frequent problems and appear in four cases each.

Insufficient policy, conflicting data and misused data are the next most frequent and are in three cases each. Attitude attributed to conflicting personalities, using impressions instead of data, using the incorrect instrument, and failure to abide by time requirements are the next most frequent and are included in two cases each. Lack of trust, unwillingness to communicate, limited communication skills, inconsistent language in policy, observations not open and honest, ambiguity of the instrument, novice evaluators, failure to determine the need for remediation, failure for the teacher to participate in remediation, lack of training prior to evaluation and singled out as an example are the least frequent types of problems and appear in one case each. 


\section{Illustrated Problems of Teacher Evaluation}

\section{Types of Problems}

The 31 types of problems with teacher evaluation are presented next. Each problem is defined and illustrated. The illustrations are chosen from the cases used in the study and represent the best excerpts of relevant text. All examples of relevant text that were highlighted and coded in all of the cases appear in Appendix D. The problems were identified, defined and categorized as described in Chapter Three.

Problems with attitude. The first category is attitude. Attitude problems refer to a mental state, positive or negative, that is communicated to others. Attitude problems include: toward others in the school/district, toward negative evaluations, attributed to conflicting personalities, and lack of trust.

The first type of attitude problem is attitude toward others in the school/district. This refers to a teacher's expression of a negative attitude about students or other educators working in the same school/ district. Illustrations of attitude toward others include:

1. 'It isn't that I don't like little children, it's that I don't like having to teach them" (Squire v. BOE of Red Clay, 2006).

2. "She had a confrontational and combative attitude when offered assistance or direction in her teaching" (St. Tammany v. Hearty, 2002).

A second type of attitude problem is toward negative evaluations. This problem is defined as the expression of a negative attitude in reference to issuing or receiving a poor evaluation rating. Attitude toward negative evaluations is a problem for both administrators and teachers. The illustrations include: 
a. "Trying to be a halfway decent humane person, I did not want to wipe her [the teacher] out totally the first year or second year" (Wilt v. Berkeley Co., 1982).

b. “Appellant, didn't really know if she was going to make any changes...because she only had three years left" (Squire v. BOE of Red Clay, 2006).

Attitude attributed to conflicting personalities is the next type of problem. It is defined as the expression of a negative attitude because personalities of the teacher and the principal are in opposition of each other. An illustration is:

a. "This began as a personality conflict between a teacher and a principal and escalated grievously from that point" (Maxey v. McDowell Co., 2002).

The final type of attitude problem is lack of trust. Lack of trust means not having confidence in or not being able to rely upon another educator. An illustration for this problem is:

1. "Clearly, at this point, there was not mutual trust and confidence between Mr. Spencer, as the school's principal, and Mrs. Maxey, as one of the school's veteran teachers..." (Maxey v. McDowell Co., 2002).

Problems with communication. Communication is the second category. Communication is defined as the exchange of ideas, knowledge, and information, about job performance through a conversation or in written form by educators. Communication problems include: unwillingness, lack of skill and inadequate feedback. 
The first type of communication problem is unwillingness. This is defined as teachers and principals that are reluctant to communicate with each other. It is illustrated by:

1. "There was a substantial, perhaps mutual, inability or unwillingness to communicate" (Maxey v. McDowell Co., 2002).

Another type of communication problem is lack of skill. Lack of skill refers to the narrow or restricted ability of the principal to communicate ideas, knowledge, or information to a teacher about job performance. It is illustrated in the following passage:

1. "Consideration was not given to any blame to be attributed to Mr. Spencer for his limited communication skills... or his failure to address his concerns in a more constructive posture" (Maxey v. McDowell Co., 2002).

The third type of communication problem is inadequate feedback. Inadequate feedback is defined as insufficient information, type or amount, being provided to a teacher following an observation. Two illustrations of this problem are:

1. "The court held that the school's principal failed to inform the teacher during an evaluation and observation that she was having problems" (Wilt v. Berkeley Co., 1982).

2. "In December, after the first observation Orange and Baird met briefly but, at least according to Orange, did not discuss her teaching performance" (Harper Co. v. Orange, 1992).

Problems with policy. Policy is the next category. Three types of problems are included in the policy category: insufficient policy, inconsistent policy and failure to 
follow policy. Policy refers to the statutes or regulations governing the process of teacher evaluation.

The first type of policy problem is insufficient policy. An insufficient policy means that the locally developed policy on teacher evaluation does not contain all of the conditions that are required. Evidence of an insufficient policy appears in the following case:

1. 'The county board did not 'adopt evaluation procedures' as the State Board's resolution provided it "shall' do" (BOE of Anne Arundel $v$. Barbano, 1980).

The second type of problem with policy is inconsistent language. Inconsistent language means that the language could be interpreted differently by individuals reading the policy and districts attempting to follow it. A local district misinterpreting the language of a state statute is illustrated in the following text:

1. "The statute [\$16-24-14(e); personnel record in regards to employment performance documents] we are now charged with construing is quite confusing and internally inconsistent; we encourage the Legislature to reexamine and to clarify it" (State Tenure Comm. v. Lucy Jackson, 2003).

The third type of policy problem is failure to follow. Failure to follow policy is defined as the principal or the BOE not going along with the requirements for teacher evaluation. Illustrations of this problem include: 
1. "In the case of probationary teacher Edward F. Barbano, it is uncontested that there has been less than absolute adherence to the State Board guidelines" (Anne Arundel Co. v. Barbano, 1980).

2. "She further asked for a finding that the District failed to provide her with her rights pursuant to KY. Rev. Stat. KRS 156.101 and 704 KAR 3:345" (Jamison v. Gullett, 1997).

Problems with data. Data is the fourth category.. Five problems make up the data category: insufficient, conflicting, misused, ignored and using impressions instead of data. Data is defined as the facts collected by the principal for reference and information in the evaluation of a teacher's job performance.

The first type of data problem is insufficient. This means that the preponderance of evidence does not support the principal's judgment of a teacher's job performance. Example cases illustrating insufficient data include:

1. "It [Court of Appeals] concluded that less than satisfactory performance on evaluations and assistance schedules was insufficient to establish that Wise deliberately or willfully neglected her duties" (Wise v. Bossier Parish, 2003).

2. "The trial judge ... found that the school district had failed to prove by a preponderance of the evidence that the teacher should be dismissed on the grounds of instructional ineffectiveness and unsatisfactory teacher performance" (Weston v. ISD \#5 of Cherokee Co., 2007).

The second type of problem with data is conflicting. Conflicting data means data exists both for and against the judgment of the teacher's evaluation. Illustrations include: 
1. "The panel also found the evidence was conflicting on whether Orange was performing her duties at the 'level of competence known to be expected or required by [School] (Harper Co. v. Orange, 1992).

2. "Favorable comments are recorded even in areas where the ten documented instances upon which Mr. Spencer later relied could fairly be said to raise doubts about Appellant's performance" (Maxey v. McDowell Co., 2002).

The third type of data problem is misused. Misused data refers to the wrong or improper data being used in the evaluation of a teacher's job performance. An example is:

1. "School board relied exclusively on past conduct. - The Supreme Court concluded that conduct in the preceding school year cannot be used exclusively to terminate a teacher at the beginning of the subsequent school year; Ark. Code Ann. 6-17-1507(a) (Repl. 1993)." (Hannon v. Armorel School District, 1997).

The fourth type of problem with data is ignored. Ignored data refers to data or circumstances of life that are omitted from consideration when judging a teacher's job performance. This problem is illustrated in the following:

1. "The Board accepted the Superintendent's recommendation without examining Brown's performance evaluations" (Wilmer-Hutchins v. Brown, 1995).

2. "Consideration was not given to the role of psychological turmoil, mental exhaustion, and recent bereavement" (Maxey v. McDowell Co., 2002). 
The fifth type of problem in this category is principals using impressions instead of data to evaluate a teacher. Using impressions instead of data means that a principal is ruled by impression rather than data in making a judgment about a teacher's job performance. Illustrations of this problem include:

1. "Baird admitted he conducted Orange's evaluation with a predisposed opinion that she was not a competent teacher and aware that seventh graders at School frequently had a difficult time making a transition from grade school to junior high school” (Harper Co. v. Orange, 1992).

2. "One alleged flaw in the evaluation process, according to Calhoun, is that past comments allegedly made by S.T.E.P. evaluator Baker suggested her 'bias’ against Calhoun” (Calhoun v. Marlboro Co., 2004).

Problems with process. Process is the fifth category. Process problems include:

observations that were not open and honest, instrument, failure to abide by time requirements, failure to provide each component, inadequate components, evaluators, and repercussions results from unsatisfactory evaluations.

The first type of process problem is observations that are not open and honest. When observations are not open and honest, access to all the data collected for use in the evaluation of a teacher's job performance is not granted. This means the evaluation rating could be based on factors other than the collected data. A case that has evidence of observations not being open and honest is:

1. "We find that the 1979-80 evaluation completed by Greenfield lacked the openness and honesty required by 5300(6)(a)" (Wilt v. Berkeley Co., 1982). 
The second type of process problem is instrument. Instrument is defined as the approved evaluation form for rating a teacher's job performance. Instrument problems include: the use of an incorrect form and ambiguity. An incorrect form means the instrument used in the evaluation of a teacher's job performance is not the appropriate one. Illustrations include:

a. "The school board did not use a particular evaluation form as visualized by the school board's policy" (McKenzie v. Webster Parish, 1995).

Ambiguity refers to terms that are used on the evaluation instrument being understood differently by the School Board than by the principal. An illustration of this problem is:

1. "Any ambiguity must be construed against the School Board who prepared the form and whose agent completed the form" (McKenzie v. Webster Parish. 1995).

The third type of process problem is failure to abide by time requirements. This problem is defined as not adhering to the guidelines about the time that is to be designated for each procedure involved in the evaluation process. Illustrations of this problem include:

1. "There is no question that the principal failed to specify a reasonable time [for remediation]" (House v. Muskogee Co., 1997).

2. "Mack argues that the evaluations were not performed within the proscribed ninety-day period and did not include four period-long evaluations" (Mack v. Charleston Co., 2007). 
The fourth type of process problem is failure to provide each component of the evaluation process. Omitting a step in the evaluation process (e.g., observation, conference) is the definition used for failure to provide a component. Examples include:

1. "No formal evaluation of [Ms. James] was conducted during school year 1988-89" (Board of School Commissioners of Baltimore City v. Davis, 1993).

2. “Although appellee was informally observed by her supervisor in late March or early April, there were no conferences with or reports to appellee in order to guide and assist her attempts to improve her performance" (BOE Baltimore County v. Ballard, 1986).

The fifth type of problem with process is an inadequate component. An inadequate component means that the step of the evaluation process is provided but performed in a less than thorough manner. Illustrations of this problem are:

1. "It is beyond cavil that the principal terminated the conference in order to go to lunch duty before any meaningful discussion of the criticisms contained in the attachment to the observation form could be had..." (Maxey v. McDowell Co., 2002).

2. "On several occasions, the two of them had met in his office and the conference ended abruptly and with [petitioner's] voice being raised in the process" (Davis v. Macon Co.BOE, 2006).

The sixth type of process problem is the evaluator. An evaluator is defined as the person responsible for completing the evaluation of a teacher's job performance and is 
usually the principal. This subcategory is divided into three specific problem areas: multiple evaluators lacking agreement, novice evaluators, and attitude toward the job. Multiple evaluators lacking agreement is defined as the failure of two or more evaluators to agree about a teacher's job performance. Two illustrations are:

1. "Lee testified that she saw no significant improvement in Hannon's performance. Sydney Kennedy, on the other hand, also evaluated Hannon during the 1991-92 school year and gave her above average marks for her teaching acumen" (Hannon v. Armorel School District, 1997).

2. "RB Hunt assessed Ms Cagle's skills in the classroom giving Ms. Cagle overall good marks with several suggestion for improvement...Principal Barbara Stevens conducted an unannounced observation of Ms. Cagle's classroom... which was not favorable" (Cagle v. St. John's Co., 2006).

A novice evaluator is a principal in year one of his/her position and is lacking in experience pertinent to the position. The novice principal as a problem appears in the following illustration:

1. "The record also strongly suggests that the new principal simply could not deal with the early manifestations of this behavior except to set upon a course of 'documenting' conduct he found objectionable and conducting two formal classroom observations" (Maxey v. McDowell Co., 2002). 
Attitude toward the job is the third evaluator problem. Attitude toward the job refers to the expression of a negative attitude about completing the assigned duties and responsibilities of being a principal. Illustrations of this problem include:

1. "Rather, it is alleged, Atkinson delegated that responsibility [evaluation of a teacher] to the head football coach of the school" (Belcher $v$. Jefferson Co. BOE, 1985).

2. "Consideration was not given to any blame to be attributed to $\mathrm{Mr}$. Spencer for ... his distinct fear of confrontation" (Maxey v. McDowell Co., 2002).

The seventh type of process problem is a repercussion from a teacher's unsatisfactory evaluation. This refers to the occurrence of non-constructive behavior following an unsatisfactory evaluation rating. Examples from cases that illustrate repercussions are:

1. "Teacher ... chose to name Principal as the owner of the pornographic material in retaliation for Principal requiring Teacher to submit a plan of action six months earlier" (Hawzipta v. Noble Co., 2000).

2. "During this conference you showed a great degree of intemperance including threatening your own life and threatening to shoot Mr. Spencer in the head" (Maxey v. McDowell Co., 2002).

Problems with remediation. Remediation is the sixth category. The types of remediation problems include: failure to determine the need, failure to provide an adequate plan, failure for the teacher to participate and failure for the teacher to comply. 
Remediation refers to a plan developed to assist teachers who have not achieved the desired proficiency necessary for successful performance in the classroom.

The first type of problem with remediation is failure to determine the need. This means that administrators can't decide if the behavior of the teacher is correctable or not. Illustrations include:

1. "Dr. Roberts recognized her stress sufficiently to call for police assistance, but failed to address the issue of whether any of the teacher's bizarre conduct could be corrected under an improvement plan" (Maxey v. McDowell Co., 2002).

The second type of remediation problem is failure to provide an adequate plan. It means that the principal does not present the teacher the opportunity for a remediation plan or that the designed plan is less than thorough. Illustrations of this problem include:

1. "Rentz testified that no remediation plan was ever given to McKenzie" (McKenzie v. Webster Parish, 1995).

2. 'Mrs. Gaulden argues that the board's only effort at 'remediation,' giving her a one-page list of reference books to read, came nowhere near the relief contemplated by either the statute or the board's own regulations. We are inclined to agree" (Gaulden v. Lincoln Parish, 1989).

The third type of remediation problem is failure for the teacher to participate. It means that the teacher does not take part in the development of the remediation plan. The problem is illustrated in the following: 
1. “Appellant was allowed to contribute to her IIP's development, but she declined. This is significant, as it relates to one of the grounds for appeal" (Squire v. BOE of Red Clay, 2006).

The fourth type of remediation problem is failure for the teacher to comply. It is defined as the teacher not following the remediation plan. This remediation problem is illustrated by:

a. "Ms. James has flagrantly and consistently failed to adhere to the implementation steps of her professional assistance plan as documented by Jude Pasquariello, instructional specialist, F. Michel Vaeth, Language Arts department head, and the principal" (Brd. of Sch. Comms. of Baltimore City v. James and Davis, 1992).

b. "This testimony further indicated the following: (1) Calhoun was given remedial programs that she largely ignored or failed to complete" (Calhoun v. Marlboro Co., 2004).

Problems with emerging issues. Emerging issues is the final category. Emerging issues refers to types of problems that do not fit into the six previously identified categories based upon definition. Emerging issues include: lack of training prior to evaluation and singled out as an example. Illustrations include:

1. "Appellant only received minimal, peer-to-peer training on the system, largely at her initiative. Appellee failed to provide complete tech manuals, much less formal training on the system" (Squire v. BOE of Red Clay, 2006). 
2. "The trial judge found that test scores for the same grade taught by different teachers at the school revealed some grades higher than Weston's and some grades lower that Weston's classes, and that the administration had not taken action against teachers whose classes tested lower than Weston's" (Weston v. ISD \# of Cherokee Co., 2007).

\section{Problems of Teacher Evaluation in Case Law and in the Literature}

The 31 types of problems that are manifested in case law are grouped by category. Using the process described in Chapter 3 for the construction of Appendix F, Table 4, an abbreviated version of the appendix, was also constructed. Table 4 contains the types of problems and identifies if they are found in literature or not. Types of problems identified in column one that occurred in the literature of the field have an X placed in column two. An empty cell in this column means that the problem is not documented in the literature. Types of problems identified in column one that are revealed in case law have an $\mathrm{X}$ placed in column three. An empty cell in this column means that the problem is not located in the case law. 
Table 4: Problems of Teacher Evaluation Found in the Literature and in Case Law

\section{PROBLEM OF TEACHER EVALUATION IN LITERATURE IN CASE LAW}

\section{Attitude:}

- Toward others in the school/district

- Toward negative evaluations

$\mathbf{X}$

$\mathbf{X}$

- Attributed to conflicting personalities

$\mathbf{X}$

- Lack of trust

$\mathbf{X}$

$\mathbf{X}$

\section{Communication:}

- Unwillingness

- Lack of Skill

- Inadequate feedback

\section{Policy:}

- Insufficient

- Inconsistent language

- Failure to follow

\section{Data:}

- Insufficient

- Conflicting

- Misused

- Ignored

- Using impressions instead of data
$\mathbf{X}$

$\mathbf{X}$

$\mathbf{X}$

$\mathbf{X}$

$\mathbf{X}$

$\mathbf{X}$

$\mathbf{X}$

$\mathbf{X}$

$\mathbf{X}$

$\mathbf{X}$

$\mathbf{X}$

X

X

X

X

X

X

X

\section{Process}


- Observations not open and honest

$\mathbf{X}$

$\mathbf{X}$

$\mathbf{X}$

$\mathbf{X}$

$\mathbf{X}$

$\mathbf{X}$

$\mathbf{X}$

$\mathbf{X}$

- Multiple evaluators lacking agreement

- Novice evaluators

- Evaluator's attitude toward job

- Repercussions from a teacher's unsatisfactory evaluation

$\mathbf{X}$

$\mathbf{X}$

$\mathbf{X}$

$\mathbf{X}$

$\mathbf{X}$

$\mathbf{X}$

$\mathbf{X}$

$\mathbf{X}$

$\mathbf{X}$

$\mathbf{X}$
$\mathbf{X}$

$\mathbf{X}$

- Failure to determine need

$\mathbf{X}$

$\mathbf{X}$

$\mathbf{X}$

$\mathbf{X}$

- Failure for teacher to comply

Emerging Issues

- Lack of training on new duties

$\mathbf{X}$

- Singled out as an example
$\mathbf{X}$

Eleven types of teacher evaluation problems are not found in the literature. These types of problems do not have an $\mathrm{X}$ in column two but do have an $\mathrm{X}$ in column three. This indicates that the problem appears in case law but is not documented in the 
literature. Two types of attitude problems are not reflected in the literature: attitude toward others in the school/district and attitude attributed to conflicting personalities. One type of problem with communication does not appear in the literature: limited communication skills. Two types of data problems appear only in case law: conflicting and misused. Two types of process problems are not found in the literature: novice evaluator, and evaluator's attitude toward the job. Two types of remediation problems are absent from the literature: failure for teacher to participate, and failure for the teacher to comply. Neither emerging issue is found in the literature: lack of training due to new duties and singled out as an example.

Twenty problems with teacher evaluation are found in the literature. These problems have an $\mathrm{X}$ in column two and in column three. The presence of the two Xs indicates that the problem appears both in case law and in the literature of the field. Eight of these are process problems: observations not open and honest, incorrect instrument, instrument ambiguity, failure to abide by timelines, failure to provide each component, inadequate components, multiple evaluators lacking agreement, and repercussions from a teacher's unsatisfactory evaluation. Three types are policy problems: insufficient, inconsistent, and failure to follow. Three are data problems: insufficient, ignored and using impressions instead of data. Two are communication problems: unwillingness to communicate and inadequate feedback. Two are attitude problems: attitude toward negative evaluations and lack of trust. The final two are remediation problems: failure to determine need and failure to provide an adequate plan.

A related finding is that some types of problems found in the literature are not found in case law. Problems written about but not manifested in case law in this study 
include: teacher's participation in data selection, observing the atypical lesson, the evaluator's lack of training, the evaluator's lack of subject matter expertise, the evaluator's lack of time, the evaluator's dual role, the lack of central office support, and the infrequent evaluation of tenured teachers.

An Exemplar Case: Maxey v. McDowell Co. (2002)

\section{The Narrative}

The case from this research that had the greatest number of problems with teacher evaluation was a West Virginia case, Maxey v. McDowell Co. (2002). Ample text was available about the case including a dissenting opinion by Justice Maynard and a concurring opinion by Justice Starcher. The case is presented in narrative form to reveal the types of problems with teacher evaluation that have occurred in case law. The narrative uses the language of the case. The opinion of the court was presented by Justice Albright.

Marjorie Maxey was a West Virginia school teacher for 16 years. The last 13 were in McDowell County where she taught a split $7^{\text {th }} / 8^{\text {th }}$ grade class in an elementary school. Her exemplary classroom performance was documented on an unknown number of "classroom performance evaluations" (Maxey v. McDowell Co., 2002, Facts I). Mrs. Maxey chose to change classrooms in the fall of 1996 to teach a split 4th/5th grade class. It was at this time that she became acquainted with Mr. James Spencer, the newly appointed building principal (Maxey v. McDowell Co., 2002, Facts I).

It was not known what precipitated the principal's actions but during September 1996 Mr. Spencer began documenting incidents involving Mrs. Maxey because the teacher "appeared to be unnerved" (Maxey v. McDowell Co., 2002, Facts I) about 
scheduling issues. When Mr. Spencer requested that Mrs. Maxey refrain from talking about certain issues with students present, the teacher responded by throwing book bags, crying and making a comment that she wished she would die. The principal placed telephone calls about Mrs. Maxey to Mr. Larry Lane, Assistant Superintendent, and reported on her alleged "intransigence" (Maxey v. McDowell Co., 2002, Facts I). Mr. Lane instructed Mr. Spencer to follow the proper evaluation procedures.

During October 1996, three more events occurred that Principal Spencer documented. First, Mrs. Maxey again voiced her wish to die when she said she might jump out a window because she was having a bad day. Second, Mrs. Maxey allowed her students to go with her on an in-building errand but was seen by Mr. Spencer who expressed his displeasure and sent her and the students back to the classroom. Third, Mr. Spencer felt it was poor judgment when he saw Mrs. Maxey moving a heavy cabinet by herself after being offered assistance by two other employees. Principal Spencer also documented various complaints from co-workers and administrators about Mrs. Maxey's lesson plans, grading of papers, and monitoring the paperwork on her special education students (Maxey v. McDowell Co., 2002, Footnote 2). As a new principal, Mr. Spencer apparently knew no other way to deal with Mrs. Maxey aside from documenting the behaviors on the evaluation form (Maxey v. McDowell Co., 2002, Applications IV). During this time, Mrs. Maxey was the primary caregiver for her mother, a stroke victim. Her father-in-law died in December 1996, and an uncle passed away in January 1997 (Maxey v. McDowell Co., 2002, Footnote 9). It was possible these emotional issues affected her behavior, in the opinion of the Court (Maxey v. McDowell Co., 2002, 
Footnote 12). There was no indication that Principal Spencer considered the stress of Mrs. Maxey's personal life.

Mr. Spencer observed Mrs. Maxey’s classroom on November 18, 1996 following the guidelines of Policy 5300, and commented in five of the forty-five areas on the observation instrument. Each of the five comments regarded incidents he had previously documented about Mrs. Maxey: (1) Mr. Spencer noted that Mrs. Maxey had called him “Napoleon” (Maxey v. McDowell Co., 2002, Footnote 3), (2) that she needed to communicate better with parents, (3) that she fell to her knees during an emotional conference with a parent, and (4) that a parent of a special education student in Mrs. Maxey's class complained that her child had two red marks on his neck and wanted an explanation for their presence (Maxey v. McDowell Co., 2002, Footnote 3).

The contents of the observation were presented to Mrs. Maxey two-hours after the end of a school day when the teacher was leaving the building to visit her mother in the hospital. Mr. Spencer stopped the teacher and gave her the observation with an attached needs assessment list. Mrs. Maxey claimed that she did not want to sign the form because she could not understand Mr. Spencer's explanation of the needs assessment. The teacher said of their interaction that Mr. Spencer "considered it communication" (Maxey v. McDowell Co., 2002, Facts I.A.) but she did not. There was in fact no "meaningful discussion" (Maxey v. McDowell Co., 2002, Applications IV).

Mrs. Maxey’s second observation occurred on March 3, 1997 and lasted about thirty minutes (Maxey v. McDowell Co., 2002, Facts I.B.). “Mrs. Maxey’s performance in her profession of teaching continued to be exemplary" (Maxey v. McDowell Co., 2002, Facts I.B.), a statement that conflicted with the data contained in the attachment Mr. 
Spencer prepared. The attachment to the observation form stated that too many children were not in their seats during instruction and that discipline problems occurred. The principal also addressed two complaints. The first complaint was from the parent of one of Mrs. Maxey's students who requested a mid-term grade to no avail. The second complaint was issued by Principal Spencer and concerned Mrs. Maxey making negative remarks in front of students (e.g., Mr. Spencer promotes "a laid-back atmosphere;" Maxey v. McDowell Co., 2002, Footnote 4).

There were three problems with the attachment to the observation instrument First, the majority of the problems listed on the attachment related "either to events that occurred prior to the March 3 observation or matters that did not occur in the classroom" (Maxey v. McDowell Co., 2002, Facts I.B.), an example of misused data. Second, Mrs. Maxey did not understand the attachment. Third, data on the attachment conflicted with data on the observation form. Mrs. Maxey's performance was still exemplary on the observation form and there were favorable comments in the areas directly related to incidents of concern that the attachment addressed (Maxey v. McDowell Co., 2002, Facts I.B.).

There were problems with the conference that has been described as "a comedy of errors (Maxey v. McDowell Co., 2002, Applications IV). Mrs. Maxey had joined Principal Spencer in his office and when the principal finished reading the list of problems, "he immediately jumped up, very abruptly, and said, 'I have to go for lunch duty" (Maxey v. McDowell Co., 2002, Facts I.B.). The conference was inadequate because Mrs. Maxey needed additional clarification of the attachment so that she could understand it completely. She continued looking over the list of problems and alleged that 
a gust of wind from an open window blew the paper from her hand onto the floor. Mrs. Maxey stated that she quickly placed her foot on the paper to stop it from blowing away. However, Mr. Spencer stated that the teacher stomped on the paper as she refused to sign it. A "childish" act in the opinion of the Court (Maxey v. McDowell Co., 2002, Applications IV). Mrs. Maxey claims she would not sign it because she was not given “an adequate opportunity to discuss" (Maxey v. McDowell Co., 2002, Facts I.B.) it. Mrs. Maxey then asked the principal "what he had against myself or my family because I have nothing against you or yours" (Maxey v. McDowell Co., 2002, Facts I.B.) The principal left the office. He later stated that he left because he anticipated more confrontation and wished to avoid it.

Two days later Mr. Spencer supplied Mrs. Maxey with a clean copy of the observation form and asked the teacher to sign it. Mrs. Maxey again refused to sign the document because she still was not provided an adequate opportunity to discuss the allegations. Mr. Spencer told the teacher she would have to appear before the Board of Education (BOE) for not signing the observation form. Mrs. Maxey made an "uncalled for" (Maxey v. McDowell Co., 2002, Applications IV) comment offering to draw Mr. Spencer a map to the BOE office (Maxey v. McDowell Co., 2002, Facts I.B.).

Without providing notice to Mrs. Maxey, the principal arranged a meeting for the two of them with Dr. Kenneth Roberts, Superintendent, and Mr. Lane on March 7, 1997 at the BOE office. On March $7^{\text {th }}$, Mr. Lane contacted Mr. Maxey, the teacher's husband and also a BOE employee, telling him that his wife and Mr. Spencer had another “incident" (Maxey v. McDowell Co., 2002, Footnote 5) and Mr. Maxey needed to bring his wife to the BOE office (Maxey v. McDowell Co., 2002, Facts I.C.). 
Mr. Spencer went to Mrs. Maxey's classroom and "ordered her to his office" (Maxey v. McDowell Co., 2002, Facts I.C.) where she found her husband waiting. Mrs. Maxey called Mr. Spencer "Napoleon” (Maxey v. McDowell Co., 2002, Facts I.C.) The principal, who then moved behind his desk out of fear, later said he had been afraid to come to work that morning because of her behavior the day before.

At the BOE office, the four met and Mrs. Maxey was told by the Superintendent that "the conference was to try to address what had taken place and to see what steps needed to be taken" (Maxey v. McDowell Co., 2002, Facts I.C.) about her concerns and problems. The court later described the meeting as bordering "on the ridiculous" (Maxey v. McDowell Co., 2002, Applications IV). For the first 45 minutes Mr. Spencer listed his observations about Mrs. Maxey’s behavior and her refusal to sign the observation forms. Mrs. Maxey testified later that she was not provided a reasonable opportunity to participate in the discussion about her deficiencies in the central office meeting and that Dr. Roberts disallowed interjections from her. Mrs. Maxey was asked to wait until the conclusion of the principal's comments before she spoke. The teacher said "communication to them meant a one-way street" (Maxey v. McDowell Co., 2002, Footnote 6). Mrs. Maxey testified later that she felt like 'a caged animal' and that she was being treated like "an inanimate object" (Maxey v. McDowell Co., 2002, Facts I.C.).

During the meeting, Dr. Roberts directed Mrs. Maxey to sign the observation instrument or face further disciplinary action. Mrs. Maxey responded by telling Mr. Spencer that she should have blown his head off with a shotgun. During the testimony later, there were differing opinions as to the exact wording of the statement but all were similar. Mr. Spencer left the meeting for about fifteen to twenty minutes. When he 
returned, Mrs. Maxey told the principal that if she was going to blow his head off, she would have done so already. Mr. Spencer then left and did not return to the meeting (Maxey v. McDowell Co., 2002, Facts I.C.).

Dr. Roberts told Mrs. Maxey that he was going to recommend suspension and termination for insubordination. Dr. Roberts said Mrs. Maxey's behavior during the meeting led him to believe the complaints Mr. Spencer had against her. Dr. Roberts asked his secretary to call 911 because of the high degree of stress in the meeting and instructed her to type a letter to Mrs. Maxey about the decision to seek her termination. The letter was presented to Mrs. Maxey before she left (Maxey v. McDowell Co., 2002, Facts I.C.). Dr. Roberts did not address the emotional stress in Mrs. Maxey's life.

Dr. Roberts advised Mr. Maxey that his wife had threatened Mr. Spencer and that he felt she needed psychiatric help. The superintendent stated that he was concerned for her safety which is why the sheriff was contacted (Maxey v. McDowell Co., 2002, Facts I.C.).

Mrs. Maxey later said she knew the comments were inappropriate and she apologized for making them. She blamed her actions on her emotional state and her frustration at not being able to defend herself against the allegations. Mrs. Maxey explained that she meant no harm to Mr. Spencer and that "a lot of times, I will make offhanded, deprecating comments in order to get the other person to listen..." (Maxey $v$. McDowell Co., 2002, Facts I.C.).

The McDowell County Board of Education granted the superintendent's recommendation for termination. Mrs. Maxey filed a grievance with the Grievance Board which upheld the Board's decision. Mrs. Maxey appealed and the Circuit Court agreed 
with the findings of the Grievance Board. The case was then appealed to The Supreme Court of Appeals of WV (Maxey v. McDowell Co., 2002, Facts I.D.).

The Court's Decision

The Supreme Court overturned the Circuit Court and the Grievance Board and ruled for Mrs. Maxey. The Court added that they did not sanction Mrs. Maxey's irrational behavior or comments toward Mr. Spencer. The court stated in their conclusion that "we hold that the failure to pursue the question of whether these performance deficiencies could be corrected and an improvement plan prepared for that purpose, violated Policy 5300, and is contrary to our cases interpreting its interplay with West Virginia Code §18A-2-8." The Court further stated that the Grievance Board and the circuit court both committed errors when Mrs. Maxey's dismissal was affirmed.

The decision of the Supreme Court was to "reverse the termination and remand the matter to the Grievance Board for further proceeding." The Grievance Board was instructed to decide if Mrs. Maxey's behavior was correctable through the use of an improvement plan. The Grievance Board was to calculate the back pay and the Circuit Court was to address the possibility of awarding it. The County Board was given the burden of showing that Mrs. Maxey's conduct was not correctable. If the behavior was correctable and the "stress and anger-control issues" were under reasonable control, Mrs. Maxey would be permitted to return to the classroom and provided with an Improvement Plan.

Justice Starcher wrote the concurring opinion (Maxey v. McDowell Co., 2002) and stated that: 
A school board, in all but the most extreme cases, MUST follow progressive discipline. That means that in the instant case, because Mrs. Maxey acted out of line, she must be disciplined appropriately AND given a meaningful opportunity to improve, to assure her employer that this sort of conduct is not likely to reoccur. To simply drop the axe on a teacher with long- time service _ most of which was exemplary _ is neither fair to the teacher nor the system in which she teaches. (Concurring Opinion, 2002, n.p.)

In Justice Maynard's dissenting opinion (Maxey v. McDowell Co., 2002) he wrote:

I wonder just what a teacher has to do to be insubordinate in West Virginia schools today. Apparently, threatening to shoot or kill the principal is not enough. Throwing an observation form on the floor and stomping on it is not enough either. Nor is repeatedly refusing to sign that form. (n.p.) Justice Maynard contended that even if Mrs. Maxey's statement did not fit the definition of threat, her words were "very violent, chilling, and threatening" and "furthermore, it is certainly language that simply has no place in our schools" (Dissenting Opinion). The Justice added that "her experience does not excuse her conduct. It is an unfortunate fact that in today's world, the possibility of shootings in the workplace and in our schools has become a frightening reality." Putting the threat aside, the Justice still felt Mrs. Maxey warranted dismissal based upon insubordination. Insubordination was the issue, the Justice believed, because the teacher refused to sign the observation form. Justice Starcher was of the opinion that "almost any kind of conduct" could be construed as insubordinate and would invite "abuse" in WV's system. The Justice alleged 
that "more than a few WV classroom teachers" would be guilty of such statements and then added that "the fact is that good people who are under severe stress can get angry and afraid and say stupid things _ but that is not a reason to fire them" (Concurring Opinion, 2002, n.p.).

The Researcher's Interpretation

Maxey v. McDowell Co. (2002) had 17 types of problems with teacher evaluation. It had the greatest number of problems in any of the cases in this study. Table 5 identifies each problem and its category. 
Table 5: Teacher Evaluation Problems Evidenced in Maxey v. McDowell Co. (2002)

\begin{tabular}{cc}
\hline Category of Problem & Type of Problem (N=17) \\
\hline Attitude & Toward Others in the School/District \\
Attitude & Toward Negative Evaluations \\
Attitude & Attributed to Conflicting Personalities \\
Attitude & Lack of Trust \\
Communication & Unwillingness \\
Communication & Limited Skill \\
Communication & Inadequate Feedback \\
Policy & Failure to Follow \\
Data & Conflicting \\
Data & Misused \\
Data & Ignored \\
Process & Failure to Determine Need for Remediation \\
Process & Failure to Provide \\
Process & Nopercussions from a Teacher's Unsatisfactory \\
Process & Novice Evaluator \\
Remediation & Evaluator's Attitude Toward the Job \\
&
\end{tabular}

Attitude and Process were the two categories with the most problems. Each had four types of problems. Communication and Data were the two categories that were the 
next most frequent. Each had three types of problems. The category Remediation had two problems and Policy had one.

Attitude. One problem with attitude was conflict arising from differing personalities. The conflict between Mrs. Maxey and Mr. Spencer was best manifested when the principal handed the observation to the teacher for her signature and she threw it on the floor and stomped on it, reminiscent of a small child's tantrum. Later, the teacher blamed a gust of wind blowing through the window and claimed that she placed her foot on it to stop it from blowing away. Instead of the principal addressing the teacher's behavior immediately, he abruptly left the room. Principal Spencer claimed he left suddenly and without communication in an attempt to avoid further confrontation.

Mrs. Maxey often referred to Mr. Spencer as "Napoleon" (Maxey v. McDowell Co., 2002, Footnote 4). The teacher threatened to shoot the principal in the head, repeating it twice in front of the superintendent. Mrs. Maxey offered to draw the principal a map to the board office when he told her that failure to sign the observation would result in a mandatory appearance visit to the superintendent.

There were incidents that demonstrated the teacher's attitude toward others she worked with in the school. She became "unnerved" because of schedule changes Mr. Spencer had made, and threw book bags and cried. She would talk about "jumping out a window and giving the proceeds to her children" (Maxey v. McDowell Co., 2002, Footnote 2) when she was having a bad day. Against her principal's advice, she refused offers of assistance when moving her heavy cabinet between classrooms (Maxey $v$. McDowell Co., 2002, Footnote 2). She made a comment in front of her students that "her class was an administrative failure" (Maxey v. McDowell Co., 2002, Footnote 4). 
Communication. There were problems with communication for both Mrs. Maxey and Principal Spencer. The teacher had problems communicating with parents and with the principal. She fell to her knees once while conferencing with a parent who wanted "an explanation for how her special education child had two red marks around his neck area" (Maxey v. McDowell Co., 2002, Footnote 3). The principal had received complaints about Mrs. Maxey’s failure to discuss "routine" (Maxey v. McDowell Co., 2002, Footnote 4) items such as mid-term grades. In addition, she had an "unwillingness to communicate" (Maxey v. McDowell Co., 2002, Facts I.B.) with the principal.

Mr. Spencer, a novice principal, had communication problems. Principal Spencer's lack of communication skills and unwillingness to communicate were evident from the beginning of the case. Instead of the principal speaking to the teacher about what he termed "disagreeable incidents" (Maxey v. McDowell Co., 2002, Facts I.), Mr. Spencer began documenting them on an attachment for the evaluation form. The principal did not confront the teacher when she called him Napoleon, when she fell to her knees during a conference with a parent, nor when Mrs. Maxey offered to draw him a map to the Board office. There was no evidence Mr. Spencer sought to identify why the teacher wanted to jump out the window or made an attempt to talk with her.

Apparently Mr. Spencer had problems communicating in written form, also. He prepared an observation form and a conflicting attachment. The observation was positive while the attachment contained data that was negative. The attachment also contained "matters that did not occur in the classroom" (Maxey v. McDowell Co., 2002, Facts I.B.), an example of data that was being misused. 
The court's finding that the school district did not inquire if Mrs. Maxey's "bizarre conduct" (Maxey v. McDowell Co., 2002, Applications IV) was affected by the emotional issues in her personal life, was another example of a communication problem. Three administrators witnessed her behavior and emotional state but did not choose to make an "inquiry into whether that conduct is correctable" (Maxey v. McDowell Co., 2002, Syllabus). Failure to consider if Mrs. Maxey's behaviors were correctable was the primary reason for the reversal of the decision by the court. "Consideration was not given to the role of psychological turmoil, mental exhaustion, and recent bereavement" (Maxey v. McDowell Co., 2002, Applications IV), an example of ignored data. The court pointed out that the superintendent responded to the Mrs. Maxey's stress during the meeting by calling the sheriff but did not recognize it sufficiently to provide assistance with her classroom performance.

By not recognizing how stress affected Mrs. Maxey’s teaching performance, the court charged the school district with failure to abide by Policy 5300 which governed teacher evaluation. If the administrators deemed the behavior was correctable then remediation in the form of an improvement plan should have been offered to the teacher. "What is 'correctable' conduct does not lend itself to an exact definition but must ... be understood to mean an offense or conduct which affects professional competency" (Maxey v. McDowell Co., 2002, Standard of Review II). Their failure to do neither of these caused two more types of problems with teacher evaluation: failure to determine the need for remediation and failure to provide an adequate remediation plan.

It was interesting to note that the court mentioned the negative behavior of the principal. "It is not clear whose professional performance was more disappointing" 
(Maxey v. McDowell Co., 2002, Applications IV) was said about the March 1997

conference. And, "consideration was not given to any blame to be attributed to Mr. Spencer for his limited communication skills, his distinct fear of confrontation, or his failure to address his concerns in a more constructive posture" (Maxey v. McDowell Co., 2002, Applications IV).

The court determined that the earliest conflicts between Mrs. Maxey and Principal Spencer "were primarily performance related and reflected a personality conflict and the absence of constructive communication" (Maxey v. McDowell Co., 2002, Applications IV). Because it was performance related and no inquiry was made "to ascertain why a veteran teacher of seventeen years with an exemplary record suddenly committed acts which the Board found intolerable and worthy of a letter of termination," (Maxey v. McDowell Co., 2002, Applications IV), the court found that Policy 5300 was not adhered to by McDowell County's administrators and Board. Given the circumstances of this case as presented, it is the opinion of the researcher that the disrespect demonstrated by Mrs. Maxey toward the principal did not require a plan of improvement and the outcome, reversed and remanded, was not warranted.

\section{Chapter Four Summary}

One hundred thirty-five cases were produced from electronic searches to determine the problems associated with teacher evaluation as manifested in case law. The five criteria for case law selection included: retrieved from one of the sixteen SREB states, occurred within the timeframe 1980 to 2008, dismissal based upon teacher evaluation, teacher evaluation referenced in the context of the judgment and the dismissal 
involved a classroom teacher. Thirty-seven cases met the criteria and were selected for use in this study.

A content analysis of these cases revealed 31 types of problems with teacher evaluation that were manifested in case law. The problems were distributed within 7 categories: Attitude, Communication, Policy, Data, Process, Remediation and Emerging Issues. Process was the category with the greatest frequency of problems.

There were 31 types of problems with teacher evaluation found in the cases. The range of problems was $1-17$. The cases averaged 2.7 problems per case. The problem was counted once regardless of how many times it was referenced in an individual case. Inadequate feedback was the most frequently appearing problem and was present in nine cases. Each of the 31 problems was presented with its definition. Examples from case law text were used to illustrate the problem.

A table was constructed to present the types of problems that were found in the literature and the types of problems that were manifested in case law. Twenty problems of teacher evaluation found in case law were also found in the literature of the field. Eleven problems appearing in case law were not found in the literature.

This chapter presented findings in both chart and narrative form. Table 2 presented the number of cases analyzed from each of the sixteen states. Table 3 showed the number of cases with problems in each category. Table 4 identified the problems of teacher evaluation as manifested in case law and indicated which of those problems appeared in the literature. Table 5 illustrated the types of problems found in the exemplar case, Maxey v. McDowell Co. (2002). 
A matrix of the categories, subcategories, definitions and illustrations of pertinent text was presented in Appendix D. Appendix E presented the 31 types of problems and the number of cases illustrating each problem. The number of cases (37), the number of problems (99), the range of problems per case (1 to 17) and the average number of problems per case (2.7) also appeared on this appendix. Appendix F lists the problems of teacher evaluation found in the literature and in case law. Appendix G listed the 37 cases used in this study.

An exemplar case, Maxey v. McDowell Co. (2002), was presented, discussed and interpreted. This WV case was chosen because of the number of problems evidenced in it and the amount of text available about it. In the opinion of the researcher, problems with teacher evaluation that led to the court's reversal and remandment of the case were created by the novice principal and his limited communication skills. Maxey v. McDowell Co. (2002) could serve as a great teaching case. 


\section{CHAPTER FIVE}

Summary of Findings, Conclusions, Discussion, and Recommendations

The purposes of chapter five are to present the summary of findings, conclusions, discussion, and recommendations for training, practice and further research. The purpose of this study was to analyze case law related to teacher dismissals based on evaluation between 1980 and 2008 in the 16 SREB states to determine the problems associated with teacher evaluation and to determine if these problems were documented in the literature or were not. A content analysis of the cases was completed. A data matrix and four tables were constructed to present the data.

\section{Summary of the Findings}

One hundred thirty-five cases were identified through electronic searches to determine the problems associated with teacher evaluation. The criteria for case law selection were: retrieved from one of the sixteen SREB states, occurred within the timeframe 1980 to 2008 , dismissal based upon teacher evaluation, teacher evaluation referenced in the context of the judgment and the dismissal involved a classroom teacher. Thirty-seven cases met the criteria and had evidence of thirty-one types of problems with teacher evaluation. Twenty of the problems were documented in the literature of the field and eleven were not.

This case law evidence supports the belief that teacher evaluation is a problematic practice. These problems may prevent teacher evaluation from achieving its accountability goal (i.e., ensuring that each teacher's job performance is satisfactory). I identified a variety of problems that may have a detrimental effect on the process of 
teacher evaluation and will expand on two of these: attitude and repercussions from negative evaluations.

A teacher or principal with a negative attitude may have an adverse effect on the evaluation process. 'It isn't that I don't like little children, it's that I don't like having to teach them" (Squire v. BOE of Red Clay, 2006, n. p.) was the response of a librarian/media specialist who, as an effort to raise students' low standardized test scores, was now required to teach reading to elementary children. The expression of this sentiment demonstrated the presence of the teacher's negative attitude toward her change in duties. Mrs. Squire failed to accept her new responsibilities and "all but admits that she did not do well in the role" (Squire v. BOE of Red Clay, 2006, section IV). Her negative attitude also affected her involvement in the evaluation process. The teacher "failed to demonstrate a willingness to work with or cooperate with observations made by different professionals [five evaluators generated eight evaluations and three remediation plans over a five-year period]," (section IV) refused to take part in the development of her remediation plan, and failed to complete her remediation plan stating that she "didn't really know if she was going to make any changes because she only had three years left" (section IV) before retirement.

A principal's attitude may also negatively impact the evaluation process. "Trying to be a halfway decent humane person, I did not want to wipe her out totally the first year or second year" (Wilt v. Berkeley Co., 1982) was the explanation a principal offered the court when the judge found that Mrs. Wilt's observations were not open and honest. The principal, unbeknown to the teacher, listened in to the classroom over the public address system, revealing himself only when he elected to use the speaker to reprimand a student. 
Knowing that the teacher lacked classroom management skills, the principal did not thoroughly document the unsatisfactory performance. This attitude led to the teacher's belief that she was performing better than she actually was. After two years of poor classroom performance, the principal finally did not recommend she be rehired.

Repercussions from negative evaluations are another problem that has a detrimental effect on teacher evaluation. A principal being called names and threatened with having his head blown off (Maxey v. McDowell Co., 2002), subjected to a false, retaliatory charge of having pornographic material on school grounds (Hawzipta v. Noble Co., 2000), and squirted with a water gun in front of students (Davis v. Macon Co., 2006) may prevent the administrator from giving negative evaluations in the future.

In addition to the principal being called names and receiving a threat to be shot, the Maxey v. McDowell Co. (2002) case illustrated other types of repercussions from a teacher receiving a negative evaluation. The teacher threatened to kill herself by jumping out the window, she stomped on her evaluation form and refused to sign it, and, the principal stated that he felt fear and was afraid to come to work the day after he had to confront Mrs. Maxey about her behavior. Principals must be able to honestly evaluate a teacher without fear of reprisal. If not, the chance of a poor performing teacher receiving a satisfactory evaluation remains.

\section{Research Question One}

What are the problems of teacher evaluation as found in selected teacher dismissal cases of the states in the Southern Regional Education Board (SREB) between 1980 and 2008 and what is the frequency of each? There are seven categories of problems associated with teacher evaluation. The most frequent category is process and 
the least frequent are remediation and emerging issues. There are 31 types of problems and the most frequent is inadequate feedback. There are eleven problems that are the least frequent. Table 3 in Chapter 4 lists the frequencies of all the categories and their types of problems.

This question is answered from the data matrix. A matrix is a visual display of data that is presented systematically to help the researcher make valid conclusions (Miles \& Huberman, 1994). The data matrix for this research has seven sections, one for each category. The first row in each section contains the category name and its definition. The categories include: attitude, communication, policy, data, process, remediation and emerging issues. The goal of the matrix is to show the full range of teacher problems as manifested in the 37 cases used in this study (see Appendix D).

\section{Research Question Two}

Which of these problems are documented in the literature of teacher evaluation? Most of the problems, 2/3, are found in the literature. They are: observations not open and honest, incorrect instrument, instrument ambiguity, failure to abide by timelines, failure to provide each component, inadequate components, multiple evaluators lacking agreement, repercussions from a teacher's unsatisfactory evaluation, insufficient policy, inconsistent policy, failure to follow policy, insufficient data, using impressions instead of data, unwillingness to communicate, inadequate feedback, attitude toward negative evaluations, lack of trust, failure to determine need for remediation and failure to provide an adequate remediation plan.

Table 4 in Chapter Four is referenced to answer this question. A visual analysis of the table is completed to determine the problems that are manifested in case law and 
appear in the literature. This is apparent when there are Xs in both column two, Found in Literature, and column three, Found in Case Law.

Research Question Three

Which of these problems are not documented in the literature of teacher evaluation? Approximately $1 / 3$ of the problems are not found in the literature. They are: attitude toward others in the school/district, attitude attributed to conflicting personalities, limited communication skills, conflicting data, misused data, novice evaluator, evaluator's attitude toward the job, failure for teacher to participate in remediation, failure for the teacher to comply with the remediation plan, lack of training for new duties and singled out as an example.

This question is answered by using Table 4 in Chapter 4 . The table is visually analyzed to find those problems lacking an $\mathrm{X}$ in column two, Found in Literature. An empty cell in column two indicates that the problem is not found in the literature.

\section{Conclusions}

1. Problems revealed in case law provide evidence that teacher evaluation is a problematic practice and may be prevented from achieving its accountability goal.

2. Since not all of the types of problems with teacher evaluation that are manifested in case law are revealed in the literature, there are partial but selective gaps that exist.

\section{Discussion of Findings}

Historically, teacher evaluation has always been problematic. The analysis of case law for this study reinforces that not only are there problems with teacher evaluation but there are more problems than those being written about. 


\section{Process and Data Problems with Teacher Evaluation}

If we assume that the problems in case law do in fact represent some semblance of the problems that administrators face with teacher evaluation and how it is conducted, then it can be understandable why many believe the practice is ritualistic and lacking effectiveness. During the judicial process, the intense scrutiny of the evaluator's actions in completing a teacher's evaluation and forming a professional judgment can be both frightening and intimidating for the principal. Principals may also be concerned with possible repercussions from the BOE if the case is not successfully defended.

Process. When viewing the problems and their frequencies listed in Table 3, it is expected that process problems would be the most prevalent because process problems are frequently grieved (Hazard, 1993). This is expected because the majority of states have been involved in legislating the specifics in the evaluation process since the 1980s (Furtwengler, 1995). Process refers to how the evaluation of teachers is conducted. When a teacher receives an unsatisfactory evaluation rating, it is not uncommon for the teacher to allege that the process was faulty. By grieving some part of the process, the teacher seeks to invalidate it which could thereby invalidate the unsatisfactory rating.

Two things may decrease the occurrence of process problems in case law. The first item is increased teacher participation in developing the process. Scholars (Nolan \& Hoover, 2007; Peterson, 2001) are encouraging teachers to become more involved in the design of their own evaluation. Assisting the principal with the choice of data to be used for evaluation would be one way teachers could participate. When teachers are included in designing their evaluations, their understanding of the evaluation process should increase. 
The second item that may decrease process problems is the establishment of performance standards for teachers' performance evaluations. Standards are described as the foundation (Stronge \& Tucker, 2003) and the cornerstone (Danielson \& McGreal, 2000) of evaluation. Their use may result in professionally sound and legally defensible evaluations. When performance standards are adopted and teachers increase their participation in the design of the evaluation process, we may anticipate a decrease in process problems emerging in case law.

Data. The emergence of problems with data (i.e., insufficient, conflicting, misused, ignored) is interesting. Data was seldom a problem before 2000. The data source for teacher evaluation in the 1940s and 1950s was teacher traits, followed by the teacher's behavior in the classroom as seen in classroom observations during the 1960s and 1970s. In the 1980s and 1990s, the teacher's methods of instruction were noted. By the late 1990s there was an increased focus on instruction and how it related to student learning. As the move toward accountability progresses, we can anticipate student achievement becoming the focus for providing data for teacher evaluations.

In this study, the outcomes of two cases involving the use student achievement data were reversed. The FL Court o Appeals overturned the lower court rulings in both Sherrod v. The Palm Beach School District (2006) and Young v The Palm Beach School District (2006) and ruled in favor of the teachers because the evaluations were not primarily based on student achievement as stated in FL law. We can anticipate an increase of data problems being manifested in case law as there is an increase in the use of student achievement as a data source for teacher evaluation. 
Several states in addition to FL (e.g., SC, TN, TX) have begun requiring evidence of student learning to be the "preponderant condition" (National Council on Teacher Quality, 2007) for teacher evaluation while some states (e.g., AL, DE, GE, MS, NC, OK) require only the inclusion of evidence of student learning. As data-driven decision making emerges as a practice to help schools meet adequate yearly progress (Hazi, Garman \& Fuentes, 2007), more states may add student achievement as a data source. Data-driven decision making refers to the collection and review of various types of data to formulate decisions in regards to increasing students' success (Hazi et al., 2007).

Authors are addressing the use of student achievement as a data source for evaluation and the problems that may result. Marshall (2005) and Hazi (2008) both presented information regarding the use of student achievement data and associated problems. Hazi (2008) referred to the use of student achievement data as "provocative" and having "the potential to be the most controversial and problematic of new developments to influence the practice of teacher evaluation" (p. 11). What evidence of student learning will be used and how can it be equitably collected? Who will determine the student learning data that is the best to use? How will other conditions of student learning be taken into consideration? Does student learning equate to teacher performance? These are examples of problems that may arise from using evidence of student learning as a data source.

\section{Factors Possibly Effecting Teacher Evaluation Problems}

The search of problems with teacher evaluation in the SREB resulted in the identification of 31 types of problems. Would the results be different in another region of 
the United States? What role if any would collective bargaining play? Would the types of problems in a union state differ?

"To bargain collectively is the performance of the mutual obligation of the employer and the representative of the employees to meet at reasonable times and confer in good faith with respect to wage, hours and other terms and conditions of employment" (National Labor Relations Board [NLRB] 2008, p. 6). The northeast section of the country is primarily made up of collective bargaining states which historically allow greater autonomy for its school districts (Furtwengler, 1995). It can be anticipated that there would be a greater number of grievances if procedures for teacher evaluation were not followed in one of these states.

In addition, progressive discipline has greater use in states with collective bargaining (Stone, 1981). As a result, the number of process problems in case law may be less.

Teachers' unions have been confrontational in teacher dismissal cases and have caused increased spending of both cost and time during the dismissal process (Goldstein, 2007). Viewed by some as an unbeatable adversary, the union may prompt principals contemplating teacher dismissal to hesitate. In union states we may see administrators seeking alternatives to the dismissal process. An administrator in Keeling v. Jefferson Co. $B O E$ (2003), a Kentucky case, arranged an alternative agreement with the teacher in order to avoid going through the dismissal process, if possible. Mrs. Keeling received an evaluation with deficiencies. The director of employee relations offered to postpone action on the unsatisfactory rating if Mrs. Keeling would agree to four items.

1. A neutral principal would evaluate the teacher. 
2. Mrs. Keeling must immediately submit a letter of resignation that would become effective if the neutral principal found her performance unsatisfactory. If the new evaluation was satisfactory the resignation would be rescinded but the complaints of the principal would remain in the teacher's file.

3. Mrs. Keeling must promise to drop all grievances she had filed against the principal. One grievance charged that the principal had violated the 1992 collective bargaining agreement.

4. Mrs. Keeling must not call the union concerning the settlement agreement. The neutral principal also found Mrs. Keeling's performance to be deficient, prompting the administration to accept the resignation.

Could collective bargaining and unions be used to structure reform? The strength of unions is well recognized. One of the factors that differ between the Peer and Assistance Review (PAR) process (see p. 85) and traditional evaluation is the inclusion of the union. The union must sign off on a district's creation of a PAR program and the union president must agree to be the co-leader of the PAR panel. The union is then acting as a defender of the teaching professions instead of individual teachers (Goldstein, 2007).

\section{The Practice of Personnel Evaluation}

The purposes of evaluation include teacher improvement and an accountability mechanism for personnel decisions. The practice of evaluation began based on the assumption that untrained teachers had access to a captive audience of students. At the time, most teachers were women without any formal training other than their own 
experiences. In time a single course was offered as preparation to work as a teacher. The single training course eventually evolved into teacher preparation programs.

Few teachers receive unsatisfactory ratings and few are dismissed (Medley \& Coker, 1987; Tucker, 1997). The current system is not working. Why have problems with evaluation persisted so long? Is the process too complex? Is it fixable? How do other fields perform personnel evaluations? How could these contrasting methods be used in education?

Military. The critical incident technique evaluates military leaders during military conflicts and was developed during World War II "to identify successful and nonsuccessful aspects of combat leadership" (Burton, 2008, n.p.). An alternative to traditional evaluation, this technique could be applied when a teacher has high failures, when the majority of the students do not meet mastery on the yearly test or when there are an inordinate amount of parental/student/peer complaints. The data is analyzed by a team, strengths and weaknesses of the instruction and teacher are identified, and then relevant training is provided to the teacher.

Medical field. The medical field often uses a version of the critical incident technique called a significant event audit (Burton, 2008). Following a medical critical incident (e.g., numerous injuries treated in the emergency room following a multi-car accident, the treatment of employees and nearby residents following a chlorine gas leak at a local chemical plant) the response efforts and treatment process are evaluated. In education, a team is evaluated instead of an individual teacher. Following a significant event (e.g., $40 \%$ of freshmen boys earned a C or less in English/LA for the first nineweeks of a school year), the cases are systematically analyzed to determine what can be 
learned about the quality of instruction. The team looks at the types of improvements that are needed to improve the learning. The evaluation would be of all of the $9^{\text {th }}$ grade math teachers instead of one.

Legal field. In contrast to the field of education, many legal firms suggest quarterly evaluations instead of annual ones for associates ("How to Fire Lawyers," 2003). Others conduct mid-year performance reviews ("Don't Get Rid of Mid-Year Reviews", 2001). The reason for increasing the frequency is to identify issues and problems early and often so that negative behaviors can be corrected. The length of time the lawyer has been an associate does not alter the frequency of the evaluation. It also suggests that law firms measure the performance of the evaluators (i.e., partners and managers) while they are conducting the evaluations of the associates. Law firms also encourage the self-appraisal of associates so that "supervisors get a better idea of how those being evaluated perceive themselves" ("Don't Get Rid of Mid-Year Reviews," 2001, p. 3).

It could be beneficial to review these and other evaluation practices of different professions. There may be aspects of these evaluation processes that can be adapted for use in the field of education.

\section{The Literature Gap}

Administrators need to be aware of the types of problems that are causing teachers to seek litigation for judicial resolution. Awareness of the problems may impact future practice (Rossow, 1992). One source of awareness is the literature of the field. According to the results of this study, writers are not reporting on all of the problems with teacher evaluation that are manifested in case law. 
Why aren't authors writing about all the problems with teacher evaluation? Are some problems considered more important than others? Are writers unaware of some of the problems in case law? Are they avoiding writing about problems for which they have no solutions to offer? Are some problems more important than others?

One possible reason that not all problems manifested in case law appear in the literature is the time lapse between the occurrence of some problems and the publication of the judicial resolution of their cases. Appeals may cause a case to be in the court system for a number of years (e.g., Maxey v. McDowell Co. began in 1996 and the final resolution occurred ten years later in 2006). This time lapse could cause a delay for scholars in acquiring knowledge of some of the problems in case law and to write about them. In essence, literature needs time to catch up with some of those problems being manifested in case law.

A second possible reason that not all problems in case law appear in the literature may be the complexity of a problem. Encarta (2007) defines complexity as having a complicated nature. The complicated nature of some problems with teacher evaluation (e.g., attitude attributed to personality conflicts, communication skill) may cause the problem to be difficult to analyze, understand and solve. Writers may not be choosing to write about a complex problem because of these complications.

\section{Recommendations}

\section{Recommendations for Evaluator Training}

Teachers look to the courts to challenge terminations that were based upon negative evaluations. Administrators must be aware of the types of problems with 
evaluation to avoid or lessen the chance of a judge reversing or dismissing a case. For this reason, the following are recommended for evaluator training:

1. Evaluator training should include the use of real-world applications. Case law that provides evidence of the problems of teacher evaluation should be presented and discussed. The matrix can serve as a resource for such cases.

2. Maxey v. McDowell Co. (2002) is a good case to review and understand as it is illustrative of what kinds of problems principals can expect in practice. Reading the text and the researcher's interpretation of the case are recommended.

\section{Recommendations for Practice}

The identification of problems with teacher evaluation can affect policies governing the practice and therefore, the practice itself. Awareness of litigation involving problems with policy, data, process and remediation, and the judicial resolutions can be used to benefit policymakers, teachers and administrators by assisting in the creation of informed policies and practices. Changes resulting from litigation need to be addressed as quickly as possible to ensure the most efficient and fair means of evaluating teachers. Teacher evaluation is one instrument school districts have to assist in providing effective teachers in the classroom. Recommendations for practice include:

1. The use of the data matrix as a reference by principals could deter administrators from committing similar errors and behaviors in practice that have led to litigation.

2. The data matrix may be used by central office and the school board when deciding whether or not to challenge a ruling in a case. The matrix may provide 
information so that decisions could be made in reference to: should the case be challenged and is an appeal worthwhile.

3. The information in the data matrix may be used by the superintendent and the school board when reviewing and amending local policy on teacher evaluation. Ensuring that local policy contains all requirements of the state, that it is written in language lacking ambiguity, and that it is made available and explained to all teachers and principals.

\section{Recommendations for Research}

Litigation increased in the early to mid 1980s, leveled off in the latter 1980s, and leveled off or declined in the 1990s (Lupini \& Zirkel, 2003). Still, the studies completed in education litigation have not produced enough information "for prudent decision making" (Lupini \& Zirkel, 2003). For this reason, research in education litigation needs to continue.

1. Research should be conducted in collective bargaining states to assess the impact of collective bargaining agreements on the number of teacher evaluation problems associated with teacher dismissal cases.

2. Research should be conducted in additional states to find if the frequency of problems with teacher evaluation in the SREB is indicative of the frequency in other geographic regions.

3. Research should be conducted to see if there are differences in the types of problems with teacher evaluations in different time periods. 
4. Research should be conducted to determine the correlation between the level of control of teacher evaluation (e.g. Hazi \& Arredondo Rucinski [2009]) by the state and the number of teacher dismissal cases. 


\section{References}

Alicias, E.R. Jr., (2005, May 6). Toward an objective evaluation of teacher performance: The use of variance partitioning analysis. Education Policy Analysis Archives 13(30). Retrieved April 4, 2008 fromihttp://epaa.asu.edu/epaa/v13n30h.

Allee, J.G. (Ed). (1984). Webster's dictionary. (11 ${ }^{\text {th }}$ ed.) Chicago: Wilcox \& Follett Book Company.

Allen, K.H. \& Jarvis, M.E. (1983, April). Analogizing teacher evaluation policies and procedures with case law [Abstract]. Paper presented at the Annual Meeting of the American Educational Research Association (AERA), San Francisco, CA.

American Psychological Association. (2001). Publication manual of the American Psychological Association (5 ${ }^{\text {th }}$ ed.). Washington, DC: Author.

Auerbach, C. \& Silverstein, L. (2003). Qualitative data: An introduction to coding and analysis. New York, NY: New York University Press.

Ballou, D. \& Podgursky, M. (1993). Teachers'attitudes toward merit pay: Examining conventional wisdom. Industrial and Labor Relations Review, 47(1), 50-61.

Batagiannis, S.C. (1984). Teacher dismissal: litigation resulting from incompetency and reduction in force on the basis of teacher evaluation (Doctoral dissertation, Indiana State University, 1984). Dissertation Abstracts International, 45, 993. Beckham, J. \& Zirkel P.A. (1983). Legal issues in public school employment. (Report No.ISBN-0-87367-789-7). Bloomington, IN: Phi Delta Kappa. (ERIC Document Reproduction Service No. ED245371)

Beebe, L.H. (2007, October). What can we learn from pilot studies? Perspectives in Psychiatric Care, 43(4), 213-218. 
Bernardi, L.M. (2003). Nine steps to effective discipline. Canadian Manager, 28(4), 1921.

Bridges, E.M. (1993) The incompetent teacher: Managerial responses. Washington, DC: The Falmer Press.

Bridges, E.M. \& Groves, B. (1984). Managing the incompetent teacher. ERIC/CEM School Management Digest Series, 29.

Bridges, E.M. \& Groves, B. R. (1999). The macro- and micropolitics of personnel evaluation: A framework. Journal of Personnel Evaluation in Education, 13(4), 321-337.

Brito v. Zia Co., 478 F.2d 1200 (10 ${ }^{\text {th }}$ Cir. 1973).

Burton, Chloe. (2008). Significant event audit. Available at !http://Www.patient.co.uk/showdoc/40024612/,

Burton, L.L. (2003). An analysis of Georgia state board of educational dismissal appeal decisions from 1991 to 2001. Unpublished doctoral dissertation, University of Georgia.

Cambron-McCabe, N.H., McCarthy, M.M. \& Thomas, S.B. (2004). Public school law: Teachers' and students' rights ( $5^{\text {th }}$ ed.). Boston: Allyn \& Bacon.

Chance v. Board of Examiners, 496 F.2d 820 (2d Cir. 1974).

Cohen-Vogel, L. \& Osborne-Lampkin, L. (2007). Allocating quality: collective bargaining agreements and administrative discretion over teacher assignment. Educational Administration Quarterly, 43(4), 433-461.

Commission on No Child Left Behind. (2007). Beyond NCLB: Fulfilling the promise to our nation's children. Retrieved January 26, 2008, from 
hattp://WwW.aspeninstitute.



Conley, S.\& Glasman, N.S. (2008). Fear, the school organization, and teacher evaluation. Educational Policy, 22(1), 63-85.

Danielson, C. \& McGreal, T.L. (2000). Teacher evaluation to enhance professional practice. Alexandria, VA: Association for Supervision and Curriculum Development.

Darling-Hammond, L. (1988). The futures of teaching. Educational Leadership. 4-10.

Darling-Hammond, L., Wise, A.E. \& Pease, S.R. (1983). Teacher evaluation in the organizational context: A review of the literature. Review of Educational Research 53(3). 285-328.

DelPo, A. \& Guerin, L. (2007). Dealing with problem employees: A legal guide $\left(4^{\text {th }}\right.$ Ed). Berkeley: NOLO.

DeSander, M.K. (2000). Teacher evaluation and merit pay: Legal considerations, practical concerns. Journal of Personnel Evaluation in Education, 14(4), 307-317.

Dobinson, I. \& Johns, F. (2007). Qualitative Legal Research. In McConville, M. \& Chui,W.H. (Eds), Research Methods for Law (pp. 16-43). Edinburgh: Edinburgh University Press.

Don't get rid of mid-year reviews - iprove them. (2001, June). Law Office and Administration Report, 1(6), p. 2-3. Available at http://web.ebscohost.com.www.libproxy.wvu.edu/ehost/pdf?vid=12\&hid=13\&sid $=2 \mathrm{~b} 64 \mathrm{f} 699-99 \mathrm{eb}-42 \mathrm{f} 5-864 \mathrm{c}-387 \mathrm{ea} 7 \mathrm{a} 3 \mathrm{~b} 676 \% 040$ sessionmgr3 
Duke, D.L. \& Stiggins, R.J. (1986). Teacher evaluation: Five keys to growth (Report No. ISBN-0-8106-1536-3). Washington, DC: National Institute of Education. (ERIC Document Reproduction Service No. ED 275 069)

Encarta World English dictionary [North American Edition]. (2007). Available at hittp:/lencarta.msn.com/encnet/features/dictionary/dictionaryhome.aspxi

Enz, B.J. \& Searfoss, L.W. (1993, April). Who evaluates teacher performance? Mismatched paradigms, the status quo, the missed opportunities. Paper presented at the Annual Meeting of the American Education Research Association, Atlanta, GA.

Equal Employment Opportunity Commission. (2008a). Disability Discrimination. Retrieved July 1, 2008 from ihttp://WwW.eeoc.govi

Equal Employment Opportunity Commission. (2008b). Uniform employee selection guidelines questions and answers. Retrieved July 15, 2008 from hhttp://www.uniformguidelines.com/questionandanswrs.htm

Erdogan, B., Kraimer, M.L. \& Liden, R.C. (2001). Procedural justice as a twodimensional construct: An examination in the performance appraisal context. The Journal of Applied Behavioral Science, 37(2), 205-222.

Falcone, P. (1997, February). The fundamentals of progressive discipline - employee discipline. HR Magazine. Retrieved July 3, 2008 from hitp://findarticles.com/p/articles/mi $3495 / \mathrm{is} \mathrm{n} 2 \mathrm{v} 42 / \mathrm{ai}-1922463 \%$

Fossey, R. (1998). Secret settlement agreements between school districts and problem employees: Some legal pitfalls. Journal of Personnel Evaluation in Education, 12(1), 61-67. 
Freedom of Information Act, 5 U.S.C. § 552 (2002).

Furtwengler, C.B. (1995, February 15). State actions for personnel evaluation: Analysis of reform policies, 1983-1992. Education Policy Analysis Archives, 3(4). Retrieved August 1, 2007 fromihttp://epaa.asu.edu/epaa/v3n4.htmi

Garman, N. (1994, August 5). Qualitative inquiry: Meaning and menace for educational researchers. Keynote speech at the mini-conference on qualitative research, Flinders Institute or the Study of Teaching, The Flinders University of South Australia, Adelaide.

Gay, L.R., Mills, G.E. \& Airasian, P. (2006). Educational research: competencies for analysis and applications. ( $8^{\text {th }}$ ed.). Upper Saddle River: Pearson Merrill Prentice Hall.

Glesne, C. (2003). Becoming qualitative researchers: An introduction. Boston, MA: Pearson.

Goldstein, J. (2007). Easy to dance to: Solving the problems of teacher evaluation with peer assistance and review. American Journal of Education, 113, 479-508.

Goldstein, J. \& Noguera, P.A. (2006). A thoughtful approach to teacher evaluation. Educational Leadership, 63(6), 31-37.

Griggs v. Duke Power Co., 401 U.S. 424 (1971).

Grote, R.C. (2006). Disciplining without punishment: The proven strategy that turns problem employees into superior performers $\left(2^{\text {nd }}\right.$ ed.). Available at hittp://books.google.com. 
Guba, E.G. \& Lincoln, Y.S. (1994). Competing paradigms in qualitative research. In N.K. Denzin \& Y.S. Lincoln (Eds.), Handbook of Qualitative Research. London: Sage.

Halverson, R., Kelley, C. \& Kimball, S. (2004). Implementing teacher evaluation systems: How principals make sense of complex artifacts to shape local instructional practice. In W.K. Hoy \& C.G. Miskel (Eds.), Educational administration, policy and reform: Research and measurement research and theory in educational administration. Vol. 3. Greenwich, CT: Information Age Press.

Hazard, W.R. (1993). Legal aspects of teacher evaluation. Paper presented at the Annual Convention of the National Organization on Legal Problems in Education, Philadelphia, PA.

Hazi, H.M. (1992). Discovering and releasing the voices of authority in education law inquiry. In Haggerson, N. \& Bowman, A. (Eds), Informing education policy and practice through interpretive inquiry (pp.251-259). Lancaster-Basel, Australia: Technomic Publishing Co.

Hazi, H.M. (1995). On the importance of discourse about legal research in the law and education. Paper presented at the American Educational Research Association (AERA) SIG Roundtable on Legal Research, San Francisco, CA.

Hazi, H.M. (2008). Teacher evaluation in the states: Trends and forecasts. Paper presented at the annual meeting of the National Evaluation Institute, Wilmington, NC. 
Hazi, H.M. \& Arredondo Rucinski, D. (2006, April). Complicating the ritual of teacher evaluation. Implications for supervision. Paper presented at the annual meeting of the American Educational Research Association (AERA), San Francisco, CA.

Hazi, H.M. \& Arredondo Rucinski, D. (2009). Teacher evaluation as a policy target for improved student learning: A fifty state review of statute and regulatory action since NCLB. Education Policy Analysis Archives, 17(5). Available at http://epaa.asu.edul

Heathfield, S.M. (2007). Human resources: Discipline (progressive discipline). Retrieved July 3, 2008 from hihtp://humanresources.about.com/od/glossaryd/a/discipline.htm?

How to fire lawyers so they don't fire back. (2003, June). Compensation \& Benefits for Law Offices, 3(6), p. 1-5. Available at


$=2 \mathrm{~b} 64 \mathrm{f} 699-99 \mathrm{eb}-42 \mathrm{f} 5-864 \mathrm{c}-387 \mathrm{ea} 7 \mathrm{a} 3 \mathrm{~b} 676 \% 040 \mathrm{sessionmgr3}$

Joint Committee on Standards for Education Evaluation, Inc. (1988). The personnel evaluation standards. Thousand Oaks: Corwin.

Joint Committee on Standards for Education Evaluation, Inc. (2007). The personnel evaluation standards ( $2^{\text {nd }}$ ed). Retrieved August 10, 2008, from Western Michigan University, The Evaluation Center Web site: WwW.Wmich.edu/evalctr/jet

Joint Committee on Standards for Educational Evaluation. (2009). The personnel evaluation standards ( $2^{\text {nd }}$ ed. $)$. Thousand Oaks, CA: Sage. 
Kleiman, L.S. \& Durham, R.L. (1981). Performance appraisal, promotion and the courts: A critical review. Personnel Psychology, 34, 103-121.

Kyriakides, L., Demetriou, D. \& Charalambous, C. (2006). Generating criteria for evaluating teachers through teacher effectiveness research. Educational Research, $48(1), 1-20$.

Lee, J. \& Adler, L. (2006). Qualitative research redux: Researching contemporary legal issues concerning education. In S. Permuth \& R.D. Mawdsley Research Methods for studying legal issues in education,(pp. 25-56). Dayton, OH: Education Law Association.

Lenze, L.F. \& Warner, M.S. (1995, October). Summative evaluation and formative feedback. NEA Update, 1(4), 1-4. Retrieved April 3, 2008, from http://Www2.nea.org/he/heupdate/images/upv1no5.pdfi

Linquanti, R. \& Peterson, J. (2001). An enormous untapped potential: A study of the feasibility of using national board for professional teaching standards certification to improve low-performing schools. (Report No. SP040569). San Francisco, CA: West Ed. (ERIC Document Reproduction Service No. ED462385)

Loos, E.E., Anderson, S., Day, D.H., Jordan, P.C. \& Wingate, J.D. (Eds.). (2003). Glossary of linguistic terms. Available at http://www.sil.org/linguistics/GlossaryofLinguisticTerms

Lupini, W.H. \& Zirkel, P.A. (2003). An outcomes analysis of education litigation. Educational Policy. Available at http://epx.sagepub.com/cgi/content/abstract/17/2/257, 
Marshall, K. (2005). It's time to rethink teacher supervision and evaluation. Phi Delta Kappan, 86(10), 727-735.

Marshall, C. \& Rossman, G.B. (1995). Designing qualitative research $\left(2^{\text {nd }}\right)$. Newbury Park: Sage.

McColskey, W. \& Egelson, P. (1993). Designing teacher evaluation systems that support professional growth (Report No. RP1002010). Washington, DC: Office of Educational Research and Improvement. (ERIC Document Reproduction Service No. ED 367662).

McDaniel, M.A. (2007, April). Progressive discipline policies and employment at will. Paper presented at the Texas Leadership Institute: Employment Law Basics. Retrieved July 2, 2008 from



Mclaughlin, S. (2006). Valuing insight and judgement: A hermeneutic perspective on the development of validating contexts for practice-based research in design. Speculation and Innovation applying practice led research in the Creative Industries.

McNergney, R.F. \& Herbert, J.M. (1998). Foundations of education: The challenge of professional practice ( $2^{\text {nd }}$ ed.). Boston: Allyn and Bacon.

Medley, D.M. \& Coker, H. (1987). The accuracy of principals' judgments of teacher performance. Journal of Educational Research, 80(4), 242-247.

Menuey, B.P. (2005). Teachers' perceptions of professional incompetence and barriers to the dismissal process. Journal of Personnel Evaluation in Education, 18, 309-325. 
Merriam, S.B. (1988) Case study research in education: A qualitative approach. San Francisco,CA: Jossey-Bass.

Metcalf, M.O. (1992). Historical study of the Arizona courts' interpretations of teacher dismissals due to inadequate classroom performance (Doctoral dissertation, Northern Arizona University, 1992). Dissertation Abstracts International, 53, 3761.

Miles, M.B. \& Huberman, A.M. (1994). Qualitative data analysis (2 ${ }^{\text {nd }}$ Ed). Thousand Oaks, CA: Sage.

Munk, L.G. (1998). Collective bargaining: Bringing education to the table. (Report No. MCPP-598-04). Midland, MI: Mackinac Center for Public Policy. (ERIC Document Reproduction Service No. EA031157)

National Board for Professional Teaching Standards. (1987). The five core propositions. Available at,http://WWW.nbpts.org

National Commission on Excellence in Education. (1983). A nation at risk: The imperative for educational reform. Available at 'http://WwW.ed.gov/pubs/NatAtRisk/risk.htm!

National Commission on Teaching and America's Future. (September, 1996). What matters most: Teaching for America's future. Available at http://WwW.nctaf.org/documents/WhatMattersMost.pdf.

National Council on Teacher Quality. (2007). State teacher policy yearbook progress on teacher quality. Available at: WWw.nctq.org/stpy / 
National Governors Association Center for Best Practices. (2002, December). Improving teacher evaluation to improve teaching quality (Issue Brief). Washington, DC: Goldrick, L.

National Institute for Excellence in Teaching. (2008) Teacher advancement program. Retrieved August 9, 2008 from 'hittp://www.talentedteachers.org/index.tafi

National Labor Relations Board. (2008). National labor relations act. Retrieved July 19, 2008 from

Nolan, J. \& Hoover, L.A. (2007). Teacher supervision and evaluation: Theory into practice $\left(2^{\text {nd }}\right.$ ed.). Hoboken, NJ: John Wiley \& Sons, Inc.

Nolo’s Legal Glossary. (2008). Available at hittp://WwW.nolo.com/glossary.cfm

Obama, B.H. (2009). Taking on education. Available at 'htttp://Www.whitehouse.gov/blog/09/03/10/Taking-on-Education.

Patton, M. (1990). Qualitative evaluation and research methods $\left(2^{\text {nd }}\right)$. Newbury Park: Sage.

Perry v. Sindermann, 408 U.S. 593 (1972).

Peshkin, A. (1988). In search of subjectivity_One's own. Educational Researcher, 17(7), 17-21

Peterson, K.D. (1987). Teacher evaluation with multiple and variable lines of evidence. American Educational Research Journal, 24(2), 311-317.

Peterson, K.D. (2001). Research on school teacher evaluation. NASSP Bulletin, 88(639), $60-79$. 
Peterson, K.D. (2008). Politics of school quality: A national controversy with implications for teacher evaluation. Available at hittp://Www.teacherevaluation.net/Essay/polit.html

Peterson, K. \& Kauchak, D. (1982) Teacher evaluation: Perspectives, practices, and promises. (Evaluative/Feasibility Report No. 142). Salt Lake City, Utah: Utah University,Graduate School of Education, University of Utah, Center for Educational Practice.

Peterson, K.D., Wahlquist, C., Bone, K., Thompson, J. \& Chatterton, K. (2001, February). Using more data sources to evaluate teachers. Educational Leadership, $40-43$.

Pickering v. Board of Education of Township High School District 205, Will County, 391 U.S. 563 (1968).

Podgursky, M. \& Springer, M.G. (2007). Credentials versus performance: Review of the teacher performance pay research. Peabody Journal of Education, 82(4), 551-573.

Ponticell, J.A. \& Zepeda, S.J. (2004). Confronting well-learned lessons in supervision and evaluation. NASSP Bulletin, 88(639), 43-59.

Rossow, L.F \& Parkinson, J. (1992). The law of teacher evaluation. (NOLPE Monograph/Book No 42). Topeka, KS: National Organization on Legal Problems of Education.

Russo, C.J. (2006). Legal research: The "traditional" method. In S. Permuth \& R.D. Mawdsley, Research methods for studying legal issues in education (pp. 5-24). Dayton, OH: Education Law Association. 
Saidens, M.H. (1980). Collective bargaining in government: An introduction and teaching guide. Old Westbury, NY: State University of New York, The Empire State College Center for Business \& Economic Education.

Sawa, R. (1995). Teacher evaluation policies and practices. Retrieved August 2, 2007 from 'htttp://saskschoolboards.ca/research/instruction/95-04.htm

Sawchuk, S. \& Robelen, E.W. (2009). First education stimulus aid flows to states. Available at www.edweek.org/ew/articles/2009/04/01/28guidance.h28.html?tkn=OZSFaYTH9 py13ToTW+H3yrLJtyy5HZThxJjl\&print=1

Schacter J. \& Thum, Y.M. (2005). TAPping into high quality teachers: Preliminary results from the teacher advancement program comprehensive school reform. School Effectiveness and School Improvement, 16(3), 327-353.

Sclan, E.M. (1994). Performance evaluation for experienced teachers: An overview of state policies. Trends and issues paper, no. 10. (Report No. ISBN-0-89333-1236). Washington, DC: Office of Educational Research and Improvement. (ERIC Document Reproduction Service No. ED 373 054)

Scriven, M. (1980, October). Teacher personnel policies: Equity, validity, and productivity. Paper presented at the meeting of the Midwest Policy Seminar, St. Louis, MO.

Scriven, M. (1988). Evaluating teachers as professionals. (Report No. EA020239). Nedlands, Australia: University of Western Australia. (ERIC Document Reproduction Service No ED300882) 
Scriven, M. (1997). Due process in adverse personnel action. Journal of Personnel Evaluation in Education, 11, 127-137.

Scriven, M. (2001). Evaluation: Future tense. American Journal of Evaluation, 22(3), 301-307.

Section 60-3. Uniform Guidelines on Employee Selection Procedures (1978); 43 FR 38295 (August 25, 1978).

Sherman, M.R. (2005). Blackwell encyclopedic dictionary of human resource management. Oxford, England: Blackwell Publishing Ltd.

Smith, E. (2008). Raising standards in American schools? Problems with improving teacher quality. Teaching and Teacher Education, 24(3), 610-622.

Soar, R.S. \& Soar, R.M. (1975). Problems in using pupil outcomes for teacher evaluation. Washington, DC: National Education Association. (ERIC Document Reproduction Service No. ED150187).

Soltis, J. (1984). On the nature of educational research. Educational Researcher, 13(10), $5-10$.

SREB. (n.d.) About SREB. Retrieved November 7, 2008 from hittp://WWW.sreb.org/main/SREB/index.asp

Steinmetz, L.L. (1969). Managing the marginal and unsatisfactory performer. Reading MA: Addison-Wesley.

Stone, R.F. (1981). Managing employees through progressive discipline. Educational Leadership, 38(5), 407-408.

Stronge, J.H. \& Tucker, P.D. (2003). Handbook on teacher evaluation: Assessing and improving. Larchmont, NY: Eye on Education, Inc. 
Strauss, A. \& Corbin, J. (1990). Basics of qualitative research: grounded theory procedures and techniques. Newbury Park, CA: Sage.

Stufflebeam, D.L. and Pullin, D. (1998). Achieving legal viability in personnel evaluations. Journal of Personnel Evaluation in Education, 11, 215-230.

Sullivan, K.A. \& Zirkel, P.A. (1998). The law of teacher evaluation: Case law update. Journal of Personnel Evaluation in Education, 11, 367-380.

Taylor, M.S., Tracy, K.B., Renard, M.K., Harrison, J.K. \& Carroll, S.J. (1995). Due process in performance appraisal: A quasi-experiment in procedural justice. Administrative Science Quarterly, 40, 495-523.

Toch, T. \& Rothman, R. (2008, January). Rush to judgment: Teacher evaluation in public education. Retrieved March 12, 2008, from the Education Sector Web site: hittp://Www.educationsector.org/usr doc/RushToJudgment ES Jano 08 dedfi

Trenta, L., Newman, I., Newman, C., Salzman, J., Lenigan, D. \& Newman, D. (2004, May 15). Integrating mixed methods and stakeholders participation in the evaluation of a teacher induction program. International Electronic Journal for Leadership in Learning 8(3). Retrieved April 10, 2008 from http://www.ucalgary.ca/ iejil/volumes/Trenta3.htm

Tucker, P.D. (1997). Lake Wobegon: Where all teachers are competent (or, have we come to terms with the problem of incompetent teachers?). Journal of Personnel Evaluation in Education 11, 103-126.

Tucker, P.D., Stronge, J.H., Gareis, C.R. \& Beers, C.S. (2003). The efficacy of portfolios for teacher evaluation and professional development: Do they make a difference? Educational Administration Quarterly 39(5), 572-602. 
U.S. Department of Education. (2002). No Child Left Behind, a reauthorization of the Elementary and Secondary Education Act. Washington, DC: U.S. Department of Education.

U.S. Department of Education. (2007). Answers to questions about no child left behind. Available at http://answers.ed.gov/cgi-bin/education

U.S. Department of Education. (2009). ED.gov. Available at hittp://www.êd.gov/index.jhtml

VanDyke, M.J. (1984). The effects of advisory versus binding decisions on cases of teacher dismissal in New York state under 3020A (arbitration, conflict, legislative history). (Doctoral dissertation, State University of New York at Albany, 1984). Dissertation Abstracts International, 45, 3259.

van Schooten, B.W. (1998). About objective dialogue evaluation methods. The Netherlands: University of Twente, Department of Computer Science. van Teijlingen, E. \& Hundley, V. (2002). The importance of pilot studies. Nursing Standard, 16(40), p. 33-36.

Veir, C.A. \& Dagley, D.L. (2002). Legal issues in teacher evaluation legislation: A study of state statutory provisions. B.Y.U. Education and Law Journal, 1-16.

Weiss, E.M. \& Weiss, S.G. (1998). New directions in teacher evaluation. (Report No. ). Washington, DC: ERIC Clearinghouse on Teaching and Teacher Education. (ERIC Document Reproduction Service No. ED429052)

West Virginia Department of Education. (2008a) Minimum requirements for the licensure of professional/paraprofessional personnel and advanced salary classifications (5202). Available from, http://wvde.state.wv.us/policies/p5202.doo 
West Virginia Department of Education. (2008b). WV Task Force on Professional Teaching Standards. Available from



Wiliam, D. (2006). Formative assessment: Getting the focus right. Educational Assessment, 11(3 \& 4), 283-289.

Wise, A.E. \& Darling-Hammond, L. (1984). Teacher evaluation and teacher professionalism. Educational Leadership, 28-33.

Wise, A.E., Darling-Hammond, L., McLaughlin, M.W. \& Bernstein, H.T. (1984). Teacher evaluation: A study of effective practices. (Report No. ISBN-0-83300583-9). Washington, DC: National Institute of Education. (ERIC Document Reproduction Service No. ED 245 559).

Wolf, K., Lichtenstein, G. \& Stevenson, C. (1997). Portfolios in teacher evaluation. Paper presented at the annual meeting of the American Educational Research Association, Chicago, IL.

Yin, R.K. (1984). Case study research design and methods. Beverly Hills, CA: Sage Publications, Inc.

Zirkel, P.A. (2001/2002). Decisions that have shaped U.S. education. Educational Leadership, 6-12. 


\section{Appendix A}

\section{Pilot Study}

Purpose

1. A trial run of the proposed study to mine existing Supreme Court and Court of Appeals cases in the 16 Southern Regional Education Board (SREB) states from 1980 to 2008 for the selection of criteria in the identification of potential problems with teacher evaluation as appearing in appealed case law.

\section{Criteria for Selection}

1. Supreme Court and Court of Appeals case law from the SREB states of Alabama, Arkansas, Delaware, Florida, Georgia, Kentucky, Louisiana, Maryland, Mississippi, North Carolina, Oklahoma, South Carolina, Tennessee, Texas, Virginia and West Virginia between 1980 and 2008.

2. Case law keywords contain "teacher dismissal," "teacher" and "unsatisfactory performance," "teacher termination," or the state policy number regulating teacher suspension and dismissal.

3. Evaluation is central to the judgment issued.

4. Educator must be a classroom teacher at time of dismissal.

Method

1. LexisOne internet searches using keywords "teacher dismissal," "teacher" and "unsatisfactory performance," "teacher termination," and the state policy number regulating teacher suspension and dismissal for the 980 to 2008 time frame.

2. Supreme Court and Court of Appeals internet searches for each of the sixteen states using keywords "teacher dismissal," "teacher and unsatisfactory 
performance," "teacher termination," and the state policy number regulating teacher suspension and dismissal for the 1980 to 2008 time period.

3. Read cases and identify information concerning context of judgment.

4. Identify if criteria for inclusion of case is present.

5. Provide chosen cases to second reader.

6. Compile matrix of evaluation problems.

Number of Cases Found

1. Alabama - one case

2. Arkansas - five cases

3. Delaware - two cases

4. Florida - one case

5. Georgia - one case

6. Kentucky - thirteen cases

7. Louisiana - one case

8. Maryland - one case

9. North Carolina - one case

10. Oklahoma - four cases

11. South Carolina - four cases

12. Tennessee - four cases

13. Virginia - one case

14. West Virginia - six cases

15. Total $=45$

Relevant Case Laws Mined (Reference $=$ State abbreviation and case number) 
1. Board of School Commissioners of Mobile County v. Marion Dunn (AL-1)

2. Glenda Hannon v. Armorel School District \#9 (AR-1)

3. Foreman School District No. 25 v. Leo Pat Steele (AR-2)

4. Alice Brenda Squire v. Board of Education of the Red Clay Consolidated District (DE-1)

5. Board of Education of Fayette County v. Melinda Lewis Cobb (KY-1)

6. Clara Denise Jamison v. Board of Education of Greenup County (KY-2

7. Board of Education of Fayette County v. Janice Sevre-Duszynska (KY-3)

8. Sonja Wise v. Bossier Parish School Board (LA-1)

9. Linda Farris v. Burke County Board of Education (NC-1)

10. Jerry Hagen v. Independent School District No. I-004 (OK-1)

11. Rocky Weston v. Independent School District No. 35 (OK-2)

12. Hall v. Sumter County School District No. 2 (SC-1)

13. Shawn Runions v. Bill Emerson, et al (TN-1)

14. Marjorie J. Maxey v. McDowell County Board of Education (WV-1)

15. Brian M. Powell v. Steven Paine, State Superintendent (WV-2)

16. Kanawha County Board of Education v. William A. Hayes (WV-3)

Cases Reviewed by Dr. Hazi to Corroborate Criteria

1. DE-1

2. NC-1

3. $\mathrm{WV}-1$

Evaluation Problems Unveiled in Case Law

1. Principal 
a. First evaluator to find teacher unsatisfactory

b. Strained relationship between administrator and teacher

c. Administrator poor communicator

d. Differing opinions of evaluators

2. Teacher

a. Strained relationship between teacher and administrator

3. Process

a. Data

1) Student test scores from one test

2) Parent and student surveys

3) Information from observation did not occur in the classroom or occurred prior to the observation

4) Contradiction of data from observation and formerly documented disagreeable incidents

5) Data consisted of two observations only

6) Parent and Student complaints used as "hearsay"

7) Behavior during an extracurricular duty

8) Must consider all performance data

9) No rational nexus presented

10) Lack of a written record of teacher performance

11) Insufficient evidence

b. Instrument

1) Inapplicable Performance Standards 
2) Discretionary form modified at local level

3) Teacher failed to sign form

4) Procedure

5) Failure to grieve change in evaluators

6) Confusion about progress of improvement plan

7) Failure to meet about disagreeable incidents

8) Poor post-conferences

9) Failure to identify if behavior correctable and if so the provide an improvement plan

10) Failure to provide all data (due process)

11) No progressive discipline

12) Nature of conference, "no discussion"

13) No improvement plan or warning given teacher for insubordination

14) Willful neglect does not equate to unsatisfactory performance (wrong terminology used)

15) "Major procedural errors"

16) Failure to follow policy

17) Timeline

18) "Procedurally deficient" 


\section{Appendix B}

Teacher Evaluation Problems as Found in Literature by Source

The Principal:

1. Lack of, Limited or Inadequate Training: Goldrick, 2002; Halverson, Kelley and Kimball, 2004; Peterson, 2001; Scriven, 1988; Toch and Rothman, 2008; Tucker, 1997; and, Wise, Darling-Hammond, McLaughlin and Bernstein, 1984.

2. Lack of Subject Matter Expertise: Duke and Stiggins, 1986; Halverson, Kelley and Kimball, 2004; Toch and Rothman, 2008; and, Wise, Darling-Hammond, McLaughlin and Bernstein, 1984.

3. Using Impressions Instead of Data: Kleiman and Durham, 1981; and, Medley and Coker, 1987.

4. Lack of Time: Marshall, 2005; and, Peterson, 2001.

5. Avoid Giving Negative Evaluations: Bridges, 1993; and, Tucker, 1997.

6. Conflicting Dual Roles: Formative versus Summative: Hazard, 1993; Peterson, 2001; and, Scriven, 1988.

The Teacher:

1. Lack of Trust: Hazard, 1993; and, McColskey and Egelson, 1993.

2. Lack of Involvement in Evaluation Design: Conley and Glasman, 2008; Peterson, 1987, 2001; Ponticell and Zepeda, 2004; and, Trenta, Newman, Newman, Salzman, Lenigan and Newman, 2004. 
The Evaluation Process:

1. The Atypical Lesson Observed: Bridges, 1993; and, Marshall, 2005.

2. Poor Evaluation Instrument: Bridges, 1993; Danielson and McGreal, 2002; Duke and Stiggins, 1986; Kyriakides, Demetrious and Charalambous, 2006; Marshall, 2005; McColskey and Egelson, 1993; Peterson and Kauchak, 1982; Scriven, 1988; Soar and Soar, 1975; Toch and Rothman, 2008; Wise and DarlingHammond, 1984; and, Veir and Dagley, 2002.

3. Use of One Data Source: Duke and Stiggins, 1986; Peterson, 1987, 2000; Peterson and Kauchak, 1982, Scriven, 1988; Stronge and Tucker, 2003; Toch and Rothman, 2008; and, Wise and Darling-Hammond, 1984.

4. Failure to Provide Adequate feedback: Bridges, 1993; Duke and Stiggins, 1986; Halverson, Kelley and Kimball, 2004; and, Toch and Rothman, 2008.

5. The Lack of Central Office Support: Bridges, 1993; Danielson and McGreal, 2000; Kyriakides, Demetrious and Charalambous, 2006; Marshall, 2005, Peterson, Wahlquist, Bone, Thompson and Chatterton, 2001; Scriven, 1988; Toch and Rothman, 2008; and, Tucker, 1997.

6. Infrequent Evaluation: Hazi and Rucinski, 2006; NCTQ, 2007; and, Scriven, 1988. 
Appendix C

Data Matrix

\section{Problems with Teacher Evaluation}

Frequency

Sources of Information

of

Presenting the Problem

Occurrence

Total

Appears in Times

Appears in Case Law by Manifested

Literature by Name and in Case

Author Number Law

1. Lack of,

limited or

inadequate

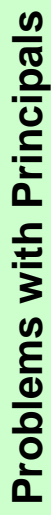

training

2. Lack of

subject

matter

expertise

3. Use of

personal

impressions 


\author{
instead of \\ data to rate a \\ teacher \\ 4. Lack of \\ time to \\ conduct \\ evaluations \\ 5. Failure to \\ give a \\ negative \\ evaluation
}

6.

\section{Responsibility \\ of performing \\ conflicting \\ dual roles}

1. Lack of trust in the principal
Sources of Information

Presenting the Problem

Appears in

Appears in Literature by

Author Number
Frequency of Occurrence Total Times Case Law by Manifested Name and in Case

Law 


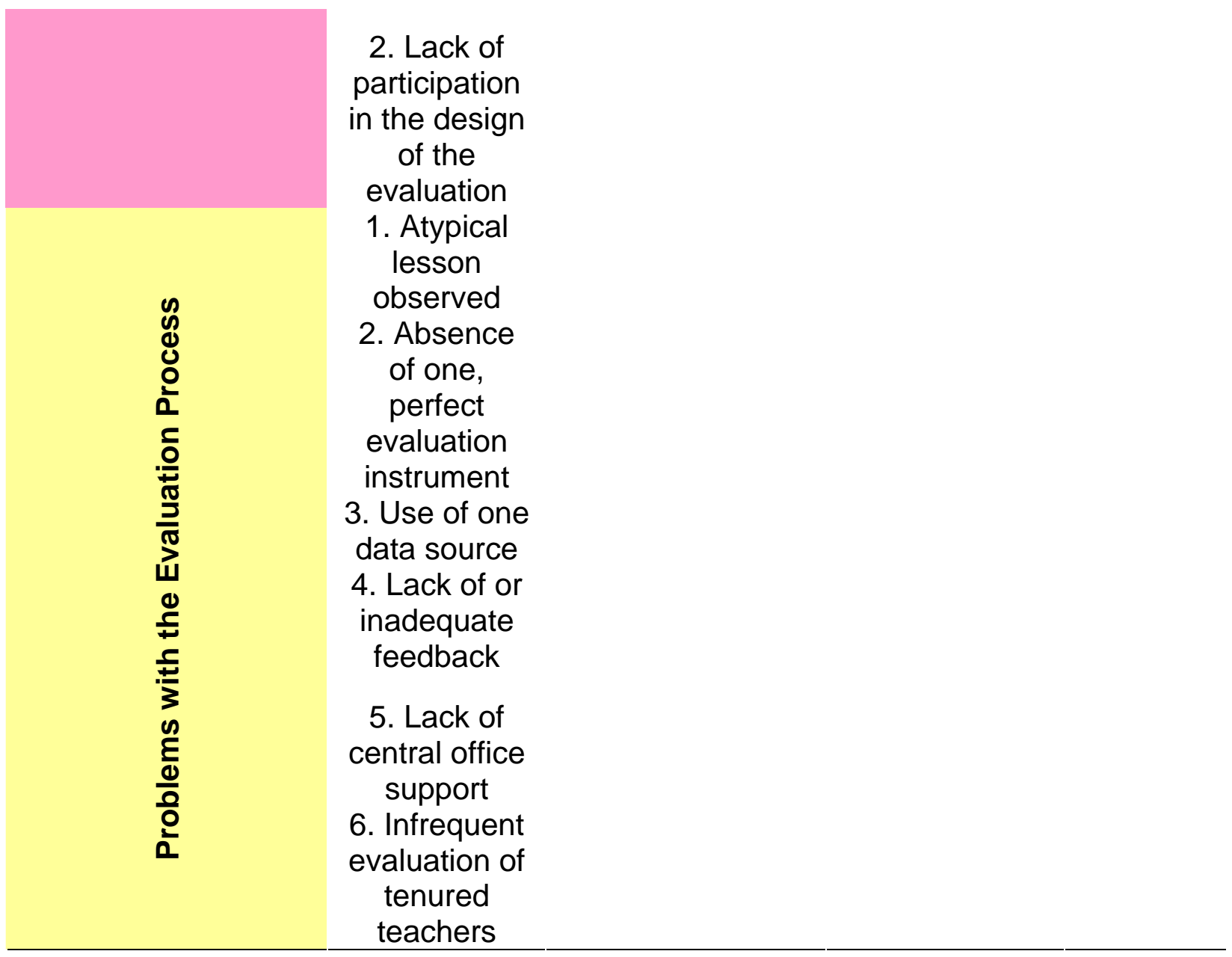


Appendix D

Revised Data Matrix

\section{Problems with Teacher Evaluation}

\section{Sub-category Definition Illustrations}

I. Attitude - A mental state, positive or negative, communicated to others.
A. Toward Others in A teacher's
1. Childers v. ISD \#1 of Bryan Co. (1981) the School/
expression of a
a. "There was repeated and continuing friction
District
negative attitude between Appellee and the administrators and about students or between Appellee and other school teachers, other educators to the extent that it disrupted the school."
working in the
2. Fields v. of Tulsa Co. (2002)
same school/
a. "The members met with Fields again on
district.
January 18, 2001, to inform her of their observations and the deficiencies in her job performance. Fields reportedly was resistant and uncooperative during this meeting."

3. Maxey v. McDowell Co. (2002)

a. "Failing to demonstrate an appropriate level of respect for her supervisor..."

4. St. Tammany v Hearty (2002)

a. "She had a confrontational and combative attitude when offered assistance or direction 
in her teaching."

\section{Davis v. Macon Co. BOE (2006)}

a. "Specifically, the plaintiff alleged that the members of her support team were personally biased against her.”

6. Squire v. BOE of Red Clay (2006)

a. 'It isn't that I don't like little children, it's that I don't like having to teach them."

B. Toward Negative The expression of a Evaluations negative attitude in reference to issuing or receiving a poor evaluation rating.
1. Wilt v. Berkeley Co. (1982)

a. "Trying to be a halfway decent humane person, I did not want to wipe her out totally the first year or second year."

\section{Wilmer-Hutchins v. Brown (1995)}

a. "During this meeting, [petitioner] was told that she was marked down with "below standard" in two areas. Rather than inquiring into why this occurred, she proceeded to tell [the principal] that she was going to talk with her attorney."

\section{Hawzipta v. Noble Co. (2000)}

a. 'Teacher's attitude became "resentful, defiant."

4. Maxey v. McDowell Co. (2002) 
a. "The Appellant ... refused to sign it.

5. St. Tammany v. Hearty (2002)

a. "The claimant refused to sign because she disagreed with the process and did not feel that it was fair."

6. Wise v. Bossier Parrish (2003)

a. "Wise refused to sign the form her supervisor, Kenneth Kruithof, prepared."

7. Squire v. BOE of Red Clay (2006)

a. "The record shows that Appellant's choice ...is part of a pattern of conduct by Appellant, which the hearing officer characterized as "uncooperative." Another example is her adamant refusal to sign every unfavorable evaluation."

b. 'Appellant, didn't really know if she was going to make any changes [in her evaluation] because she only had three years left."

C. Attributed To Conflicting Personalities
The expression of a negative attitude

because

personalities of the

teacher and the
1. Maxey v. McDowell Co. (2002)

a. "This began as a personality conflict between a teacher and a principal and escalated grievously from that point."

b. "While the record does not reflect precisely 
principal are in

opposition of each

other.
As a result of a

negative attitude, an

educator does not

have confidence or

reliance upon

another educator. how the relations between Mr. Spencer and the Appellant initially became strained, the record reflects that Mr. Spencer began keeping a record of what he considered disagreeable incidents involving Mrs. Maxey at the school as early as September 1996."

2. Wise v. Bossier Parrish (2003)

a. "Wise contends that her failure to conference with her supervisors was the result of a personality conflict with the principal."

1. Maxey v. McDowell Co. (2002)

a. "Clearly, at this point, there was not mutual trust and confidence between Mr. Spencer, as the school's principal, and Mrs. Maxey, as one of the school's veteran teachers..."

II. Communication - The imparting, conveying, or exchange of ideas, knowledge, information about job performance through a conversation with or in written form by an educator.
A. Unwillingness
Teachers and
1. Maxey v. McDowell Co. (2002)

principals reluctant

a. "There was a substantial, perhaps

to communicate mutual...unwillingness to communicate" with each other.

B. Limited Skill The narrow or

1. Maxey v. McDowell Co. (2002) 
restricted ability of

the principal to

communicate ideas,

knowledge, or

information to a

teacher about job

performance.

C. Inadequate

Feedback
Insufficient

information, type or

amount, is provided

to a teacher

following an

observation. a. "Consideration was not given to any blame to be attributed to Mr. Spencer for his limited communication skills... or his failure to address his concerns in a more constructive posture."
1. Wilt v. Berkeley Co. (1982)

a. "The court held that the school's principal failed to inform the teacher during an evaluation and observation that she was having problems."

b. "The court then noted that an evaluation and letter subsequent to criticism of the teacher was considerably more positive and could have left her with the impression that she was improving."

2. Belcher v. Jefferson Co. BOE (1985)

a. "she was not informed of Abbott's recommendation that she not be reemployed"

3. Harper Co. v. Orange (1992)

a. "In December, after the first observation Orange and Baird met briefly but, at least according to Orange, did not discuss her teaching performance." 


\section{McKenzie v. Webster Parish (1995)}

a. "Principal Jones testified that he did not evaluate McKenzie's performance as being "unsatisfactory" in writing because he wanted to encourage him. He obviously did not tell McKenzie at the post-evaluation conference...that his performance was unsatisfactory and that he was recommending that his employment be terminated."

5. Fields v. Tulsa Co. (2002)

a. "The court further found many of the complaints about Fields's perceived failings, if communicated to Fields at all, were never made in writing as required by 70 O.S. $2001 \S 6-$ 101.24”

\section{Farris v. Burke Co. (2002)}

a. "Mr. Sherrill failed to make suggestions to [petitioner] for professional improvement following his December 8, 1997 observation and evaluation of [petitioner]"

b. "Although never having given her any documentation or warnings, he rated her as being below standard or unsatisfactory in three 
categories in which he had never previously

evaluated her."

\section{Maxey v. McDowell Co. (2002)}

a. "Although Mr. Spencer documented the ten incidents and used them in the termination hearing before the County Board, he did not share with Mrs. Maxey any written warning, criticism, or a suggested improvement plan."

b. "It does not appear that a discussion, as that term is commonly defined, occurred concerning ... the perceived performance inadequacies."

c. "She said of that conference that Mr. Spencer considered it communication. But he presented me this. He presented a listing. At the end of the conference he said, 'Do you or do you not want to sign?' I said, 'Sir, I do not want to sign this because I could not understand his needs assessment that he wished to attach."

\section{Sheets v. Dollarway School District (2003)}

a. "Here, although the record does support that some assistance was provided to appellant in an attempt to salvage his basketball programs, the district failed to provide written notice of the 
problems or evaluations as required by the Act."

9. Weston v.ISD \#5 of Cherokee Co.(2007)

a. "He testified that the principal told him that he was concerned about a test score, but that he was not shown the test scores nor were test scores discussed.”

\section{Policy - Statutes or regulations governing the process of teacher evaluation.}

A. Insufficient

The locally

developed policy

does not contain all

of the conditions

required.

\section{BOE of Anne Arundel v. Barbano (1980)}

a. "The county board did not "adopt evaluation procedures" as the State Board's resolution provided it "shall" do."

2. Thompson v. BOE of Henderson Co. (1993)

a. "Any review of a non-tenured certified teacher's evaluation by the appeals committee must contain a degree of fairness. The policy currently adopted by the Henderson School Board does not contain the requisite fairness under the circumstances presented here."

\section{Jamison v. Gullett (1997)}

a. "Although SEAP found that the Greenup County Board of Education certified evaluation plan is inconsistent with both statutory and regulatory provisions, including the absence of the right to a 
hearing, lack of notice, and review of all documents."

B. Inconsistent

Language

C. Failure to Follow
Language that can

be interpreted

differently by

individuals reading

the policy and

districts attempting

to follow the

evaluation policy.

\section{State Tenure Comm. v. Jackson (2003)}

a. "The statute [\$16-24-14(e); personnel record in regards to employment performance documents] we are now charged with construing is quite confusing and internally inconsistent; we encourage the Legislature to reexamine and to clarify it."
The principal or the

BOE does not go

along with the

requirements for

teacher evaluation.
1. BOE of Anne Arundel v. Barbano (1980)

a. "In the case of probationary teacher Edward F. Barbano, it is uncontested that there has been less than absolute adherence to the State Board guidelines."

2. Board of School Commissioners of Baltimore City

\section{v. James and Davis (1993)}

a. "I further conclude, as a matter of law, that the Board of School Commissioners of Baltimore City failed to comply with its own procedures in seeking to discharge the Appellant procedures."

\section{McKenzie v. Webster Parish (1995)}

a. "The Board completely disregarded its evaluation 
policy."

\section{Childs v. Roane Co. BOE (1996)}

a. 'the Chancellor's finding that the vaguely worded complaint raising due process issues sufficed to raise the violation of the Board's policy is appropriate"

5. Jamison v. Gullett (1997)

a. "She further asked for a finding that the District failed to provide her with her rights pursuant to KY. Rev. Stat. KRS 156.101 and 704 KAR 3:345."

6. Maxey v. McDowell Co. (2002)

a. "We find that Policy 5300 was controlling in the present case, and the Board of Education failed to comply with the specific requirements of that policy"

b. "The insubordination claim was derivative of the original performance issue. In other words, the emergence from the performance issue of secondary acts, allegedly constituting insubordination, cannot be held to totally eclipse the underlying performance issues and cannot subvert the employee's right to the protections of 
Policy 5300. By permitting the has [sic] simply chosen to label the conduct as insubordination and has thwarted the purpose of Policy 5300."

IV. Data - The facts collected for reference and information in the evaluation of a teacher's job performance.

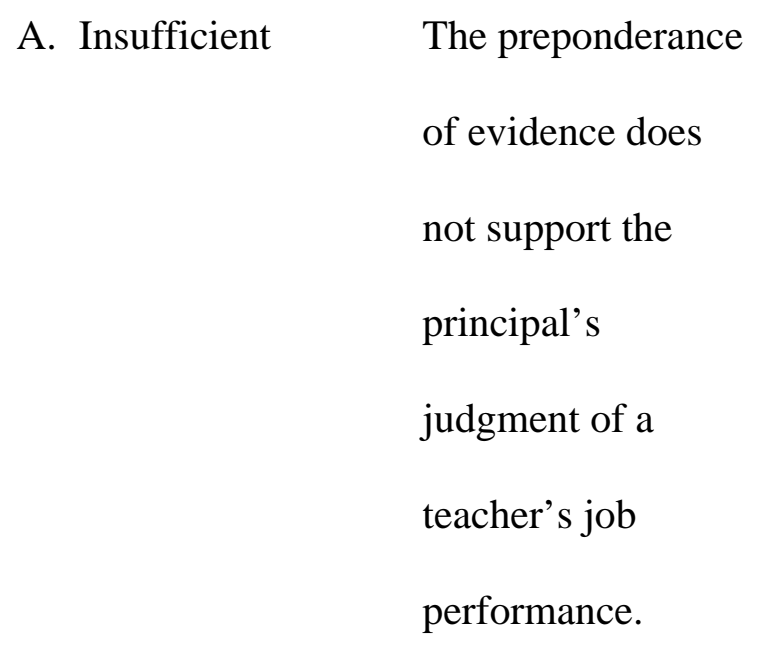

1. Harper Co. v. Orange (1992)

a. "The hearing panel stated School had failed to prove by a preponderance of the evidence that Orange had "knowingly or purposefully failed to perform one or more essential job duties."

2. Fields v. Tulsa Co. (2001)

a. "The trial court found that School District failed to prove by a preponderance of the evidence that it adequately complied with the requirements of the admonishment statute, 70 O.S. $2001 \S 6$ 101.24."

3. Wise v. Bossier Parrish (2003)

a. "It concluded that less than satisfactory performance on evaluations and assistance schedules was insufficient to establish that Wise deliberately or willfully neglected her duties."

4. Weston v.ISD \#5 of Cherokee Co. (2007)

a. "The school district had failed to prove by a 
preponderance of the evidence that the teacher should be dismissed on the grounds of instructional ineffectiveness and unsatisfactory teacher performance"

B. Conflicting
Data exists both for

and against the

judgment of the

teacher's

evaluation.

\section{Harper Co. v. Orange (1992)}

a. "The panel also found the evidence was conflicting on whether Orange was performing her duties at the 'level of competence known to be expected or required by [School].'

2. Maxey v. McDowell Co. (2002)

a. "Favorable comments are recorded even in areas where the ten documented instances upon which Mr. Spencer later relied could fairly be said to raise doubts about Appellant's performance."

\section{Knight v. Winn (2005)}

a. "Commissioner presented evidence from Knight's former students, their parents, her co-workers, and others that Knight engaged in inappropriate behavior, despite the fact that Knight had received satisfactory evaluations during the same time period."

C. Misused

The wrong or improper data was

\section{Hannon v. Armorel School District (1997)}

a. "School board relied exclusively on past conduct. 
used in the

evaluation of a

teacher's job

performance.
- The Supreme Court concluded that conduct in

the preceding school year cannot be used

exclusively to terminate a teacher at the

beginning of the subsequent school year; Ark.

Code Ann. 6-17-1507(a) (Repl. 1993)"

b. "Without a ground for termination in the 1992-93

school year, there was no basis for Hannon's

termination. We hold that Hannon's termination

by the School Board, which relied exclusively on

past conduct, was arbitrary and capricious."

\section{Maxey v. McDowell Co. (2002)}

a. "The majority of them relate either to events that occurred prior to the March 3 observation or matters that did not occur in the classroom."

\section{Moulder v. Bartow County (2004)}

a. "A hearing was held before the Local Board on July 9. At the hearing, the parties agreed that Moulder had not done anything after the February 12 incident that would lead to her termination. All of the incidents presented by the Local Board had occurred before it offered Moulder a contract for the 2002-2003 school year."

b. "Undisputably, Moulder was a tenured teacher 
whose contract of employment was terminated based solely on misconduct that occurred before the Local Board's annual decision to renew the contract."

D. Ignored

Data or

circumstances of

life omitted from

consideration when

judging a teacher's

job performance.
1. Wilt v. Berkeley Co. (1982)

a. "At that time, Greenfield told the appellant that he would not recommend her for reemployment, even though his latest observation was quite positive and there had been no other observation or conference between the time of the November 5, 1979 observation, and the lengthy conference held on February 4, 1980."

\section{Wilmer-Hutchins v. Brown (1995)}

a. "The Board accepted the Superintendent's recommendation without examining Brown's performance evaluations.

\section{Maxey v. McDowell Co. (2002)}

a. "Consideration was not given to the role of psychological turmoil, mental exhaustion, and recent bereavement."

\section{James v. Sevre-Duszynski (2003)}

a. "The school improperly failed to consider the circumstances of Ms. Sevre-Duszynski's absence 
from teaching."

5. Sherrod v. Palm Beach Co. (2006)

a. "Nor can it be said that its assessment primarily use[d] data and indicators of improvement in student performance assessed annually as specified in s.1008.22."

\section{Young v. Palm Beach Co. (2006)}

a. "Regardless of the good intentions of the School Board in relying on what it felt were suitable criteria to evaluate teacher performance, by depending on an assessment procedure not primarily based on student performance as measured by state FCAT tests or local assessments, the School Board failed to follow the applicable law."

E. Using

$$
\text { Impressions }
$$

Instead of Data
A principal who is

ruled by impression

rather than data in

making a judgment

about a teacher's job performance.

\section{Harper Co. v. Orange (1992)}

a. "Baird admitted he conducted Orange's evaluation with a predisposed opinion that she was not a competent teacher and aware that seventh graders at School frequently had a difficult time making a transition from grade school to junior high school."

2. Calhoun v. Marlboro Co.(2004) 
a. "One alleged flaw in the evaluation process, according to Calhoun, is that past comments allegedly made by S.T.E.P. evaluator Baker suggested her 'bias' against Calhoun."

\section{Process - a series of procedures directed toward the evaluation of a teacher's job} performance and the tools necessary to complete the procedures.

A. Observations Not Access to all the Open and Honest data collected for use in a teacher's job performance evaluation is not granted and the evaluation may be based on factors other than the collected data.
1. Wilt v. Berkeley Co. (1982)

a. "As a result of the combination of the actions and factors listed, with particular attention being paid to the timing of the various events, we conclude that the third observation completed on February 13, 1980, and its negative recommendation were not the result of an open and fair evaluation of the appellant's performance as a teacher."

b. “...was not an open and fair observation and was completed as a mere formality."

c. "We find that the $1979-80$ evaluation completed by Greenfield lacked the openness and honesty required by 5300(6)(a)."

B. Instrument

The approved

\section{Used Incorrect Form}

evaluation form for

1. Squire v. BOE of Red Clay (2006)

rating a teacher's

a. 'Johnson evaluated Appellant's work, using the 
job performance.

Used Incorrect

Form - the form

used in the

evaluation of a

teacher's job

performance was

not the appropriate

one.

Ambiguity - terms

used on the

evaluation

instrument are

understood

differently by the

School Board than

by the principal.

C. Failure to Abide Not adhering to the by Time Require- guidelines about the ments time to be

designated for each
Lesson Analysis form included in the DPAS'

Policy for Appraising Teachers and

Specialists...Appellant insists that because she was a specialist, not a teacher, Appellee should have evaluated her using a different form, the one meant for specialists, the Job Analysis form.”

2. McKenzie v. Webster Parish (1995)

a. "The school board did not use a particular evaluation form as visualized by the school board's policy."

\section{Ambiguity:}

\section{McKenzie v. Webster Parish (1995)}

a. "Any ambiguity must be construed against the School Board who prepared the form and whose agent completed the form."

\section{House v. Muskogee Co. (1997)}

a. "There is no question that the principal failed to specify a reasonable time."

2. Mack v. Charleston Co. (2007) 
procedure involved

in the evaluation

process. a. "Mack argues that the evaluations were not performed within the proscribed ninety-day period and did not include four period-long evaluations."

b. "There is some evidence that Ms. Siewicki's observations were not for a full ninety-minute class period."

\section{Belcher v. Jefferson Co. (1985)}

a. "He [Graham] also alleges that he was not evaluated in the spring based on fall assessments, as required by the Board policy."

b. "Belcher alleges specific non-compliance in that:

1) she was not evaluated in the spring based on fall assessments."

c. "Graham alleges that Haywood Atkinson, the principal of Hueytown High School, where Graham taught, failed to perform an evaluation of Graham as required by Board of Education policy."

\section{BOE Baltimore County v. Ballard (1985)}

a. "Athough appellee was informally observed by her supervisor in late March or early April, there were no conferences with or reports to appellee in 
order to guide and assist her attempts to improve her performance."

b. "By omitting the visits, conferences and reports required by Rules 4118.1, paragraphs 8 and 9 , [the County Board] did not follow their own regulations."

3. Board of School Commissioners of Baltimore City

\section{v. James and Davis (1993)}

a. "No formal evaluation of [Ms. James] was conducted during school year 1988-89."

b. "The Local Board "failed to confer upon [Ms. Davis] an important procedural benefit," in that her 1988-89 year end evaluation did not contain an observation by a non-school-based observer as specified in the Baltimore City school procedures."

c. "During the same year, Ms. James was not accorded pre-observation or post-observation conferences before or after any observation."

\section{McKenzie v. Webster Parish (1995)}

a. "The deposition testimony of the personnel director and the superintendent clearly indicates that these procedures [evaluation and conference] 
had not been specifically followed in McKenzie's evaluation and dismissal."

\section{Childs v. Roane (1996)}

a. "The Board concedes that such notice [of unsatisfactory performance] was not given."

\section{Jamison v. Gullett (1997)}

a. "Board policy and procedure were not completely followed in the evaluation and recommended that another observation cycle and summative evaluation be completed by another evaluator."

\section{Sheets v. Dollarway School District (2003)}

a. "Appellant states that the district violated Arkansas Code Annotated sections 6-17-1504(a) et. seq. by failing to provide him with an annual teacher evaluation ..."

\section{Squire v. BOE of Red Clay (2006)}

a. "Appellee failed to complete successfully both the formative and the performance appraisal phases of the DPAS appraisal process."

E. Inadequate The step of the

Component evaluation process

was provided but

performed in a less
1. Wilt v. Berkeley Co. (1982)

a. "The court held that Policy No. 5300(6)(a) required that school employees be properly evaluated and informed with regard to job 
than thorough

manner. performance. Applying a strict interpretation in favor of the teacher, the court held that these requirements were not met."

\section{Farris v. Burke Co. (2001)}

a. "Except for his approximately one hour observation of [petitioner] on December 8, 1997, Mr. Sherrill spent no other time observing [petitioner] or monitoring her teaching ability."

\section{Maxey v. McDowell Co. (2002)}

a. "It is beyond cavil that the principal terminated the conference in order to go to lunch duty before any meaningful discussion of the criticisms contained in the attachment to the observation form could be had, thus relieving the teacher of any responsibility to sign the form at that time."

b. "The Appellant testified that she was not provided an adequate opportunity to discuss the criticisms prior to being asked to sign the evaluation document. She chose not to sign, she said, since she had not been given an adequate opportunity to discuss the allegations with Mr.

Spencer."

\section{Davis v. Macon Co. BOE (2006)}


a. "On several occasions, the two of them had met in his office and the conference ended abruptly and with [petitioner's] voice being raised in the process. There was a water gun incident in which [petitioner] squirted the principal after being told not to do so."

F. Evaluator

The person

responsible for

completing the

evaluation of a

teacher's job

performance,

usually the

principal.
Multiple Evaluators Lack Agreement:

\section{Board of School Commissioners of Baltimore City}

v. Davis (1993)

a. "Ms. Davis was observed informally on numerous occasions by three different people; two of them, including her principal, assessed her as "needs improvement" during most of these observations."

\section{McKenzie v. Webster Parish (1995)}

Multiple Evaluators Lack Agreement the failure of two or more evaluators to agree about a teacher's job

3. Hannon v. Armorel School District (1997)

performance. a. "Burnham testified his observations revealed more severe problems than the observation of Jones; however, the two never documented their differences of opinion concerning McKenzie."

a. "Lee testified that she saw no significant improvement in Hannon's performance. 
Sydney Kennedy, on the other hand, also evaluated Hannon during the 1991-92 school year and gave her above average marks for her teaching acumen."

\section{Cagle v. St. John's Co. (2006)}

a. "RB Hunt assessed Ms Cagle's skills in the classroom giving Ms. Cagle overall good marks with several suggestions for improvement...Principal Barbara Stevens conducted an unannounced observation of Ms.

Novice - a

principal in year

one of his/her

position and

therefore lacking in

experience

pertinent to the

position. Cagle's classroom...which was not favorable."

\section{Novice Evaluators:}

\section{Maxey v. McDowell Co. (2002)}

a. "The record also strongly suggests that the new principal simply could not deal with the early manifestations of this behavior except to set upon a course of 'documenting' conduct he found objectionable and conducting two formal classroom observations."

Attitude Toward

Job - the

expression of a

negative attitude

\section{Attitude Toward Job:}

1. BOE of Anne Arundel v. Barbano (1980)

a. "Added to these primary concerns was the danger of losing a good teacher by a jaded 
about completing

the assigned duties

and responsibilities

of being a principal. supervisor who unchecked may abuse his

discretion. At the same time we are not

unmindful of the danger of abuse of discretion,

of the danger that a bright and resourceful new

teacher could be penalized by a principal or

supervisor who has grown old and tired in his

job and feels himself threatened."

\section{Belcher v. Jefferson Co. (1985)}

a. "Rather, it is alleged, Atkinson delegated that responsibility [evaluation] to the head football coach of the school."

3. Maxey v. McDowell Co. (2002)

a. "Consideration was not given to any blame to be attributed to Mr. Spencer for ... his distinct fear of confrontation"

b. "[Principal] Spencer's emotional response, leaving the meeting twice, the second time, never to return, together with his testimony that earlier in the day he was "in fear" and "afraid to come to work" suggests that more than one person attending the meeting had issues of emotional stability with which to deal that very well might affect job performance.” 


\section{Childers v. Bryan Co. (1981)}

a. "Because of the fact that under the statutory procedures, the dismissal or non-renewal of a teacher requires a long and time-consuming effort, school administrators and Boards of Education are often reluctant to institute such procedures against teachers who ought to be dismissed."

\begin{tabular}{|c|c|}
\hline G. Repercussions & The occurrence of \\
\hline from a Teacher's & non-constructive \\
\hline Unsatisfactory & behavior following \\
\hline Evaluation & an unsatisfactory \\
\hline & evaluation rating. \\
\hline
\end{tabular}

1. Wood v. Pottawatomie Co. (1983)

a. "She was also criticized for the amount of controversy generated in the school regarding her evaluations and for obtaining assistance of counsel in framing responses to her evaluations.

2. Hawzipta v. Noble Co. (2000)

a. Teacher either had not spoken to BRS as he claimed, or had been given correct information from BRS but nevertheless chose to name Principal as the owner of the pornographic material in retaliation for Principal requiring Teacher to submit a plan of action 6 months earlier."

b. Teacher's attitude became "resentful, defiant."

3. Maxey v. McDowell Co. (2002) 
a. "She called me "Napoleon" and then, I moved back behind my desk. I - - I was very - - After she was telling me to get a roadmap the previous day, I knew that there was nothing good going to be said, and I didn't want to say anything to Mrs. Maxey. I had fear. I can't say who else did, but I was afraid to go to work that morning."

b. "During this conference you showed a great degree of intemperance including threatening your own life and threatening to shoot $\mathrm{Mr}$. Spencer in the head."

\section{Harlandale v. Rodriguez (2003)}

a. "White threatened to hold the poor evaluation of March 2 over into the next school year. However, Rodriguez says Quijano told him if he would take a job with another district, she would upgrade his evaluation. Rodriguez resigned and took a job with another district, at a lower rate of pay."

\section{Remediation - a plan developed to assist teachers who have not achieved the desired proficiency necessary for successful performance in the classroom.}
A. Failure to
Administrators
1. Maxey v. McDowell Co. (2002)

Determine Need couldn't decide if

a. "The decision to seek termination of her 
the behavior of the

teacher was

correctable or not.

B. Failure to Provide The principal did an Adequate Plan not present the teacher an opportunity for a remediation plan or employment, without any attempt to correct her performance deficiencies, or at least, determine if they were correctable."

b. "Dr. Roberts recognized her stress sufficiently to call for police assistance, but failed to address the issue of whether any of the teacher's bizarre conduct could be corrected under an improvement plan."

c. "we hold that the failure to pursue the question of whether these performance deficiencies could be corrected and an improvement plan prepared for that purpose, violated Policy 5300, and is contrary to our cases interpreting its interplay with West Virginia Code §18A-2-8."

d. "The effect of West Virginia Board of Education Policy 5300 is to require an initial inquiry into whether that conduct is correctable. Such inquiry is utterly absent in the present case."

\section{Gaulden v. Lincoln Parish School (1989)}

a. "Mrs. Gaulden argues that the board's only effort at 'remediation,' giving her a one-page list of reference books to read, came nowhere near the relief contemplated by either the statute or the 
the designed plan

was less than

thorough.

C. Failure for

Teacher to

Participate

take part in the board's own regulations. We are inclined to agree."

\section{McKenzie v. Webster Parish (1995)}

a. "Rentz testified that no remediation plan was ever given to McKenzie. Rentz admitted a "formal" assistance schedule was not prepared."

3. Farris v. Burke Co. (2002)

a. "[Petitioner] was not given ... a plan for improvement or any written notification that Mr. Sherrill viewed her as being insubordinate or having neglected her duty as a result of the food items that were found in her classroom or office."

\section{Fields v. Tulsa Co. (2002)}

a. "The court reasoned that because School District's written instructions regarding the ways in which Fields needed to improve lacked specificity, and the assistance Fields received to help her improve her teaching methods was insufficient...."

The teacher did not

\section{Squire v. BOE of Red Clay (2006)}

a. “Appellant was allowed to contribute to her IIP's development, but she declined." remediation plan. 
D. Failure for

Teacher to

Comply with Plan remediation plan.

\section{Board of School Commissioners of Baltimore}

City v. James and Davis (1992)

a. "Ms. James has flagrantly and consistently failed to adhere to the implementation steps of her professional assistance plan as documented by Jude Pasquariello, instructional specialist, F. Michel Vaeth, Language Arts department head, and the principal."

2. Fields v. Tulsa Co. (2002)

a. Dr. Reyes met with Fields and gave her a memorandum to indicate closure of the Job Targets Report period and the dissolution of the Assistance Team. Dr. Reyes concluded that Fields had failed to meet any of the objectives of the Job Targets Report.

3. St. Tammany v. Hearty (2002)

a. "she failed or refused or was unable or unwilling to correct her deficiencies in her teaching in accordance with the Louisiana Components of Effective Teaching"

4. Wise v. Bossier Parish (2003) 
a. "Although she was given professional assistance plans to address her educational deficiencies and numerous opportunities to correct her teaching inadequacies, she failed to implement the plans provided to improve her teaching methods."

5. Calhoun v. Marlboro Co. (2004)

a. "This testimony further indicated the following: (1) Calhoun was given remedial programs that she largely ignored or failed to complete."

\section{Emerging Issues: the definitions of the subcategories do not fit into previously identified} categories.

A. Lack of Training The teacher is not

Prior to provided training

Evaluation for skills he/she

will be evaluated

on.

B. Singled Out as an Action is taken on Example one teacher when

two or more

teachers share a

similar problem
1. Squire v. BOE of Red Clay (2006)

a. “Appellant only received minimal, peer-to-peer training on the system, largely at her initiative. Appellee failed to provide complete tech manuals, much less formal training on the system."

1. Weston v. ISD \#5 of Cherokee Co. (2007)

a. "The trial judge found that test scores for the same grade taught by different teachers at the school revealed some grades higher than Weston's and some grades lower that 
Weston's classes, and that the administration had not taken action against teachers whose classes tested lower than Weston's." 
Appendix E

Number of Cases Illustrating Each Subcategory

Number of

Category

Subcategory

Cases

Illustrating the

Problem

$\begin{array}{lll}\text { Communication } & \text { Inadequate Feedback } & 9 \\ \text { Process } & \text { Failure to Provide Each Component } & 8 \\ \text { Attitude } & \text { Toward Negative Evaluations } & 7 \\ \text { Attitude } & \text { Toward Others in the School/District } & 6 \\ \text { Policy } & \text { Failure to Follow } & 6 \\ \text { Data } & \text { Ignored } & 6 \\ \text { Remediation } & \text { Failure for Teacher to Comply with Plan } & 5 \\ \text { Data } & \text { Insufficient } & 4 \\ \text { Process } & \text { Inadequate Component } & 4 \\ \text { Process } & \text { Evaluator: Multiple Evaluators Lack Agreement } & 4 \\ \text { Process } & \text { Evaluator: Attitude Toward Job } & 4 \\ \text { Process } & \text { Repercussions from a Teacher's Unsatisfactory } & 4 \\ & \text { Evaluation } & 3 \\ \text { Remediation } & \text { Failure to Provide an Adequate Plan } & 3 \\ \text { Policy } & \text { Insufficient } & 3 \\ \text { Data } & \text { Conflicting Data } & 3 \\ \text { Data } & \text { Misused Data } & 4\end{array}$




$\begin{array}{llc}\text { Attitude } & \text { Attributed to Conflicting Personalities } & 2 \\ \text { Data } & \text { Using Impressions Instead of Data } & 2 \\ \text { Process } & \text { Instrument: Used Incorrect Form } & 2 \\ \text { Process } & \text { Failure to Abide by Time Requirements } & 2 \\ \text { Attitude } & \text { Lack of Trust } & 1 \\ \text { Communication } & \text { Unwillingness to Communicate } & 1 \\ \text { Communication } & \text { Limited Communication Skills } & 1 \\ \text { Policy } & \text { Inconsistent Language } & 1 \\ \text { Process } & \text { Observations Not Open and Honest } & 1 \\ \text { Process } & \text { Instrument: Ambiguity } & 1 \\ \text { Process } & \text { Evaluator: Novice } & 1 \\ \text { Remediation } & \text { Failure to Determine Need } & 1 \\ \text { Remediation } & \text { Failure for Teacher to Participate } \\ \text { Emerging Issues } & \text { Lack of Training Prior to Evaluation } & 1 \\ \text { Emerging Issues } & \text { Singled Out as an Example } & \mathbf{1} \\ \text { Total Types of Problems } & \mathbf{1 7} \\ \text { Total Number of Cases } & \mathbf{2 . 7} \\ \text { Total Number of Problems } & \mathbf{3 7} \\ \text { Range of Problems per Case } & 1 \\ \text { Average Number of Problems per Case } & \mathbf{3 1}\end{array}$


Appendix F

Problems of Teacher Evaluation Found in the Literature and in Case Law

$\begin{array}{ccc}\text { THE TYPES OF PROBLEMS OF TEACHER } & \text { FOUND IN } & \text { IN CASE } \\ \text { EVALUATION BY CATEGORY } & \text { LITERATURE } & \text { LAW }\end{array}$

\section{Attitude:}

- Toward others in the school/district

$\mathbf{X}$

- Toward negative evaluations

$\mathbf{X}$

$\mathbf{X}$

- Attributed to conflicting personalities

$\mathbf{X}$

- Lack of trust

$\mathbf{X}$

$\mathbf{X}$

\section{Communication:}

- Unwillingness

$\mathbf{X}$

$\mathbf{X}$

- Lack of Skill

$\mathbf{X}$

- Inadequate feedback

Policy:

- Insufficient

$\mathbf{X}$

$\mathbf{X}$

- Inconsistent language

$\mathbf{X}$

$\mathbf{X}$

- Failure to follow

$\mathbf{X}$

$\mathbf{X}$

Data:

- Insufficient

$\mathbf{X}$

$\mathbf{X}$

- Conflicting

$\mathbf{X}$

- Misused

$\mathbf{X}$

- Ignored

$\mathbf{X}$

$\mathbf{X}$ 
- Using impressions instead of data

- Teacher's participation in data selection

\section{Process}

- Observations not open and honest

- Observing the atypical lesson

- Incorrect instrument used

- Instrument ambiguity

- Failure to abide by timelines

- Failure to provide component

- Inadequate component

- Multiple evaluators lacking agreement

- Novice evaluators

- Evaluator's attitude toward job

- Evaluator's lack of training

- Evaluator's lack of subject matter expertise

- Evaluator's lack of time

- Evaluator's dual role

- Repercussions from a teacher's unsatisfactory evaluation

- Lack of central office support for the process

- Infrequent evaluation of tenured teachers
$\mathbf{X}$

$\mathbf{X}$

$\mathbf{X}$

$\mathbf{X}$

$\mathbf{X}$

$\mathbf{X}$

$\mathbf{X}$

$\mathbf{X}$

$\mathbf{X}$

$\mathbf{X}$

$\mathbf{X}$

X

$\mathbf{X}$

$\mathbf{X}$

$\mathbf{X}$

X

$\mathbf{X}$

$\mathbf{X}$

$\mathbf{X}$

X

X

X

$\mathbf{X}$

X

X

\section{Remediation:}


- Failure to determine need

- Failure to provide adequate plan

- Failure for teacher to participate

- Failure for teacher to comply
$\mathbf{X}$

$\mathbf{X}$

$\mathbf{X}$

$\mathbf{X}$

$\mathbf{X}$

$\mathbf{X}$

\section{Emerging Issues}

- Lack of training on new duties

$\mathbf{X}$

- Singled out as an example
$\mathbf{X}$ 
Appendix G

Cases Cited in this Research

1. Belcher v. Jefferson County BOE, 474 So. 2d 1063 (Ala. 1985).

2. Board of School Commissioners of Baltimore City v. June F. James and Carrie Davis, 625 A.2d 361 (Md. Ct. App. 1993).

3. BOE of Anne Arundel County v. Barbano, 411 A.2d 124 (Md. Ct. App. 1980).

4. BOE of Baltimore County v. Ballard, 507 A.2d 192 (Md. Ct. App. 1986).

5. Cagle v. St. Johns County School District, et al., 5D05-1380 (Fla. Ct. App. 2006).

6. Calhoun v. Marlboro County School District, Unpublished Opinion No. 2004-UP505 (SC Ct. App. 2004).

7. Childers v. ISD \#1 of Bryan County, 645 P.2d 992 (Okla. 1981).

8. Childs v. Roane County BOE, 929 S.W.2d 364, 365-66 (Tenn. Ct. App. 1996).

9. Davis v. Macon County BOE, \#COA05-1337 (2006).

10. Farris v. Burke County BOE, 355 N.C. 225; 559 S.E.2d 774 (2001).

11. Fields v. ISD \#1 of Tulsa County, 84 P.3d 779 (Okla. Ct. App. 2002).

12. Gaulden v. Lincoln Parish School Board, 554 So. 29152 (La. Ct. App. 1989).

13. Hannon v. Armorel School District \#9, 96-1014_S.W.2d (Ark. 1997).

14. Harlendale Independent School District v. Rodriguez, 121 S.W.3d 88 (Tex. Ct. App. 2003).

15. Hawzipta v. ISD \#I-004 of Noble County, 13 P.3d98 (Okla. Ct. App. 2000).

16. House v. ISD I-29 of Muskogee County, 939 P.2d 1127 (Okla. Ct. App. 1997).

17. ISD \#4 of Harper County v. Orange, et al., 841 P.2d 1177 (Okla. Ct. App. 1992).

18. James v. Sevre-Duszynska et al., 173. S.W.3d 250, 256 (Ky. Ct. App. 2005). 
19. Jamison v. Gullett and BOE of Greenup County, 96-CA-002418-MR (Ky. Ct. App. 1997).

20. Keeling v. Jefferson County BOE, 2002-CA-000528- MR (Ky. 2003).

21. Knight v. Winn, Comm. of Ed., 910 So. 2d 310 (Fla. Ct. App. 2005).

22. Mack v. Charleston County School District, Unpublished Opinion No. 2007-UP046 (SC 2007).

23. Maxey v. McDowell County BOE, 575 SE2d 278, 290 (W.Va. 2002).

24. McKenzie v. Webster Parish School Board, 609 So. 2d 1028 (La. Ct. App. 1992) and McKenzie v. Webster Parish School Board, 653 So. 2d 215 (La. Ct. App. 1995).

25. Moulder v. Bartow County BOE, 599 S.E. 2d 495 (Ga. Ct. App. 2004).

26. Sheets v. Dollarway School District, 120 S.W.3d 119 (Ark. Ct. App. 2003).

27. Sherrod v. The Palm Beach County School Board, 963 So. 2 d 251 (Fla. Ct. App. 2006).

28. Squire v. BOE of Red Clay Consolidated District, CA No. 04A-11-001-FSS (Del. 2006).

29. St. Tammany Parish School Board v. State Dept. of Labor and Hearty, 2001 CA 0757 (La. Ct. App. 2002).

30. State Tenure Commission v. Jackson, 881 So. $2 d 445$ (Ala. Ct. App. 2003).

31. Thompson v. BOE of Henderson County, 838 S.W.2d 390 (Ky. 1992).

32. Weston v. ISD \#35 of Cherokee County, 2007 OK 61; 170 P.3d 539 (2007).

33. Wilmer-Hutchins ISD v. Brown, 912 S.W.2d 848 (Tex. Ct. App. 1995).

34. Wilt v. Berkeley Co., 170 W.Va. 385, 294 S.E.2d 189 (1982). 
35. Wise v. Bossier Parish School Board, 851 So. 2d 11090 (La. 2003).

36. Wood v. IDS \#141 of Pottawatomie County, 661 P.2d 892 (Okla. 1983).

37. Young v. Palm Beach County School Board, 968 So. 2d 38 (Fla. Ct. App. 2006). 
Appendix $\mathrm{H}$

KATHY S. KIDDER-WILKERSON

$\underline{\underline{\text { VITA }}}$

$\underline{\text { Home Address }}$

1312 West Street

Follansbee, WV 26037

$\underline{\text { Contacts }}$

304-737-3481 (work)

304-737-3480 (fax)

304-527-1938 (home)

kkidder@access.k12.wv.us (email)

Academic Record West Virginia University, Morgantown, WV

2004-2009

Degree - Doctor of Education

Major - Educational Leadership Studies

Minor - Instructional Design Technology

Salem International University, Salem, WV

2002-2003

Certificate - Educational Administration PK-Adult

Principal, Superintendent, and Supervisor of General Instruction

West Virginia Graduate College, Institute, WV

Summer 1992

Certificate - National Writing Project

Marshall University, Huntington, WV

1986-1988

Degree - Master of Science

Major - Vocational Technical Education

Minor - Counseling

West Liberty State College, West Liberty, WV

1981-1984

Bachelor of Science (Honors)

Majors - Biology and General Science 7-12

West Virginia Northern Community College, Weirton, WV

1976-1979

Degree - Associate of Science (Honors)

Major - Registered Nursing 
$\underline{\text { Dissertation }}$

$\underline{\text { Honors }}$

$\underline{\text { Employment }}$

$\underline{\text { Presentations }}$
An Interpretive Inquiry of Case Law of Teacher Evaluation in the Southern Regional Education States: Forecasting Pressing Problems (2009)

Who’s Who Among America’s Teachers 1994

Teacher of the Year, Brooke High School, Wellsburg, WV 1993

Outstanding High School Teacher, Westminster College, New Wilmington, PA 1992

Tandy Technology Scholars Outstanding Teacher Award for Brooke High School 1990-91

National Dean's List 1983

John C. Shaw Scholarship, West Liberty State College 1982-83

Outstanding Young Woman of America 1974

Brooke County Board of Education, Wellsburg, WV

Director of Student Services/Curriculum 2006 - present

Director of Career Technical Education July - December 2006

Principal Center 3, Brooke High School 2004-06

Science Teacher, Brooke High School 1986-2004

Diocese of Wheeling-Charleston, Wheeling, WV

Madonna High School, Weirton, WV

Science Teacher 1984-86

Ohio Valley Hospital, Steubenville, Ohio

Registered Nurse 1978-80

WV Department of Education

School System Leadership Team Conference 2005

Collaborative Teaching

WV Association of School Administrators

Summer Conference 2005

Brooke County Collaborative Classrooms

Berkeley County Schools Philosophy of Inclusion and the Coteaching Strategy Conference 2005

Co-Teaching 
Governor's Summer Institute 1994

Learning Science the Write Way

\section{Professional Memberships}

Golden Key International Honor Society

WV Association of School Administrators

National Association of Secondary School Principals

$\underline{\text { Service }}$

Instructional Strategies Trainer 2004-05

Science Content Standards Trainer 2003

Teacher Mentor 2002

High Schools That Work Technical Assistance Team Wetzel

County Schools 2002

Testing Out in Science RESA Team, Instrument Development, 1999

Writing Across the Curriculum Trainer 1992-1994

AIDS Staff Development Trainer 1991 